\title{
VI. Mittelständische Wirtschaft und Industrie
}

\section{Sommerliche Konjunktur}

Ludwig Erhard, der spätere Bundeskanzler, ist in den ersten Tagen und Wochen nach dem Einmarsch der amerikanischen Streitkräfte häufig auf den Straßen und Plätzen seiner Heimatstadt Fürth zu sehen. Er spricht mit Firmeninhabern, Belegschaftsmitgliedern und kleinen Händlern, hört interessiert zu und schreibt auf, was man ihm erzählt. Es ist nicht Neugierde oder wissenschaftliches Interesse, die den schweren, massigen Fürther, der im Krieg ein kleines „Institut für Industrieforschung“ geleitet hatte, zu seinen Streifzügen durch die Stadt veranlassen. Als neuer Chef des Wirtschaftsamts hat er den amtlichen Auftrag der amerikanischen Militärregierung, eine Denkschrift über „Probleme und Bedingungen des wirtschaftlichen Wiederaufbaus“ in Fürth zu verfassen ${ }^{1}$.

Auf seinen Wegen durch die Stadt bietet sich ihm ein trostloses Bild. Die wichtige Ortsdurchfahrt der Reichsstraße 8 ist zwar von den Amerikanern geräumt worden, die übrigen Straßen sind aber nur schwer befahrbar. In der Innenstadt türmen sich meterhohe Schuttberge, Panzersperren und „wilde“ Müllagerplätze behindern den Verkehr. Nur mühsam können sich Fahrzeuge der US-Army und Frauen mit vollgepackten Leiterwagen einen Weg bahnen. Dreißig Arbeitskräfte mit vier Lastwagen der Stadt beginnen aufzuräumen. Ein paar Schritte weiter, an den Ufern von Rednitz, Pegnitz und des Ludwig-Donau-Main-Kanals, sind Reparaturarbeiten der amerikanischen Pioniere im Gange. Alle Stege, die alte und die neue Dambacherbrücke und die große Eisenbahnbrücke waren von den deutschen Truppen noch in letzter Minute gesprengt worden. Fieberhaft wird hier fast Tag und Nacht gearbeitet, modernstes Gerät kommt zum Einsatz, und schon Anfang Mai sind Behelfsbrücken und hölzerne Notstege fertig. Über dem Zentrum hängt ätzender Gestank, der sich mit dem säuerlichen Armeleutegeruch in den düsteren Gassen vermischt; das Kanalnetz ist beschädigt, Abwässer quellen auf die Straßen. Die Wasserversorgung funktioniert zwar wieder, in manchen Straßen ist man aber oft für Stunden ohne Wasser. Auch an Strom mangelt es. Vierzehn Tage nach Kriegsende steht das große Elektrizitätswerk in der Ottostraße, das im April beschossen worden war, noch immer still. Und mehr als vier Wochen dauert es, bis das im Januar wegen Kohlenmangel abgestellte Gaswerk seinen Betrieb wieder aufnehmen kann ${ }^{2}$.

1 Vgl. Denkschrift von Ludwig Erhard an MilReg, Mai 1945, in: Ludwig-Erhard-Archiv, NL Erhard, NE 746 A. Zur Biographie Erhards vgl. Wolfgang Benz, Von der Besatzungsherrschaft zur Bundesrepublik. Stationen einer Staatsgründung 1946-1949, Frankfurt/Main 1984, S. $119 \mathrm{ff}$.

2 Zur Situation in Fürth 1945 vgl. Ammon, Fürth, S. 85-89; Wunschel, Die Kapitulation von Fürth, S. 7-16; OB Fürth an RegPräs, 3. Juli 1945, in: Stadtverwaltung Fürth, EAP 4; Annual Hist. Rep., Det. Fürth, 20. Juni 1946, in: NA, RG 260, 10/81-1/5, und Bericht der Stadt Fürth vom 7. Mai 1946, in: Stadtverwaltung Fürth, EAP 060. 
Erhard ließ sich davon nicht täuschen. In seinen Augen waren die Schäden schnell $\mathrm{zu}$ beheben und alles in allem nicht so gravierend, daß sie einen Wiederaufbau ernstlich beeinträchtigen konnten. Er wußte, daß die Arbeiter sofort nach Kriegsende wieder an ihren Arbeitsplätzen standen. Ihm war bei den Gesprächen mit Industriellen und Geschäftsleuten nicht verborgen geblieben, daß Maschinen und Fertigungshallen größtenteils nicht beschädigt und fast überall beträchtliche Vorräte an Rohstoffen vorhanden waren. Außerdem war ihm bekannt, daß die Versorgung Frankens mit Kohle aus dem mitteldeutschen Kohlegebiet und dem Ruhrgebiet relativ gut funktionierte. Die Denkschrift des Wirtschaftswissenschaftlers vom Mai 1945 fiel dementsprechend positiv aus: Die Fürther Industrie habe durch „die Luftwaffen der Vereinigten Nationen relativ geringe Zerstörungen hinnehmen“ müssen und sei in „ihrem Gesamtgefüge sofort einsatzfähig“. Die Möbelindustrie mit „14 größeren Industriebetrieben und rund 100 teilweise recht bedeutenden Handwerksbetrieben“ der wichtigste Fürther Wirtschaftszweig habe das Kriegsende fast unbeschadet überstanden. „Die teilweise beschädigten Betriebe sind nach kurzfristiger Überholung und nach Heranführung auswärtiger Lager ... produktionsbereit ... Mit wenig Ausnahmen ist die technische Produktionsbereitschaft vorhanden, wenn auch in den letzten Wochen durch Beraubungen von Werkzeugen und Material eine Minderung eingetreten ist." Rohstoffe seien, wie auch in allen anderen Branchen, noch in reichem Maße vorhanden; die Möbelindustrie könne „3-4 Monate aus verfügbaren Beständen“ produzieren. Zu Pessimismus bestehe auch deshalb kein Anlaß, weil - wie Erhard richtig erkannt hatte - die „Spezifische Eigenart der Fürther Industrie ... deren Einsatz für Rüstungszwecke nur in relativ beschränktem Umfange“ zugelassen habe ${ }^{3}$. Produktionsbeschränkungen der Besatzungsmacht, so konnte man aus der Denkschrift herauslesen, hatte die Fürther Industrie also kaum zu befürchten.

Ein amerikanischer Professor für Nationalökonomie, der im Frühjahr 1945 durch das besetzte linksrheinische Deutschland und große Teile Hessens und des Ruhrgebiets reiste, gelangte nach zahlreichen Gesprächen mit führenden Wirtschaftsexperten zu ganz ähnlichen Einschätzungen: „Im allgemeinen herrscht die Ansicht, die katastrophal schlechte Lage könne schnell und grundlegend überwunden werden ... Wir selbst sahen mehrere Maschinenfabriken und Hüttenwerke, die man vollständig abschreiben kann. Die drei großen Betriebe der I. G. Farben in Frankfurt, darunter auch das große Werk in Hoechst, weisen andererseits fast keine Schäden auf. Nach den Angaben der Offiziere der Rhine Coal Control (RCC), haben die Bergwerke an der Ruhr kaum Schäden erlitten. Der Zustand der Fördereinrichtungen würde es gestatten, sie in wenigen Monaten so weit wiederherzustellen, daß sie fast wieder die volle Produktion aufnehmen können.“ Ein Direktor bei Krupp habe versichert, „die Stahlproduktion an der Ruhr könne innerhalb von vier Monaten auf $2 / 3$ oder sogar $3 / 4$ der Kriegsproduktion steigen, wenn Kohle, Transportmöglichkeiten und Arbeitskräfte verfügbar wären. Der überraschend gute Zustand der Krupp-Werke, die sich im Zentrum des verwüsteten Essen und in dem vorgelagerten Stadtteil Borbeck befinden, läßt diese Einschätzung nicht unrealistisch erscheinen. “4

3 Denkschrift von Erhard, Mai 1945, in: Ludwig-Erhard-Archiv, NL Erhard, NE 746 A

4 Zit. nach Borsdorf/Niethammer, Zwischen Befreiung und Besatzung, S. 48. 
Erste Anzeichen einer wirtschaftlichen Erholung schienen den Optimismus der Experten zu bestätigen. Nach einer Phase des „praktischen Stillstandes“ beim Einmarsch der amerikanischen Streitkräfte waren im Juli 194510 Prozent der Industrieanlagen in der amerikanischen Zone wieder in Betrieb. Der Historiker kann die beginnende Besserung an den Zahlen ablesen: Im August erreichte die industrielle Produktion in der US-Zone 11 Prozent des Standes von 1936, im September 13 Prozent. Bis Dezember 1945 stieg sie kontinuierlich auf 20 Prozent an ${ }^{5}$. Aber was verbirgt sich hinter diesen Zahlen? Welche unternehmerischen Entscheidungen mußten oder konnten in den ersten Monaten nach dem Krieg angesichts einer unsicheren Zukunft getroffen werden? Gelang es den Betrieben, ihre alten Geschäftsverbindungen im In- und Ausland wieder aufzunehmen? Uber wieviel Kapital verfügten Gewerbe- und Industriebetriebe? Wie verhielt sich die Militärregierung, die in ihrem, von Morgenthau beeinflußten SHAEF-Handbuch angekündigt hatte, keine Schritte zu unternehmen, „die der wirtschaftlichen Wiedergesundung Deutschlands dienen " könnten ${ }^{6}$ ? Wie gestalteten sich die Binnenbeziehungen von Betriebsräten und Unternehmern?

Diese Fragen sind leicht gestellt, aber nur schwer zu beantworten. „Wie stellen Sie sich das eigentlich vor?", war von Gewerbetreibenden, Kleinindustriellen und Betriebsräten häufig zu hören, wenn man nach schriftlichen Unterlagen fragte. Kleinere Betriebe, so hieß es allgemein, führen keine Archive, oft nicht einmal eine Registratur. Tagebücher, private oder Geschäftsbriefe zu finden, war bei der ausgeprägten „Tintenscheu" von Handwerkern und kleinen Gewerbetreibenden sowieso ausgeschlossen. Vieles sei auch bei späteren Umzügen verloren gegangen, das meiste aber habe man damals überhaupt nicht schriftlich niedergelegt. Manches sei ja etwas am Rande der Legalität gewesen: Kompensationsgeschäfte und Schiebereien an den offiziellen Bewirtschaftungsstellen vorbei. Die großen traditionsreichen Eisen- und Stahlwerke im Ruhrgebiet, die Chemie- und Textilkonzerne in Südwestdeutschland und die Elektrofabriken in Berlin haben sicher mehr Gespür für ihre Geschichte entwickelt und ihre Unterlagen systematisch gesammelt. In Handwerks- und kleinen Industriebetrieben ist man dagegen sonderbar unachtsam gewesen in bezug auf die eigene Vergangenheit. Nicht einmal die Elektrofabrik Max Grundig verfügt über ein gut geführtes Werksarchiv; die Zeit des Aufbruchs nach dem Krieg war schnell, Bilanzen von heute waren morgen schon weit überholt und gerieten deshalb alsbald in Vergessenheit. Daß ein kleines Aktenbündel über die Anfänge von Grundig erhalten geblieben ist, verdankt sich dem privaten Interesse eines kleinen Angestellten in der Registraturabteilung. Die Dynamit Nobel AG hat nur drei Kisten mit Akten aus der Zeit nach der Währungsreform aufgehoben. Und auch im stattlichen Bau der Industrie- und Handelskammer Nürnberg werden nur einige Blätter über die erste Nachkriegszeit verwahrt.

Die staatlichen Stellen (Wirtschaftsämter, Landesstellen, Wirtschaftsministerien) erfuhren über die internen Probleme und Entscheidungen der Betriebe meist wenig. Sich vom Staat nicht zu sehr in die Karten gucken zu lassen - diese Mentalität ist für kleine Gewerbetreibende vielleicht noch typischer als für die große Industrie; entsprechend spärlich ist die Aktenüberlieferung in den staatlichen Archiven. Wirtschaftsäm-

5 Vgl. Werner Abelshauser, Wirtschaft in Westdeutschland. Rekonstruktion und Wachstumsbedingungen in der amerikanischen und britischen Zone, Stuttgart 1975, S. 39.

6 Zit. nach ebenda, S. 88. 
ter und -ministerien wurden meist nur dann eingeschaltet, wenn sich Beschwerden und Klagen ergaben, weshalb sich auch die zunehmenden Schwierigkeiten, die bald jegliche unternehmerische Initiative abzuschnüren drohten, sehr viel besser darstellen lassen.

Schon im Sommer 1945 machten sich die Folgen der sich mehr und mehr verfestigenden Teilung Deutschlands bemerkbar. Der traditionelle Austausch zwischen Thüringen und Franken, dem Ruhrgebiet und Württemberg war unterbrochen und kam nur schwer wieder in Gang. Manche sprachen sogar von einer „Inselstellung“ der einzelnen Landkreise und Städte. „Freier Handel mit vielen Gegenständen wurde in ganz Deutschland ermuntert", so die Militärregierung für Ober- und Mittelfranken, „aber die Hindernisse, sogar zwischen einzelnen Kreisen, waren nur schwer zu überwinden. ${ }^{“ 7}$ Wie hemmend diese Barrieren wirken konnten, darauf wies das Regierungswirtschaftsamt für Ober- und Mittelfranken hin: „Die Nürnberger Fahrradfabriken haben früher weite Gebiete Deutschlands mit Fahrrädern versorgt, sind aber zur Zeit durch den Mangel an wichtigen Zulieferungsteilen (z. B. Pedale, Speichen usw.) insbesondere aber an Bereifung, in ihrer Fertigung stark gehemmt. Die Zulieferungsteile müssen von Spezialfabriken des Rheinischen Industriegebietes bezogen werden, in den letzten Monaten konnten jedoch infolge der Unklarheiten im Interzonen-Verkehr keine ausreichenden Mengen beschafft werden ... Durch die Unmöglichkeit, die bereits fertiggestellten Fahrräder mit Reifen zu versehen, geraten die Nürnberger Fahrradfabriken immer mehr in bedenkliche finanzielle Schwierigkeiten und trachten danach, ihre Fahrradbestände unbereift abzusetzen." ${ }^{\text {"8 }}$

Die aus der NS-Zeit stammenden Vorräte, die Erhard in seinem Gutachten als wichtigen Aktivposten für eine wirtschaftliche Belebung bezeichnet hatte, gingen nach einigen Monaten zu Ende. Maurermeister, die sich vor Aufträgen kaum retten konnten, mußten oft abwinken, weil Bauholz, Kalk und Zement knapp waren. Schreiner und Tischler machten sich unbeliebt, weil sie nicht termingerecht lieferten; ihnen mangelte es an Leimen und Metallbeschlägen. Im Sommer 1945 traten auch Engpässe bei der Versorgung mit Kohle auf. Zahlreiche Stockungen im Verkehrswesen trugen dazu bei, außerdem forderten auch hier die Zonengrenzen ihren Tribut. Im Ruhrgebiet und im mitteldeutschen Kohlegebiet war nämlich die amerikanische Besatzungsmacht von den Briten und Sowjets abgelöst worden, die natürlich zuerst an die Versorgung ihrer eigenen Zonen dachten. „Damit stehen wir vor ganz neuen Tatsachen“, so lautete der Kommentar des Ansbacher Regierungspräsidenten?. Nicht einmal die wichtigsten Betriebe und öffentlichen Einrichtungen erhielten ausreichend Brennstoff. „Die Kohlenlage ist als katastrophal zu bezeichnen. Nur mit Hilfe der amerikanischen Militärregierung ist es zur Zeit möglich, die Ernährungsbetriebe - und auch hier nur zum Teil - mit Brennstoffen zu versorgen“, schrieb das Fürther Stadtoberhaupt schon am 3. Juli 1945 an den Regierungspräsidenten ${ }^{10}$. Die immer wieder als Retter in der

7 Military Government Headquarters, Ober- und Mittelfranken, an Director of OMGB, 5. November 1945, in: NA, RG 260, 10/81-3/8.

B Bericht des Regierungswirtschaftsamtes für Ober- und Mittelfranken, 21. Dezember 1945, in: BayHStA, MWi 9625.

9 Besprechung des RegPräs mit OB und LR, 9. Juli 1945, Prot. in: Stadtarchiv Ansbach, ABc T/5/3.

10 In: Stadtverwaltung Fürth, EAP 4. 
Not angerufene Militärregierung konnte freilich nicht immer helfen. Auf dem Lande mußten deshalb Bäckereien zeitweise schließen, der Betrieb der Schlachthöfe war gefährdet. Stadtväter und Dorfbürgermeister dachten angesichts des Mangels an Hausbrand mit Schrecken an den Winter. „Die Herbeischaffung von Kohle ist", so das Ansbacher Wirtschaftsamt, ,heute oberstes Gebot." ${ }^{\text {"11 }}$

Im selben Zeitraum wurden die wirtschaftlichen Grundsätze des Potsdamer Protokolls vom 2. August 1945 bekannt, die in krassem Gegensatz zur bisherigen, überwiegend konstruktiven amerikanischen Politik standen. Sie lasen sich so, als läge es in der Absicht der Alliierten, Deutschlands Notlage zu verewigen. Die Siegermächte beanspruchten die deutsche Kriegs- und Handelsflotte sowie das gesamte Auslandsvermögen und befahlen die Demontage eines großen Teils der deutschen Industrieanlagen. U. a. hieß es im Potsdamer Protokoll: „In praktisch kürzester Frist ist das deutsche Wirtschaftsleben zu dezentralisieren mit dem Ziel der Vernichtung der bestehenden übermäßigen Konzentration der Wirtschaftskraft, dargestellt insbesondere durch Kartelle, Syndikate, Trusts und andere Monopolvereinigungen ... Bei der Organisation des deutschen Wirtschaftslebens ist das Hauptgewicht auf die Entwicklung der Landwirtschaft und der Friedensindustrie für den inneren Bedarf (Verbrauch) zu legen. ${ }^{“ 12}$ Am 28. März 1946 nahm der Alliierte Kontrollrat nach langen Verhandlungen einen Industrieplan an, der jedem verdeutlichte, was sich hinter den unbestimmten Potsdamer Beschlüssen verbarg. Danach sollte die zukünftige deutsche Industrieproduktion auf 50 bis 55 Prozent des Standes von 1938 festgesetzt werden; das ensprach etwa dem Niveau des Krisenjahres 1932, als im Deutschen Reich sechs Millionen ohne Arbeit gewesen waren und ein Drittel aller Deutschen von öffentlichen Mitteln gelebt hatte $^{13}$.

In der zweiten Hälfte des Jahres 1945 traten auch die Mängel des aus der NS-Zeit stammenden Bewirtschaftungssystems, das die Alliierten beibehalten hatten, offen zutage. In der amerikanischen Zone fehlte für eine konsequente Lenkung von Produktion und Verteilung in der Industrie "jede organisatorische Voraussetzung “14. Knappe Güter sollten durch die Wirtschaftsministerien der Länder verteilt werden; bei der Vergabe von Roh- und Hilfsstoffen legte man einen sehr groben Verteilungsschlüssel an. Das Ergebnis war dürftig: Die Belieferung der Betriebe mit Kohle, Eisen oder Textilien ähnelte einem Lotteriespiel. Alles, was an Anweisungen von oben komme, sei nicht Wirtschafts-, sondern „Luftpolitik“"15, spottete deshalb der Leiter des Ansbacher Wirtschaftsamtes. Schon im Herbst 1945 wurde deutlich: Der von namhaften Experten im Frühjahr 1945 für möglich gehaltene rapide Aufschwung würde nicht eintreten; selbst die Anzeichen einer leichten Besserung schienen angesichts unüberwindlicher Probleme sehr gefährdet.

11 Bericht des Ansbacher Wirtschaftsamtes, 3. Juli 1945, in: Stadtverwaltung Ansbach, EAP 022-95/19.

12 Ernst Deuerlein (Hrsg.), Potsdam 1945. Quellen zur Konferenz der „Großen Drei“, München 1963, S. 357.

13 Vgl. Eschenburg, Jahre der Besatzung, S. $271 \mathrm{f}$.

14 Abelshauser, Wirtschaft in Westdeutschland, S.73

15 Monatsbericht des Ansbacher Wirtschaftsamtes, 25. Januar 1946, in: Stadtarchiv Ansbach, ABc T/5/6. 


\section{Ansätze zu einer Säuberung der Wirtschaft: Gesetz Nr. 8 und Treuhänderwesen}

Die Reihe der Hindernisse, die einer schnellen wirtschaftlichen Erholung im Wege standen, wurde im Herbst 1945 noch durch eine Maßnahme der Militärregierung erweitert: die Säuberung der Wirtschaft nach Gesetz Nr. 8 („Verbot der Beschäftigung von Mitgliedern der NSDAP in geschäftlichen Unternehmen und für andere Zwecke, mit Ausnahme der Beschäftigung als gewöhnliche Arbeiter") ${ }^{16}$. Dieses Gesetz erstickte nach Meinung des Fürther Landrats jede „Initiative für einen erfolgreichen Wiederaufbau“17. Seine Veröffentlichung am 29. September 1945, so urteilte die Fürther Militärregierung in ihrem Jahresbericht vom 20. Juni 1946, „verursachte die größte Bestürzung, die bis dahin ein Befehl der Besatzungsmacht hervorgerufen hatte"18.

Lucius D. Clay persönlich hatte dies heraufbeschworen. Er gab im Sommer 1945 eine Direktive in Auftrag, derzufolge auch „Nazis oder Militaristen in der Wirtschaft, im Handwerk und in anderen Berufen", die bis dahin - anders als die Parteigenossen im öffentlichen Dienst - von Entnazifizierungsmaßnahmen weitgehend verschont geblieben waren, härter angefaßt werden sollten. Diese sollten nun keine Möglichkeit mehr haben, „Reichtum, Macht und Einfluß nur deshalb zu erhalten, weil sie kein öffentliches Amt oder eine Position in einem großen finanziellen oder industriellen Unternehmen innehatten ${ }^{\text {"19. }}$. Gesetz Nr. 8, das daraufhin erlassen wurde, verpflichtete jedes Unternehmen, Mitglieder der NSDAP oder einer der ihr angeschlossenen Organisationen sofort aus „beaufsichtigenden oder leitenden Stellungen“ zu entlassen. Andernfalls würde das Unternehmen von der Militärregierung geschlossen und der „Täter durch ein Gericht der Militärregierung nach dessen Ermessen mit jeder gesetzlich zulässigen Strafe bestraft" ${ }^{\text {“20. }}$.

Die Deutschen in der mittelfränkischen Provinz hatten dem Problem einer politischen Säuberung der Wirtschaft bis dahin keine größere Beachtung geschenkt. In den vielen kleinen Betrieben war die Konfrontation in der NS-Zeit nur in Ausnahmefällen so scharf gewesen, daß es nach dem Zusammenbruch des NS-Regimes zu einer Welle von Abrechnungen gekommen wäre. Ob ein Kollege bei der NSDAP gewesen war oder nicht, spielte im innerbetrieblichen Umgang keine ausschlaggebende Rolle, vorausgesetzt freilich, daß er ,anständig“ geblieben war. Anders dagegen die Situation in den größeren Betrieben Nürnbergs und Fürths. Hier waren im Frühjahr 1945 einige verhaßte Betriebsführer von $\mathrm{CIC}$ inhaftiert worden, andere wagten sich nicht mehr an ihre Arbeitsplätze zurück. Außerdem hatten sich überall sozialdemokratische und kommunistische Betriebsräte gebildet, die NSBO-Funktionäre und leitende Angestellte, die in den zurückliegenden Jahren die Belegschaft schikaniert hatten, vor die Tür setzten. In Nürnberg beispielsweise galten im Juli 1945 alle großen Industriebe-

${ }^{16} \mathrm{Zu}$ Entstehungsgeschichte und Inhalt von Gesetz Nr. 8 und zu Ausführungsbestimmung Nr. 1 vgl. Niethammer, Entnazifizierung, S. 240-245. Vgl. auch den Gesetzestext, in: Sammlung Hemken.

17 LR Fürth, Monatsbericht vom 25. Februar 1946, in: StA Nürnberg, LRA Fürth (1962), Nr. 40/2.

18 In: NA, RG 260, 10/81-1/5.

19 Niethammer, Entnazifizierung, S. 157.

20 Gesetz Nr. 8, in: Sammlung Hemken. 
triebe als gesäubert; in einem Werk war man sogar so weit gegangen, alle Mitglieder der NSDAP und ihrer Gliederungen zu entlassen. Die Firma sei "nazirein“, meldete daraufhin der Betriebsrat an die Militärregierung ${ }^{21}$.

Gesetz Nr. 8 markierte den Höhepunkt der überzogenen amerikanischen Säuberungspolitik. Konzipiert, um eine Gleichbehandlung von Mitgliedern des öffentlichen Dienstes und der freien Wirtschaft zu garantieren, mußte es freilich in seiner Pauschalität nur neue Ungerechtigkeiten schaffen. Betroffen waren nun nicht mehr nur Pgs, die vor 1937 in die NSDAP eingetreten waren, sondern alle Parteigenossen - der „Alte Kämpfer“ ebenso wie der „Märzgefallene“ und das NSDAP-Mitglied seit $1942{ }^{22}$. Wieder hatte es die Militärregierung - wie schon beim Erlaß der Juli-Direktive, die ganze Heerscharen von Beamten und Angestellten um ihre Arbeitsplätze brachte - in erster Linie darauf abgesehen, die amerikanische Öffentlichkeit zu beruhigen und der heimischen Presse keinen Anlaß zur Kritik an mangelndem Säuberungseifer zu liefern. Ob sie dadurch der deutschen Realität während der NS-Zeit gerecht wurde, war ihr einige Monate nach der Kapitulation verständlicherweise weniger wichtig.

Daß die Militärregierung vor der Radikalität ihres eigenen Gesetzes selbst etwas zurückschreckte, zeigte sich freilich schon wenig später, als sie eine Ausführungsbestimmung erließ, in der es hieß: „Wer behauptet, daß er ... zu Unrecht entlassen ... worden ist, kann bei dem Oberbürgermeister oder Landrat ... Vorstellung erheben.“ Über diese „Vorstellung befindet in erster Linie der Prüfungsausschuß, der für jeden Kreis vom Oberbürgermeister oder Landrat mit Genehmigung und unter Aufsicht der Militärregierung eingesetzt wird." Damit war ein wesentliches Ziel erreicht, das alle deutschen Politiker seit Beginn der politischen Säuberung angestrebt hatten, nämlich die Beteiligung der Deutschen an den Säuberungsmaßnahmen der Militärregierung ${ }^{23}$.

Der deutschen Öffentlichkeit blieb dieser bedeutende Fortschritt zunächst verborgen, ihre Aufmerksamkeit war anderweitig abgelenkt. An den Stammtischen, beim Einkaufen und im Kreis der Familie diskutierte man gerade aufgeregt über die Massenentlassungen aus dem öffentlichen Dienst und die Einsetzung von Treuhändern, die - wie bald gezeigt wird - vielen kleinen Geschäftsleuten und Handwerksmeistern drohte. Mußten jetzt auch noch Vorarbeiter, Geschäftsführer und Abteilungsleiter um ihre Posten zittern, fragte man sich besorgt. Die Anweisungen seien „scharf und streng“, betonte Ansbachs Oberbürgermeister im Beratenden Ausschuß der Stadt. „Ich kann mir vorstellen“, fügte er hinzu, „daß zahlreiche Ansbacher Geschäftsleute, Gewerbetreibende, Handwerker usw. in den nächsten Wochen Böses erleben werden.“24

Die allgemeinen Befürchtungen schienen sich zu bestätigen, als die Militärregierung im Oktober 1945 auf Entlassungen in der freien Wirtschaft drängte. Leider lassen uns die Quellen fast ganz im Stich, wenn es gilt, den Personenkreis zu bestimmen,

21 Vgl. Niethammer, Entnazifizierung, S. 132; vgl. auch Alexander von Plato, Nachkriegssieger. Sozialdemokratische Betriebsräte - Eine lebensgeschichtliche Untersuchung, in: Lutz Niethammer (Hrsg.), „Hinterher merkt man, daß es richtig war, daß es schiefgegangen ist“. Nachkriegs-Erfahrungen im Ruhrgebiet, Berlin/ Bonn 1983, S. $330 \mathrm{ff}$

22 Vgl. Niethammer, Entnazifizierung, S. $240 \mathrm{ff}$.

23 Vgl. dazu auch S. 116; Beleg für die Ausführungsbestimmung in Anm. 16.

24 So Schregle am 9. Oktober 1945 im Beratenden Ausschuß der Stadt; Prot. der Sitzung, in: Stadtverwaltung Ansbach, Registratur des OB. 
der unter die neue Säuberungsmaßnahme fiel. Uns bleibt deshalb verborgen, ob und wieviele Vorarbeiter und Betriebsleiter, die in den zurückliegenden Jahren den „Nazi“ herausgekehrt, Spitzeldienste geleistet oder Fremdarbeiter traktiert hatten, ihre Stellen verloren. Lediglich in den Unterlagen des Landratsamtes Fürth finden sich einige Anhaltspunkte, die vermuten lassen, daß Gesetz $\mathrm{Nr} .8 \mathrm{im}$ mittelständischen und bäuerlich-ländlichen Milieu eher harmlose Parteigenossen betraf, mit deren Entlassung kaum jemand einverstanden war. In Ammerndorf erhielt beispielsweise der Geschäftsführer einer kleinen, für die Marktgemeinde aber wichtigen Schmiede- und Reparaturwerkstätte die fristlose Kündigung. Der neue Bürgermeister, der den Mann kannte und wie viele andere gegen die Entlassung protestierte, schilderte den Fall so: „In dem Betrieb werden nur Reparaturen durchgeführt, die für die Erhaltung der landwirtschaftlichen Betriebe in Ammerndorf von lebenswichtiger Bedeutung sind. Nach jetzt erfolgter Entlassung des Hans Berthal ist der Betrieb nicht mehr in der Lage die Reparaturen für die Bauern auszuführen, da dem Betrieb eine geeignete Ersatzkraft fehlt. In dem Betrieb arbeiten jetzt nur noch ein Geselle, der erst am 13.8.45 eingetreten ist, und ein Lehrling im ersten Lehrjahr. Ein anderer Betrieb ist in Ammerndorf nicht vorhanden, der in der Lage wäre, alle Arbeiten eines Dorfschmiedes und alle Reparaturen an landwirtschaftlichen Maschinen und allen Fahrzeugen und Kraftfahrzeugen durchzuführen." ${ }^{25}$ Wenn man den Geschäftsführer schon bestrafen wollte, so dachten die Bauern, dann sollte man ihn zu Arbeiten für die Allgemeinheit verurteilen, anstatt ihn zu entlassen und damit auch die Bauern der Umgebung zu schädigen.

Im benachbarten Zirndorf wirbelte der Fall des Mechanikermeisters Michael Almer viel Staub auf. Almer, der seit 1928 bei der Firma Röschlein, Präzisionswerkzeuge und Maschinenbau, beschäftigt war, verlor seinen Arbeitsplatz, obwohl er nur Parteianwärter gewesen war $^{26}$. Und in Cadolzburg erregte man sich darüber, daß ein tüchtiger Schlossermeister seinen Betrieb einem Treuhänder übergeben mußte. Der neue Bürgermeister beschwerte sich deshalb: „Der Schlossermeister Hans Hart ist arm geboren, ist Absolvent der Kunstschule Nürnberg, ein sehr begabter Mann, hat sich unter den größten finanziellen Schwierigkeiten eine selbständige Existenz gegründet, hat nebenbei eine kinderreiche Familie, also neben den Geschäftssorgen noch familiär schwer zu kämpfen, ist Mitglied der NSDAP geworden, um das Geschäft halten zu können, und ist schließlich gezwungen, dasselbe in andere Hände zu geben."27 Vorsichtig fügte er noch hinzu: „Wir leben wieder in einem Staat, in dem es möglich ist, die Wahrheit zu sagen und der freien Meinung Ausdruck zu geben." Wenn er im Fall Hart Partei ergreife, so auch deshalb, weil er sich frage, ob bei der „restlosen Entnazifizierung der Gewerbetreibenden nicht doch die Allgemeinheit am meisten geschädigt“ sei. Er stand damit nicht allein.

Eine ganze Reihe von Betriebsinhabern und Geschäftsführern ließ es aber gar nicht erst bis zur Entlassung kommen. Nach den zahlreichen Entlassungen im öffentlichen Dienst hatten sie erkannt, daß es der Besatzungsmacht ernst war mit der politischen Säuberung. Sie wußten deshalb nach Erlaß von Gesetz Nr. 8 sofort, was die Stunde geschlagen hatte und trafen entsprechende Vorkehrungen. Der Mühlenbaumeister Mi-

25 Fallakten in: LRA Fürth, EAP 150/7.

26 Ebenda.

27 Bürgermeister von Cadolzburg an LR Fürth, 31. Dezember 1945, in: StA Nürnberg, LRA Fürth (1962), Nr. 1135. 
chael Sommer aus Ammerndorf beispielsweise trat, noch bevor er seinen Posten räumen mußte, aus der Leitung seines Betriebes zurück und bestellte den Schreinermeister Fritz Sommer, mit dem er weitläufig verwandt war, zum offiziellen Geschäftsführer. Er selbst arbeitete in seinem Betrieb als Gehilfe weiter, behielt aber alle Fäden in der Hand ${ }^{28}$.

Schlaue Vorarbeiter und Betriebsinhaber wie Sommer hatten bei ihren Versuchen, Gesetz Nr. 8 zu umgehen, häufig leichtes Spiel, denn das Gesetz hatte gravierende Mängel. Es war so vage formuliert worden, daß ein endloser Streit entstand, wer nun eigentlich betroffen war. Mußten nur Geschäftsführer und leitende Angestellte oder auch Geschäftsinhaber entlassen werden? Bezog sich das Gesetz nur auf Angestellte in Betrieben unter 10 Beschäftigten oder auf Angestellte aller Betriebe? Konnten die Betroffenen in ihren Betrieben als einfache Arbeiter verbleiben oder mußten sie ausscheiden, damit ihr verderblicher Einfluß auf die Geschäftsführung ganz ausgeschaltet war $^{29}$ ? In den Rathäusern und Landratsämtern, die für die Ausführung der Säuberungsrichtlinie sorgen sollten, herrschte bald eine babylonische Verwirrung. Die Sachbearbeiter mochten fragen, wen sie wollten, die Antworten lauteten immer verschieden. Regierungspräsident Schregle stellte dazu in seinem Monatsbericht an die bayerische Staatsregierung vom 18. Dezember 1945 fest: „Die Auslegung und Handhabung des Gesetzes ist örtlich sehr verschieden, je nach Einstellung der örtlichen Militärregierung und der örtlichen Dienststellen und Prüfungsausschüsse. Die Herausgabe von einheitlichen Richtlinien durch die überörtliche Militärregierung wäre erwünscht. “30 Die Industrie- und Handelskammer Nürnberg pochte in einem siebenseitigen Gutachten für das bayerische Wirtschaftsministerium ebenfalls auf Anordnungen, die „in der Form klar und einfach, nicht aber undeutlich und mißverständlich" seien ${ }^{31}$.

Das war es aber nicht allein. Die Militärregierung erkannte zu spät, daß der Kreis der Betroffenen wieder einmal zu weit gezogen war und die Detachments vor Ort, die schon alle Hände voll zu tun hatten, die Säuberung des öffentlichen Dienstes voranzutreiben, für eine Entnazifizierung des Gewerbelebens nicht eingerichtet waren. Mit beiden Aufgaben gleichzeitig betraut, konnten sie nur improvisieren - mit der Folge, daß vieles einfach dem Zufall überlassen blieb: Ein Schuster aus Langenzenn mußte seinen Zwei-Mann-Betrieb schließen, während sein Kollege aus dem Nachbarort mit der gleichen Belastung weiterarbeiten durfte. Ein Betrieb hatte Gesetz Nr. 8 bereits

${ }^{28}$ LRA Fürth, EAP 150/7. Als sich solche Praktiken überall einbürgerten, schritten Anfang November 1945 das bayerische Arbeitsministerium und die Militärregierung in München energisch ein und versuchten, die Mißstände zu beheben. Vgl. Niethammer, Entnazifizierung, S. 245.

29 Vgl. dazu OB Fürth an RegPräs, 12. Dezember 1945, in: StA Nürnberg, Reg von Mittelfranken (1978), Nr. 3367; RegPräs an die LR und OB von Mittel- und Oberfranken, 28. Januar 1946, in: Ebenda.

30 Monatsbericht in: BayHStA, Reg von Mittelfranken, Berichterstattung 1945, AZ 1-64, Bd. 7. Vgl. auch die Diskussion der Landräte und Oberbürgermeister Ober- und Mittelfrankens mit dem Regierungsprāsidenten auf ihrer monatlichen Tagung vom 10. Dezember 1945, Prot. in: StA Nürnberg, LRA Scheinfeld, Nr. 367. Diese Konfusion steigerte sich noch, als die Militärregierung von Ober- und Mittelfranken ihren Kurs auch nach dem Erlaß des Gesetzes zur Befreiung von Nationalsozialismus und Militarismus im März 1946 beibehielt (vgl. dazu Monatsbericht des Wirtschaftsamts der Stadt Ansbach vom 25. März 1946, in: Stadtarchiv Ansbach, ABc T/6/5), obwohl darin eindeutig festgelegt war, daß Belastete mit kleineren Betrieben (unter 10 Mann) weiter auf ihren Posten bleiben konnten und nicht unter das Beschäftigungsverbot fielen. Noch im Sommer 1946 waren die Unsicherheiten nicht gänzlich ausgeräumt. Vgl. LR Fürth an Staatsminister für Sonderaufgaben, 7. Juni 1946, in: LRA Fürth, EAP 150/7.

31 Gutachten vom 26. November 1945 (gerichtet an das bayerische Wirtschaftsministerium), in: StA Nürnberg, Reg von Mittelfranken (1978), Nr. 3367. 
durchgeführt, ein anderer noch nicht einmal die Ausführungsbestimmungen erhalten. Außerdem zeigte sich in konkreten Einzelfällen häufig, daß den örtlichen, mit den Verhältnissen vertrauten Militärregierungsoffizieren eine scharfe Entnazifizierung weniger am Herzen lag als das Funktionieren der Wirtschaft ${ }^{32}$. Vor die Entscheidung gestellt, einen belasteten, im Betrieb aber unabkömmlichen Parteigenossen zu entlassen oder dem Einspruch des Prüfungsausschusses stattzugeben, erteilten sie oft zeitweilige Arbeitsgenehmigungen. So erging es beispielsweise einem technischen Zeichner bei der Firma Matthias Oechsler und Sohn aus Ansbach, der nach Kriegsende unbehelligt seinen Beruf ausüben konnte, obwohl er zu den prominenten Parteigenossen der Stadt gehört hatte. Er verdankte dies seinem Chef, der einige Besatzungsoffiziere davon überzeugte, daß die Produktion der Firma ohne den Zeichner nicht anlaufen könne ${ }^{33}$.

Die Auswirkungen blieben so gering: In ganz Bayern wurden etwa 12000 Entlassungen ausgesprochen, in Ansbach verloren nur 51 Personen ihren Posten ${ }^{34}$. Im Frühjahr 1945 war das Gesetz obsolet, gewissermaßen überholt vom Gesetz zur Befreiung von Nationalsozialismus und Militarismus ${ }^{35}$. Auch für „Nazis und Militaristen in der Wirtschaft" sollten nun die Spruchkammern zuständig sein. Der Sonderweg einer politischen Säuberung, den man mit Gesetz Nr. 8 eingeschlagen hatte, erwies sich so schon bald als Sackgasse und war alles in allem nur eine Episode in der Geschichte der Entnazifizierung im besetzten Deutschland.

Die Aufregung über Gesetz Nr. 8 wäre vielleicht - wie schon angedeutet - weniger groß gewesen, wenn die amerikanische Militärregierung nicht kurz nach dem Einmarsch ihrer Streitkräfte - gestützt auf Militärregierungsgesetz Nr. 52 - alle „großen wirtschaftlichen Werte und Machtmittel“ im Besitze der NSDAP und des Deutschen Reiches sowie das Vermögen abwesender nichtdeutscher bzw. deutscher Staatsangehöriger (etwa Emigranten) und politisch belasteter Parteigenossen unter Kontrolle gestellt und für unbestimmte Zeit sogenannten Treuhändern anvertraut hätte ${ }^{36}$. Allein in Ansbach befanden sich über 100 Vermögenseinheiten unter Kontrolle; darunter beispielsweise 142 Hektar Übungsgelände der Wehrmacht, $50000 \mathrm{~kg}$ Papier der Fränkischen Zeitung, die 1945 ihr Erscheinen einstellen mußte, die Fleischwerke Schafft, aber auch Wohnhäuser, Betriebe und Grundstücke der örtlichen NS-Prominenz; etwa das Wohnhaus des früheren Kreispropagandaleiters Georg Bezold und die Werkstatt des früheren Ortsgruppenleiters Hans Hagelauer ${ }^{37}$. In ganz Bayern standen 1947 rund 26000 Vermögenseinheiten im Werte von immerhin sechs Milliarden Reichsmark unter Treuhänderschaft, etwa ein Drittel davon war Vermögen von politisch belasteten Personen $^{38}$. In bürgerlichen Kreisen und vor allem in der gewerblichen Wirtschaft

32 Vgl. dazu allgemein Niethammer, Entnazifizierung, S. $244 \mathrm{ff}$.

33 Mündliche Mitteilung von Albert Oechsler vom 17. August 1983.

34 Rund 8700 Betriebe waren von dieser Maßnahme betroffen. Vgl. den Bericht des Arbeitsministeriums über den Stand der Entnazifizierung der Betriebe in Bayern vom 10. Februar 1946, in: BayHStA, Arbeitsministerium (1978), Nr. 3231/32. Vgl. Arbeitsamt Ansbach an Landesarbeitsamt Franken, 25. Mārz 1946, in: Ebenda.

35 Vgl. dazu ein Schreiben des bayerischen Wirtschaftsministers Ludwig Erhard vom 15. April 1946, in: StA Nürnberg, Reg von Mittelfranken (1978), Nr. 3367.

36 Gesetz Nr. 52, in: Sammlung Hemken.

37 Undatierte Aufstellung über „Property taken under control“, in: NA, RG 260, 9/144-1/16.

38 Vgl. Bayerischer Staatsanzeiger vom 17. Mai 1947. 
hielt man diese Maßnahme der Militärregierung für den ersten bedeutsamen Schritt zu einer gesellschaftlichen Umwälzung und verteufelte sie entsprechend. Von „stiller Sozialisierung ${ }^{\text {" }}{ }^{39}$ sprachen die einen. Es drängten sich die „übelsten“ Elemente als Treuhänder auf und es „passierten die gleichen Dinge wie bei der Arisierung “ ${ }^{400}$, meinten die anderen, während die politisch Verfolgten hofften, das beschlagnahmte Vermögen werde dazu dienen, die „Opfer des Faschismus in gebührender Form zu entschädigen “'i1.

Die Einsetzung der Treuhänder lag zunächst ganz in den Händen der Militärregierung, die in der ersten Phase der Besatzungszeit im Troß der Streitkräfte mitziehende DP's und viele Juden, die die Schrecken der KZs überstanden hatten, zu Treuhändern machte. Die Ausländer waren in vielen Gegenden alles andere als gern gesehene „Gäste“. Zur Befürchtung, das eigene Hab und Gut sei bedroht, kamen die Angst vor einer Überfremdung und antisemitische Ressentiments. „Es sind mir aus einigen Landkreisen beredte Klagen zugegangen darüber", so Regierungspräsident Schregle in einer Besprechung mit den Landräten und Oberbürgermeistern seines Regierungsbezirks am 11. März 1946, „daß sich polnische Juden in einem überaus großen Umfang als Treuhänder ... einnisten. Von einer Gemeinde, die bisher rein katholisch war, wird mir berichtet, daß dort 49 polnische Juden aufgekreuzt sind und mehrere von ihnen sich angeblich mit einer Legitimation der Militärregierung als Treuhänder eingesetzt haben. “42 Da außerdem auch zahlreiche Konjunkturritter und anderes Gelichter, das sich um die Besatzungsmacht scharte, in einflußreiche Posten gelangten und dort entsprechend abkassierten, braute sich fast überall große Mißstimmung gegen die Treuhänder zusammen. Manche Treuhänder brachten ihre ganze Familie mit und verdrängten die Geschäftsinhaber nicht nur aus den Betrieben, sondern auch aus den Wohnungen. Im Landkreis Hof machte der Treuhänder einer Papierfabrik von sich reden, er hatte sich ein hohes Gehalt ausbedungen und gleichzeitig festgelegt, „daß alle fälligen Einkommenssteuern und Abgaben von dem Inhaber der Papierfabrik ... geleistet werden müßten“. Außerdem „beanspruchte er für sich 1 Prozent vom Um-

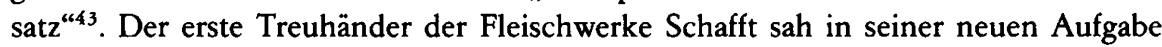
offensichtlich die Chance seines Lebens; er verschob zusammen mit dem Geschäftsführer $170000 \mathrm{~kg}$ Fleisch ${ }^{44}$. „Viele von diesen Treuhändern“, so faßte Regierungspräsident Schregle seine Erfahrungen zusammen, „erblicken die ihnen von der Besatzungsmacht übertragene Aufgabe darin, im Geschäft zu erscheinen, mit der deutlich

39 So Württemberg-Badens Justizminister Beyerle (CDU) in einem Schreiben vom 25. Juni 1946. Zit. nach AVBRD, Bd. 1, S. 579.

40 So Ehard im bayerischen Ministerrat vom 24. Oktober 1945, in: IfZ-Archiv, ED 120/354.

41 „Gedanken über die Verwaltung des Nazivermögens, welches dem Landesamt für Vermögensverwaltung und Wiedergutmachung durch Eigentumsentzug zufällt, sowie über die Nutzbarmachung des treuhänderisch zu verwaltenden jüdischen Vermögens im Interesse der Allgemeinheit“ von Staatskommissar Philipp Auerbach vom 3. Januar 1947, in: BayHStA, MWi 12031.

42 Prot. in: StA Nürnberg, LRA Scheinfeld, Nr. 367. Der Landrat von Pegnitz ergänzte: „Es sind nicht nur allein die bereits ansāssigen polnischen Juden zugezogen worden, sondern der Vertrauensmann der polnischen Juden hat noch aus Galizien Juden kommen lassen ... Sie sind von der Militärregierung als Treuhänder gegen unseren Willen und ohne jedes Wort der Verhandlung eingesetzt worden.“

43 LR Hof an RegPräs, 3. Januar 1946, in: StA Nümberg, Reg von Mittelfranken (1978), Nr. 3602. Vgl. auch Besprechung des RegPräs mit OB und LR, 8. April 1946, Prot. in: Ebenda, LRA Scheinfeld, Nr. 367.

44 Vgl. dazu Anm. 63. 
bekundeten Absicht, sich in den Besitz des Geschäfts zu setzen, sei es als Eigentümer oder Pächter." ${ }^{45}$

Um die Jahreswende 1945/46 befaßten sich das bayerische Kabinett und der süddeutsche Länderrat in Stuttgart mit dem Thema, das mittlerweile schon sehr viel böses Blut verursacht hatte. Man war sich einig: Die leidige Angelegenheit sollte so bald wie möglich in deutsche Hände übergehen, da die Militärregierung allem Anschein nach nicht in der Lage war, die Mißstände zu beseitigen. Schon in der Sitzung des bayerischen Kabinetts vom 7. Januar 1946 berichtete Ludwig Erhard, daß die Wirtschaftsminister der US-Zone einen Gesetzentwurf ausgearbeitet hätten, der von den Ministerpräsidenten bei der nächsten Zusammenkunft verabschiedet werden könne ${ }^{46}$. Der von Geiler, Hoegner und Maier in Stuttgart abgesegnete Entwurf ${ }^{47}$ ging aber noch von Ausschuß zu Ausschuß, und als er schließlich die allgemeine Zustimmung gefunden hatte, war er überholt. Die amerikanische Property Control-Abteilung hatte nämlich in der Zwischenzeit einen Teil ihrer Befugnisse auf deutsche Verwaltungsstellen (Landesamt für Vermögensverwaltung und Wiedergutmachung) übertragen, die nun im Gesetz berücksichtigt werden mußten. Den neuerlichen Vorschlag des Länderrats lehnte die Militärregierung am 28. August 1946 ab, weil ihr die deutschen Vorstellungen, die Vermögensverwaltung in die Kompetenz der Gerichte zu geben, zu weit gingen $^{48}$. „Über dem Treuhändergesetz leuchtet kein guter Stern“, so kommentierte Hans Ehard ${ }^{49}$ die Verzögerungen.

Anfang Februar 1947 waren dann endlich alle Meinungsverschiedenheiten ausgeräumt, und am 29. Mai 1947 stimmten alle Parteien des bayerischen Landtags dem Länderratsentwurf $z^{50}$. In Bayern erfolgte künftig die Bestellung, Beaufsichtigung und Abberufung der Treuhänder durch das Bayerische Landesamt für Vermögensverwaltung und Wiedergutmachung, das in allen Stadt- und Landkreisen Nebenstellen unterhielt. Zum Treuhänder konnte nur bestellt werden, „wer die Gewähr bietet, daß er die ihm anvertrauten Interessen uneigennützig wahrnimmt, und die im Einzelfall erforderliche Eignung nachweist“. Außerdem mußten die Treuhänder über jeden Schritt Rechenschaft ablegen. Fehlerhafte Geschäftsführung zog hohe Geld- und Gefängnisstrafen nach sich $^{51}$.

In der Praxis brachte das neue Treuhändergesetz, das die Politiker so lange beschäftigt hatte, keine größeren Neuerungen. Es stellte lediglich auf eine rechtliche Basis, was sich seit der Jahreswende 1945/46 aus dem improvisierten Zusammenspiel von deutscher Verwaltung und amerikanischer Militärregierung ergeben hatte. Bereits

4s Besprechung des RegPräs mit OB und LR, 8. April 1946, Prot. in: StA Nürnberg, LRA Scheinfeld, Nr. 367. Vgl. auch IfZ-Archiv, ED 120/356 und RegPräs an bay. Staatsregierung, 19. Mai 1946, in: BayHStA, Reg von Mittelfranken, Berichterstattung 1946, AZ 1-64, Bd. 6. Schregle hob hervor, daß besonders über Treuhänder auf Bauernhöfen geklagt würde: „Sie können von Bauern, deren Betrieb sie treuhānderisch verwalten, nicht zusätzlich Butter, Eier, Fett, Fleisch, Brennholz usw. verlangen. Wenn diese Mißstände nicht abgestellt werden, können die Bauern ihrer Ablieferungspflicht nicht mehr nachkommen."

46 IfZ-Archiv, ED 120/356.

$47 \mathrm{Vgl}$. AVBRD, Bd. 1, 235 f.

$48 \mathrm{Zu}$ den Auseinandersetzungen um das Treuhändergesetz vgl. ebenda, S. 578f. und Major William Kane (RGCO) an die Mitglieder des Rechtsausschusses beim Länderrat, 4. September 1946, in: BayHStA, MF 67.

49 So Ehard in der 16. Tagung des Lānderrats des amerikanischen Besatzungsgebiets in Stuttgart am 8. Januar 1947. Zit. nach AVBRD, Bd. 2, S.92.

so Vgl. 17. Sitzung des Bayerischen Landtags vom 29. Mai 1947, Sten. Berichte, S. 509.

51 Vgl. den Gesetzestext, in: BGVBl. 12/1947. 
damals hatte es sich die Militärregierung - selbst empört über die Mißgriffe bei der Auswahl der Treuhänder - zur Regel gemacht, die Bestellung und Kontrolle der Treuhänder de facto den Landräten und Oberbürgermeistern zu überlassen und sich selbst nur noch die formelle Einsetzung vorzubehalten ${ }^{52}$. Da man in den Rathäusern und Landratsämtern nach den vorangegangenen schlechten Erfahrungen wußte, daß diese Aufgabe viel Fingerspitzengefühl erforderte, waren die Ratsherren sehr darauf bedacht, nur zuverlässige und politisch einwandfreie Personen zu gewinnen. Ansbachs Oberbürgermeister sicherte sich nach allen Seiten ab und „vergesellschaftete“ mit $\mathrm{Zu}$ stimmung der Militärregierung alle unter Vermögensverwaltung fallenden Betriebe. „Nach einer Vereinbarung mit der Militärregierung übernimmt die Stadtverwaltung in jedem einzelnen Fall die Treuhänderschaft für die in Frage kommenden Firmen und

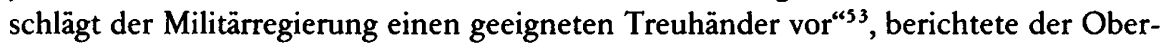
bürgermeister am 4. Januar 1946 an den Regierungspräsidenten.

So geprüft übernahm beispielsweise August Ströhlein ${ }^{54}$ aus Ansbach den Posten eines Treuhänders. Ströhlein, ein Maschineningenieur, verdankte sein Amt dem Zufall. Als er sich 1945 im Ansbacher Rathaus nach einer Anstellung erkundigte, verwies man ihn an den Leiter des Wirtschaftsamtes, der sich in der Stadtverwaltung hauptsächlich um das Treuhänderwesen kümmerte und ständig auf der Suche nach politisch unbelasteten Personen war. Ströhlein war der geeignete Mann; er stammte aus einer politisch liberal eingestellten Familie, hatte selbst der DDP angehört und war nie der NSDAP beigetreten. Nachdem sein Lebenslauf auch von CIC auf das genaueste durchleuchtet worden war, verwaltete er zunächst das kleine Mietshaus des „Alten Kämpfers" Hans Schreiner in der Baustraße. Diese Tätigkeit erforderte kaum eine Stunde Arbeit in der Woche. Ströhlein kontrollierte das Mietbuch und sah sich hin und wieder im Haus etwas um. Dem tatkräftigen, aber nicht ausgelasteten Mann kam es deshalb sehr gelegen, daß ihm zusätzlich die Treuhänderschaft bei der Nähseidenfabrik Messing und bei der Uniformeffektenfabrik Feuerlein angeboten wurde. Die Nähseidenfabrik, die 1945/46 rund 60 Personen beschäftigte, war bis 1933 im Besitz eines Zahnarztes und dessen jüdischer Frau gewesen. Nach der Machtergreifung der NSDAP hatte sich der Zahnarzt scheiden lassen, später erneut geheiratet und die Leitung der Firma seiner neuen Frau übertragen. Als Fall von gleichsam innerfamiliärer Arisierung kam die Fabrik 1945 unter Vermögenskontrolle. Die alte Inhaberin, die den Treuhänder als ernste Bedrohung ihres Besitzes ansah, behandelte Ströhlein zunächst mit großem Respekt und ungewohnter Freundlichkeit und sparte nicht mit Andeutungen über eine eventuelle Beschäftigung Ströhleins in der Firma, wenn die schweren Zeiten erst einmal vorüber wären. Die Sorgen der Inhaberin verflogen aber schnell, als sich herausstellte, daß Ströhlein sich nicht in den Betrieb einzumischen gedachte. Er überließ die Geschäfte dem langjährigen Prokuristen. „Ich selbst“, so Ströhlein, „habe etwas in den Akten geblättert, als ob ich auch etwas verstünde.“

Während Ströhlein bei Messing den Dingen ihren Lauf lassen konnte und nur etwa alle zwei Tage ins Werk kam, gestaltete sich die Treuhänderschaft bei Feuerlein schwieriger. Er fungierte in der stillgelegten Effektenfabrik, die einem „Alten Kämp-

52 Vgl. dazu etwa OB Fürth an RegPrās, 12. Dezember 1945, in: StA Nürnberg, Reg von Mittelfranken (1978), Nr. 3367.

53 OB Ansbach an RegPräs, 4. Januar 1946, in: StA Nürnberg, Reg von Mittelfranken (1978, Zusatz), Nr. 3602.

54 Mündliche Mitteilung von August Ströhlein vom 26. August 1983. 
fer" gehörte, als Geschäftsführer und sorgte für die Verwertung der ausgelagerten und z. T. versteckten Rohstoffe - ein full-time-job, der mit etwa 250,- RM dotiert war. In allen Fällen verstand sich Ströhlein als neutraler Verwalter. Er hütete sich davor, in die eigene Tasche zu wirtschaften. Er dachte aber auch nicht daran - wie manche Verfolgten erwarten mochten -, ohne politischen Auftrag Maßnahmen zu ergreifen, die zur Entschädigung von NS-Opfern beitragen konnten.

Der neutrale Ströhlein war keine Ausnahme. Durch die Einschaltung der Oberbürgermeister und Landräte gelangte das Treuhänderwesen schon bald in ruhigere Bahnen. Der Landrat von Neustadt a.d. Aisch schrieb am 12. Februar 1946: „Besondere Mißstände bei Einsetzung und Amtsführung von Treuhändern sind im Landkreis nicht aufgetreten. Auch das örtliche Handelsgremium berichtet nicht von solchen Fällen im Landkreis, übt vielmehr allgemeine Kritik an der Art, wie sich Ortsfremde und nicht bayerische Personen an solche Posten heranmachen wollen." ${ }^{\text {s5 }}$ Die Einsetzung von Treuhändern, so berichtete im Januar 1946 auch der Landrat von Hof, „ist im allgemeinen ohne Reibungen vor sich gegangen. Wirtschaftliche Störungen sind nicht aufgetreten." Der Landrat von Rothenburg ob der Tauber wußte im Februar 1946 nur von zwei Fällen, wo „der von der Militärregierung eingesetzte Treuhänder wegen Mangels an moralischer und fachlicher Eignung wieder entfernt" werden mußte ${ }^{56}$. Und im Herbst 1947 lautete das Resümee des Bayerischen Landesamtes für Vermögensverwaltung und Wiedergutmachung: Der „größte Teil der Treuhänder verwaltet ... das anvertraute Vermögen einwandfrei und bringt durch persönliche Tüchtigkeit, aber auch durch Einschaltung der Behörde manches Unternehmen besser voran als der Eigentümer es vermöchte" ${ }^{\text {(57 }}$.

Schon 1946 bestand also kaum mehr Anlaß zur Klage. Gleichwohl wurde „Treuhänder" mehr und mehr zum Reizwort. Seit Mitte des Jahres 1946 die Spruchkammern zu arbeiten begonnen hatten und Kreisleiter, Ortsgruppenleiter sowie andere prominente Nationalsozialisten mit dem Einzug ihrer Häuser, Bauernhöfe und Ersparnisse bestraften, stieg die Zahl der Vermögensobjekte in Treuhänderschaft stetig an: Anfang 1947 waren es 26000 , ein halbes Jahr später über 30000 und im Juni 1948 erreichte diese Entwicklung mit über 32600 ihren Höhepunkt. Weit über tausend Industriebetriebe, mehr als 4000 Handels- und Dienstleistungsbetriebe, über 600 Gehöfte und 16000 Grundstücke standen damals in Bayern unter Kontrolle ${ }^{58}$. Von zwei Seiten her gerieten die Treuhänder nun immer mehr unter Beschuß.

In den Kreisen der politisch Verfolgten konnte man die Enttäuschung nicht länger verhehlen, daß die treuhänderisch verwalteten Vermögen kaum für Entschädigungen der Opfer des Nationalsozialismus genutzt wurden. „Man hat eine Verwaltungsbürokratie geschaffen, mit vielleicht verwaltungsmäßig qualifizierten Beamten, die jedoch den politischen Notwendigkeiten kein Verständnis entgegenbringen können“, hieß es

5s Bericht an die Reg von Ober- und Mittelfranken, in: StA Nürnberg, Reg von Mittelfranken (1978), Nr. 3602.

s6 LR Hof an RegPräs, 3. Januar 1946; LR Rothenburg an RegPräs, 15. Februar 1946, in: StA Nürnberg, Reg von Mittelfranken (1978), Nr. 3602.

37 Jahresbericht des Bayerischen Landesamtes für Vermögensverwaltung und Wiedergutmachung vom 27. Oktober 1947, in: BayHStA, MWi 9611.

38 Vgl. dazu Comparative Statistics of Properties under Control by reason for Control, in: Akten der Bezirksfinanzdirektion München (ungeordneter Bestand); vgl. auch Bayern in Zahlen. Monatshefte des Bayerischen Statistischen Landesamts, Heft 10, Okt. 1948, 2. Jg., S. 239. 
in einer Denkschrift von Philipp Auerbach, dem Staatskommissar für die Verfolgten des Naziregimes. Es bestehe somit die Gefahr, „daß ernannte Treuhänder als Liebediener ihrer früheren Nazichefs sich als Statthalter der Nazis fühlen und in Erwartung der nächsten Amnestie ihren Chefs das entzogene Gut zurückgeben wollen" 59 . Wesentlich schärfere Kritik kam aus den Reihen von CSU und FDP. Fünf Milliarden Reichsmark (d.h. ein Drittel des bei der Vermögenssteuerveranlagung erfaßten Vermögens) befanden sich Mitte des Jahres 1947 in Bayern unter Treuhänderschaft, in der gesamten US-Zone rund zehn Milliarden ${ }^{60}$. Solche ungeheueren Summen in der Verwahrung einer staatlichen Institution mußten der in bürgerlichen Kreisen nach 1945 latenten Befürchtung, die tradierte Eigentumsordnung sei in Gefahr, gewaltigen Auftrieb verleihen. Außerdem hielten CSU und FDP die staatlichen Treuhänder für unfähig, das verfügbare Kapital unternehmerisch sinnvoll zu nutzen. Aus diesen Motiven heraus empörte sich der CSU-Abgeordnete Krempl 1947 im bayerischen Landtag: Es komme jetzt auf die „Rettung des Volksvermögens“ an. Die Wirtschaft habe unter dem „Unwesen des Treuhänderwesens ungeheuer viel gelitten“61.

Der Gedanke, der die Amerikaner 1945 vornehmlich bewegt hatte, nämlich NSVermögen sicherzustellen und politisch Belastete zu bestrafen, spielte jetzt keine Rolle mehr. Überspitzt formuliert: Was als politische Säuberung der Wirtschaft begonnen hatte, war zwei Jahre später zur Säuberung der Wirtschaft von den Treuhändern geworden. Die Träger der amerikanischen Maßnahme waren also, wie schon am Beispiel des Personals der Spruchkammern gezeigt, wieder die Sündenböcke, derer man sich schleunigst entledigen wollte. Mochte derjenige, der einen Treuhänder in seinem Betrieb akzeptieren mußte, ein großer Nationalsozialist oder ein kleiner Mitläufer gewesen sein, diese Frage war nicht so wichtig. Allein die Tatsache, daß Außenstehende oder gar „ortsfremde“ Personen plötzlich in alteingesessenen Betrieben und Geschäften den Ton angaben, ging den meisten gegen den Strich. Die Bemühungen, den „mißliebigen Treuhänder oder gar alle Treuhänder schlecht zu machen"62, um sie dadurch wieder los zu werden, stießen deshalb auf allgemeines Verständnis.

Mit welchen Mitteln man dabei gegen die Treuhänder zu Felde zog, zeigte sich am Beispiel der Fleischwerke Schafft in Ansbach. Ihr Inhaber Georg Kies, klein, dynamisch und von gewaltiger Leibesfülle, war einer der reichsten Männer Ansbachs ${ }^{63}$. Nachdem er 1926 den kleinen Metzgereibetrieb mit einem Umsatz von gerade einer Million Reichsmark erworben hatte, begann der Aufstieg zu einer Fleischwarenfabrik mit einem Kundenkreis im ganzen Deutschen Reich, die $1944 \mathrm{mehr}$ als 23 Millionen RM umsetzte. Als unpolitischer Mensch, der sich nur um seinen Betrieb kümmerte, trat Kies 1933 der NSDAP bei, nicht zuletzt, so hieß es jedenfalls in der Urteilsbegründung der Spruchkammer, weil ihm dies von seinen ,jüdischen Geschäftsfreunden, mit denen er nach wie vor seine freundschaftlichen und geschäftlichen Bindungen aufrecht hielt", geraten worden war. Sein fehlendes Engagement für die nationalsozialistische Idee kreidete man ihm in Parteikreisen an, seine Kontakte zu jüdischen Kaufhäusern trugen ihm 1937 sogar eine heftige Attacke des „Stürmer“ ein.

59 Wie Anm. 41.

60 Wie Anm. 58.

61 17. Sitzung des Bayerischen Landtags vom 29. Mai 1947, Sten. Berichte, S. 507.

62 Bayerischer Staatsanzeiger vom 17. Mai 1947.

63 Zum Fall Schafft vgl. Fränkische Landeszeitung vom 17. und 20. Dezember 1947, 10. Januar 1948 und 19. März 1949 sowie Amtsgericht München, Registratur S: Nr. 3. 
Die Weste von Kies hatte allerdings auch braune Tupfer. In seinem Betrieb gingen NS-Größen ein und aus. Prominente Bonzen bekamen laufend „RepräsentationsFleisch- und Wurstpakete“, Kies bedankte sich auf diese Weise für großzügige Aufträge der Wehrmacht. „Ganz Ansbach wußte“, so kommentierte später der Herausgeber der Fränkischen Landeszeitung, Wilhelm Wiedfeld, „daß man sich bei Schafft Freunde mit dem rationierten Fleisch“ machte. „Vor dem Fleisch dieser Firma sind im Laufe der Zeit viele kleine und große Leute zusammengeklappt, d.h. sie haben ihre persönlichen Grundsätze ... ihre Bürger- und Amtspflichten über Bord geworfen und vom ,verbotenen Fleisch' gegessen. Das war während der Nazizeit so und nach dem Krieg mit seinem vermehrten Mangel ist es auch so."64

Im Sommer 1945 erhielten die Fleischwerke Schafft einen Treuhänder, Kies selbst wurde vom Militärgericht in Hersbruck wegen „Nichtanmeldung von Reichseigentum“ zu einem Jahr Zuchthaus verurteilt, weil er im Garten seines Hauses acht Kisten mit Fleisch- und Wurstkonserven vergraben und sie später bei der Militärregierung nicht angemeldet hatte. Der erste Treuhänder, der langjährige Buchhalter der Firma, erwies sich - wie schon erwähnt - als Fehlgriff und mußte entlassen werden. Seine Nachfolge trat Ernst Czernohaus an, ein politisch Verfolgter und Flüchtling, der noch kein Jahr in Ansbach ansässig war. Daß er in dem alteingesessenen Betrieb keinen leichten Stand haben würde, dürfte ihm schon nach wenigen Wochen klar gewesen sein. Im Betrieb schnitt man ihn, und schon bald hatte er die leitenden Herren und die ganze Belegschaft gegen sich. Als der Betriebsobmann Dorfner im Juni 1947 von den Ermittlern der Spruchkammer Nürnberg über seinen früheren Chef, Georg Kies, befragt wurde, ließ er seinem Unmut über Czernohaus freien Lauf. Im Ermittlungsbericht hieß es: „Dorfner wünsche, daß der Chef (Kies) doch endlich kommen solle, denn es herrsche eine katastrophale Wirtschaft im Betrieb ... Der Treuhänder der Firma, Czernohaus, sei ein Egoist größten Ausmaßes und besitzt keinerlei Fachkenntnisse ... Er arbeitet angeblich nachts bis $2 \mathrm{Uhr}$, was, sei ihm allerdings rätselhaft." Der langjährige Werkmeister Bergtaler - nach Kies der führende Mann bei Schafft - hielt seinen Ärger ebenfalls nicht zurück: „Mit dem Treuhänder Czernohaus sei schlecht zu arbeiten. Auf dem Platz des Chefs ... säße zur Zeit ein Depp ... Kies würde dringend benötigt, denn er sei der richtige Fachmann. “65

Zwei Versuche, den ungeliebten Treuhänder beim Landesamt für Vermögensverwaltung und Wiedergutmachung in München anzuschwärzen und ihn damit zu Fall zu bringen, scheiterten. Man warf Czernohaus vor, eigenmächtig in die Bewirtschaftung eingegriffen und dabei „ungeheure Schäden“ für den Betrieb verursacht zu haben. Beide Male stellte sich aber die Property-Control-Abteilung der Militärregierung, die an Czernohaus nichts auszusetzen hatte, hinter ihn ${ }^{66}$. Im Dezember 1947 konnte ihn auch die Militärregierung nicht mehr retten. Ein alter Angestellter, der mit Czernohaus von Beginn an verfeindet gewesen war, ließ - offenbar mutwillig - Leberwurst und Knochenfett verderben. Die Fränkische Landeszeitung brachte daraufhin eine Notiz und empörte sich über diese Vorfälle. Dann trat die Belegschaft des Fleisch-

64 Fränkische Landeszeitung vom 10. Januar 1948; vgl. auch Fränkische Landeszeitung vom 19. März 1949 und ein anonymes Schreiben, in: Amtsgericht München, Registratur S: Nr. 3.

65 Ebenda.

$66 \mathrm{Vgl}$. 72. Sitzung des Bayerischen Landtags vom 14. Mai 1948, Sten. Berichte, S. 1472, wo ohne Namensnennung auf die Ereignisse bei Schafft angespielt wird. 
werks in Streik und drohte, die Arbeit solange ruhen zu lassen, bis Czernohaus, der allgemein als der Schuldige angesehen wurde, entlassen sei ${ }^{67}$. Damit war das Schicksal des Treuhänders besiegelt. Bereits vier Wochen später stand er vor dem Landgericht Ansbach, das ihn wegen fahrlässiger widerrechtlicher Vergeudung von zwangsbewirtschafteten Nahrungsmitteln zu einer Geldstrafe von $3000,-$ RM verurteilte ${ }^{68}$.

Der „angekränkelte Ruf der Treuhänder"69 wurde im Laufe der Besatzungszeit nicht besser. Im Mai 1948 erreichte die Debatte einen neuen Höhepunkt, als sich der Landtag erneut mit dem Thema befaßte. Die Treuhänder waren - wie so oft - Zielscheibe heftigster Kritik. „Wer ist denn heute Treuhänder“, fragte beispielsweise der Abgeordnete Bodesheim (FDP). „Meistens sind es Zugewanderte, die an der bayerischen Industrie überhaupt kein Interesse haben, die nur darauf bedacht sind, ihren leeren Rucksack, mit dem sie meistens gekommen sind, zu füllen und mit großen Wohnungseinrichtungen und großen Vermögen wieder abzuziehen. ${ }^{" 70}$ Im selben Monat legte das Bayerische Landesamt für Vermögensverwaltung und Wiedergutmachung einen weiteren ausführlichen Bericht über eine landesweite Erhebung vor, der in auffälligem Kontrast zum Tenor der Landtagsdebatte stand. Darin hieß es: „Es wurde festgestellt, wieviele Treuhänder seit der Errichtung des BLVW (21.7.46) bis zum 31.5.48 wegen Unfähigkeit oder Veruntreuung abberufen wurden. In diesem Zeitraum unterstanden der Aufsicht des BLVW insgesamt 9672 Treuhänder. Davon wurden entlassen: wegen Unfähigkeit $252=2,6$ Prozent, wegen Veruntreuung 127 $=1,3$ Prozent. ${ }^{\text {“71 }}$

Nach 1949 wurde es langsam stiller um die Treuhänder. Seit Mitte des Jahres 1948 gingen wieder zahlreiche Industriebetriebe, Wertpapiere und Geldmittel an ihre mittlerweile erfolgreich entnazifizierten Eigentümer zurück. Ende 1948 standen in Bayern noch 30000 Vermögen unter Kontrolle, ein Jahr später nur noch etwas mehr als 11000 , im Juni 1952 rund 3300 und 1957 waren es noch 61 Vermögen. Zwei Jahre zuvor war das Landesamt für Vermögensverwaltung und Wiedergutmachung aufgelöst, seine Aufgabe einer Zweigstelle der Oberfinanzdirektion München übertragen worden $^{72}$.

\section{Krise im Hungerwinter 1946/47}

Während die Wirtschaft unter den Auswirkungen von Gesetz Nr. 8 stöhnte und das Treuhänderwesen beklagte, stellten die Statistiker der Militärregierung eine kontinuierliche wirtschaftliche Besserung fest. In der amerikanischen Zone lag das Produktionsniveau im zweiten Quartal von 1946 bei 34 Prozent des Standes von 1936, im

67 Wie Anm. 63

$68 \mathrm{Vgl}$. Fränkische Landeszeitung vom 24. Januar 1948.

69 So der Abgeordnete Bodesheim (FDP) in der 17. Sitzung des Bayerischen Landtags vom 29. Mai 1947, Sten. Berichte, S. 505 .

70 72. Sitzung des Bayerischen Landtags vom 14. Mai 1948, Sten. Berichte, S. 1477

71 Landesamt für Vermögensverwaltung und Wiedergutmachung an alle Zweig- und Außenstellen, 5. Juli 1948, in: BayHStA, MF 67. Vgl. dazu auch eine sechs Monate nach Verkündung des Gesetzes durchgeführte Überprüfung aller vorhandenen Treuhänderschaften, in: StA Nürnberg, Reg von Mittelfranken (1978), Nr. 3602.

72 Wie Anm. 58. Vgl. auch schriftliche Mitteilung der Bezirksfinanzdirektion München vom 7. Februar 1985. 
dritten schon bei 42 Prozent. Zugleich spitzten sich aber die wirklichen Probleme, die einer weiteren Erholung im Wege standen, so sehr zu, daß „the inherent vitality of German industry“ deutlich gebremst wurde ${ }^{73}$. Mehr und mehr traten die Auswirkungen der ungeklärten Währungssituation und vor allem der vom Kontrollrat im Februar 1946 ins Leben gerufenen Steuergesetzgebung zutage, die die Steuerschraube empfindlich anzog und selbst kleinere Einkommen so rigoros besteuerte, daß sich dem Erzeuger nur wenig Anreiz bot, im Rahmen der bestehenden Vorschriften zu produzieren. „Man hört vielfach von Geschäftsleuten, Handwerkern usw. die Ansicht“, so Ansbachs Stadtoberhaupt im Juni 1946, „daß es sich gar nicht lohnt, recht viel zu arbeiten und umzusetzen, weil der Ertrag doch zum größten Teil weggesteuert wird. Es besteht die Gefahr, daß der Unternehmergeist und die Arbeitsfreudigkeit durch die drückenden Steuern stark geschwächt werden. “74 Einen Monat später wies Regierungspräsident Schregle auf ein weiteres Hemmnis hin: „In fast allen Wirtschaftszweigen gibt der von Monat zu Monat spürbarer werdende Mangel an Fach- und Hilfskräften dem Arbeitseinsatz das Gepräge ... Kräftige leistungsfähige Männer sind kaum noch verfügbar." 75

Lähmend wirkte auch die in der Öffentlichkeit heftig diskutierte Demontage-Frage. Im deutschen Südwesten hatte die französische Besatzungsmacht, die ihre Zone als „Land zu unserer Exploitation“ betrachtete, schon gleich nach dem Einmarsch mit dem Abtransport von Maschinen und Fabrikanlagen begonnen; 1947 war das Land Baden, wie der damalige Wirtschaftsminister lakonisch formulierte, „was den Maschi-

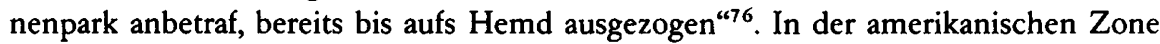
lief die Demontage um die Jahreswende 1945/46 an; im April 1946 verließ der sowjetische Frachter „Alexander Puschkin“ mit den gutverpackten Einzelteilen einer großen deutschen Schiffswerft den Bremer Hafen. Kurz darauf gingen eine Kugellagerfabrik und ein bayerisches Elektrizitäts- und Flugzeugwerk in Richtung Osten $a b^{77}$. In Ansbach und Fürth waren 1945 zwar nur die Reste der fast total zerstörten Flugzeugfabrik Bachmann, von Blumenthal und Co. sowie Teile der schwer beschädigten Dynamit-Nobel-Werke demontiert worden. Trotzdem war man auf alles gefaßt und fürchtete, da die endgültige Demontage-Liste erst im Oktober 1947 veröffentlicht wurde, weitere Eingriffe. „Wir wissen bis heute noch nicht, welche Betriebe auf die Reparationsliste gesetzt sind und wie die weiteren Reparationsleistungen ausfallen werden“, so Dr. Pollock vom Regierungswirtschaftsamt in Ansbach am 11. März 1946: „Es wird natürlich jede Planung von vornherein illusorisch, solange diese Dinge durch den Kontrollrat nicht geklärt sind. “78

In Fürth waren schon im Frühjahr deutliche Anzeichen einer sich anbahnenden Krise zu bemerken. Als das Wirtschaftsamt der Stadt ein Jahr nach der Kapitulation

73 Zit. nach Abelshauser, Wirtschaft in Westdeutschland, S.40 f.

74 OB Ansbach an MilReg, 14. Juni 1946, in: Stadtverwaltung Ansbach, EAP 022-95/19.

75 RegPräs an bay. Staatsregierung, 22. Juli 1946, in: BayHStA, Reg von Mittelfranken, Berichterstattung 1946, AZ 1-64, Bd. 6.

76 Beide Zitate in: Klaus-Dietmar Henke, Politik der Widersprüche. Zur Charakteristik der französischen Militärregierung in Deutschland nach dem Zweiten Weltkrieg, in: Claus Scharf/Hans-Jürgen Schröder (Hrsg.), Die Deutschlandpolitik Frankreichs und die französische Zone 1945-1949, Wiesbaden 1983, S.67 und 79.

77 Vgl. Klaus-Jörg Ruhl, Die Besatzer und die Deutschen. Amerikanische Zone 1945-1948, Düsseldorf 1980, S. 184.

78 Pollock in der Besprechung des RegPräs mit OB und LR, 11. März 1946, Prot. in: StA Nürnberg, LRA Scheinfeld, Nr. 367. 
eine vorläufige Bilanz zog, mußte es feststellen: „Im ganzen gesehen ging die Produktion der Industrie in allen ihren Zweigen im Monat April zurück. Natürlich gibt es Beispiele, die ihre Produktion noch erhöhten, die Rückgänge, die dem gegenüberstehen, sind aber so erheblich, daß von einem Erlahmen der Industrietätigkeit gesprochen werden kann." ${ }^{\text {"9 }}$ Im Winter 1946/47 kam die Industrie fast ganz zum Erliegen, im Februar fiel die Industrieproduktion in der amerikanischen Zone auf etwa 29 Prozent des Vorkriegsstandes (1936) zurück - ein halbes Jahr zuvor waren es noch über 40 Prozent gewesen. „Die Lage ist hoffnungslos“, so kennzeichnete das Verwaltungsamt für Wirtschaft in seinem Tätigkeitsbericht für Februar 1947 die mißliche Situation $^{80}$.

Schuld daran trug - neben den bereits beschriebenen Ursachen - namentlich der strenge Winter. Schon im Oktober 1946 registrierte man in Bayern erste starke Nachtfröste. Im Dezember fiel ein halber Meter Schnee und die Temperatur sank auf $-20^{\circ} \mathrm{C}$. Nach einer vorübergehenden Erwärmung erfaßte Mitte Januar 1947 eine dritte Kältewelle ganz Europa. „Der Westen liefert uns Lebensmittel, der Osten die Kälte", so ordnete die Süddeutsche Zeitung ${ }^{81}$ den gnadenlosen Winter etwas ironisch in den beginnenden Ost-West-Konflikt ein. Da alle größeren deutschen Flüsse ganz oder teilweise zugefroren waren, blieb nichts anderes übrig, als die Wasserkraftwerke stillzulegen. Überall kam es deshalb zu Stromabschaltungen: Ansbach war im düsteren Januar 1947 tagsüber fast ganz ohne Strom, lediglich die größeren Betriebe waren nicht von der Zufuhr abgeschnitten ${ }^{82}$.

Der strenge Winter brachte auch das "gesamte Transportsystem an den Rand des Zusammenbruchs ${ }^{\text {"83 }}$; schlecht gewartete Lokomotiven, die zwischen zwei Fahrten unter freiem Himmel stehen mußten, froren ein, die Flüsse waren nicht mehr schiffbar. Die Industriebetriebe und Haushalte merkten infolgedessen wenig davon, daß die Kohleförderung an der Ruhr im Januar 1947 die höchsten Zahlen seit Kriegsende erreichte. In Essen und Wanne-Eickel lag die lebenswichtige Kohle auf Halde, im übrigen Deutschland blieben Ämter, Krankenhäuser und Schulen geschlossen, weil sie nicht beheizt werden konnten ${ }^{84}$. Fürths Volksschüler beispielsweise kehrten erst Mitte März aus den Weihnachtsferien zurück. Bis dahin mußten sie sich täglich um $10 \mathrm{Uhr}$ vormittags in der Schule melden, empfingen dort eine Hausaufgabe und gingen dann wieder heim ${ }^{85}$. „Durch die Kälte und den Mangel an Kohlen“, kündigte die DENA in einer Meldung von Mitte Januar 1947 an, „werden in Bayern Betriebsschließungen in einem bisher nicht gekannten Ausmaß notwendig werden." ${ }^{\text {86 }}$ Kurz darauf bewahrheitete sich diese Prophezeiung. Im Februar schlossen allein in Ansbach 15 Betriebe mit je über 10 Arbeitern. Noch gravierender war die Entwicklung bei der Kurzarbeit: Während im Januar nur sieben Ansbacher Betriebe mit 222 Arbeitern kurzarbeiteten,

79 Wirtschaftsamt Fürth an Regierungswirtschaftsamt Ansbach, 18. Mai 1946, in: NA, RG 260, 9/97-2/38.

80 Tätigkeitsbericht des Verwaltungsamts für Wirtschaft der Bizone für Februar 1947, zit. nach AVBRD, Bd. 2, S. 11 .

81 Süddeutsche Zeitung vom 4. Februar 1947.

82 Vgl. Fränkische Landeszeitung vom 4. Januar 1947.

83 Benz, Von der Besatzungsherrschaft zur Bundesrepublik, S. 54.

$84 \mathrm{Vgl}$. Süddeutsche Zeitung vom 4. und 18. Februar 1947.

85 Vgl. OB Fürth an RegPräs, 22. Januar und 21. März 1947, in: Stadtverwaltung Fürth, EAP 4.

86 Süddeutsche Zeitung vom 11. Januar 1947. 
waren es im Februar 56 mit über 1300 Arbeitern $^{87}$. Fast die ganze Arbeiterschaft Ansbachs stand somit auf der Straße.

Es war ein Teufelskreis. Wegen der ausgefallenen Arbeitsstunden wurde weniger produziert. Die Ernährungs- und Versorgungskatastrophe, die sich schon Mitte 1946 angekündigt hatte, verschlimmerte sich dadurch noch weiter. Ein großer Teil der Bevölkerung habe kaum soviel, „um sich notdürftig am Leben zu erhalten“, urteilte Regierungspräsident Schregle im Februar 1947. „Hunderttausende von Menschen sind ohne genügende Nahrung und Bekleidung, man kann nun die Kleidung und Beschuhung durch schonende Behandlung strecken, aber essen muß schließlich ein jeder Mensch, wenn auch wenig und schlecht. ${ }^{\text {"88 }}$ Im Frühjahr 1947 mußten sich die Normalverbraucher in manchen Regionen mit knapp 1100 Kalorien täglich zufriedengeben, im Ruhrgebiet vorübergehend mit 700-800. Für viele kleine Beamte und Angestellte, Hilfs- und Facharbeiter waren aber selbst diese Hungerrationen zu kostspielig. Ein Maurer, verheiratet und zwei Kinder, verdiente 1946 in Ansbach etwa 130,- RM monatlich, nach Abzug aller ständigen Kosten wie Miete, Gas und Strom blieben 80,RM. Die ihm und seiner Familie zustehenden Lebensmittel kosteten aber 105,- RM. Dieses Loch in der Haushaltskasse wurde natürlich größer und größer, wenn - wie bei ungünstigem Wetter an der Tagesordnung - Arbeitsstunden ausfielen oder sich die Anschaffung von Schuhen und Hemden nicht länger aufschieben lie ${ }^{89}$. „Weiten Teilen des Volkes“ war, wie Ansbachs Oberbürgermeister bemerkte, „nur noch ein vegetieren" gestattet ${ }^{\text {"0 }}$.

Auch viele Kinder hungerten. „In den Fürther Schulen ist festzustellen“, so berichtete Schregle im Oktober 1946 nach München, „daß im Knabenschulhaus am Kirchenplatz von 566 Schülern 199 kein Zehn-Uhr-Brot zur Verfügung haben, 92 essen in der Pause Kartoffeln statt Brot, 140 Kinder kommen vollkommen nüchtern in die Schule. In der Schule in Dambach haben 98 Kinder überhaupt keine Schuhe, 172 haben nur ein Paar, meist schlechte Schuhe, 26 sind ohne warmes Mittagessen, 175 ohne Frühstücksbrot, 146 ohne Seife zum Waschen. Im Rosenschulhaus sind etwa 26 Prozent der Kinder nüchtern, 35 Prozent ohne Pausenbrot, 16 Prozent essen statt Brot Kartoffeln und nur ca. 24 Prozent haben ausreichend Essen."91 Bei den monatlichen Wiegeaktionen kamen die zuständigen Gesundheitsämter zu deprimierenden Resultaten: Der größte Teil der Bevölkerung war unterernährt. Viele Erwachsene hatten in den zurückliegenden Jahren 15, manche sogar 20 bis $30 \mathrm{~kg}$ ihres Normalgewichts verloren. Hohlwangig, ausgemergelt, einige nur noch Haut und Knochen, waren sie eine leichte Beute bald grassierender Krankheiten ${ }^{92}$. Lungentuberkulose, Typhus und Krätze nahmen ein erschreckendes Ausmaß $a^{93}$. Zugleich wurde im Hungerwinter 1946/47 eines der dunkelsten Kapitel der deutschen Kriminalgeschichte aufgeschla-

87 Vgl. Fränkische Landeszeitung vom 5. März 1947.

88 RegPräs an bay. Staatsregierung, 3. Februar 1947, in: BayHStA, Reg von Mittelfranken, Berichterstattung 1947, AZ 1-64, Bd. 5.

89 Vgl. Fränkische Landeszeitung vom 2. November 1946.

90 OB Ansbach an MilReg, 1. April 1947, in: Stadtverwaltung Ansbach, EAP 022-95/19.

91 RegPräs an bay. Staatsregierung, 18. Oktober 1946, in: BayHStA, Reg von Mittelfranken, Berichterstattung 1946, AZ 1-64, Bd. 6.

92 Vgl. RegPräs an bay. Staatsregierung, 3. Februar 1947, in: Ebenda, Bd. 5.

93 Vgl. die Berichterstattung des RegPräs an die bay. Staatsregierung aus den Jahren 1946/47, in: Ebenda, Bd. 5 und 6. 
gen. Hühner und Kaninchen verschwanden nachts aus den Ställen, Lebensmittel aus den Kellern und Vorratskammern. Nichts war mehr sicher. Am hellichten Tag kam es auf offener Straße zu Mundraub94. In allen größeren Städten bildeten sich Banden, die bei Einbruch der Dunkelheit ihre Raubzüge begannen.

In dem namenlosen Elend, das der Hungerwinter 1946/47 mit sich brachte, war die Not der Flüchtlinge am größten. Seit Anfang 1946 stieg die Zahl der einströmenden Neubürger unaufhörlich"s. 1947 wurden in Fürth rund 13000 Flüchtlinge gezählt: 2000 bis 3000 kamen aus den Gebieten östlich der Oder-Neisse-Linie, ca. 1000 aus anderen ost- und südosteuropäischen Ländern und mehr als zwei Drittel aus dem Sudetenland ${ }^{96}$. Viele hatten Schlimmes hinter sich. Sie waren aus ihren Häusern vertrieben und geschlagen worden, hatten ihr Hab und Gut verloren oder waren wochenlang in erbärmlichen Lagern inhaftiert gewesen. Es war ihr tragisches Schicksal, daß sie als Gruppe Objekt von Entscheidungen der Anti-Hitlerkoalition wurden und zugleich als einzelne - ob persönlich schuldig oder nicht - ,in ihrer ost- und südosteuropäischen Heimat für die menschenverachtende Politik und Kriegführung des Deutschen Reiches persönlich haftbar gemacht wurden ${ }^{\text {(97 }}$. Eine Sudetendeutsche berichtete über ihre schrecklichen Erlebnisse im Lager Friedek-Mistek ${ }^{98}$ : „Schläge und Schimpfnamen waren die Begrüßung im Lager. Von 7 Uhr früh bis oft in die Nacht hinein mußten wir schwere und schmutzige Arbeit verrichten. Zum Essen bekamen wir nichts anderes als Kaffee, Wassersuppe und $180 \mathrm{~g}$ Brot pro Tag. Oft wurden wir in der Nacht von unseren Schlafstellen herausgejagt, mußten am Lagerhof antreten, dann tanzen, singen, einander Ohrfeigen verabreichen, auf allen Vieren herumkriechen usw. Diese sadistischen Akte wiederholten sich immer wieder und viele meiner Mitgefangenen begingen aus Verzweiflung Selbstmord." Ein Mann erzählte über die Austreibung aus Saaz"9: „Nach Ankunft in Postelberg (Juni 1945) ging die Marter los, und zwar wurde geprügelt, erschlagen und erschossen, so daß diese furchtbare maßlose Ausschreitung vier Tage währte und die Opfer immer größer wurden, ja, es ging so weit, daß die Väter zusehen mußten, wenn ihre Jungens im Knabenalter furchtbar verprügelt und nachher vor den Augen der Väter erschossen wurden.“

Diesen Schrecken entronnen, hofften die Flüchtlinge und Vertriebenen im Westen auf eine rasche Besserung ihrer Situation. Sie wurden oft bitter enttäuscht. Für viele, die bei Flucht und Vertreibung noch recht glimpflich davongekommen waren, begann erst jetzt die Leidenszeit. Niemand war auf den gewaltigen Zustrom vorbereitet gewesen; es existierten weder Pläne, Organisationen, noch finanzielle Mittel, um die Not der Flüchtlinge zu lindern. Die örtlichen Flüchtlingsbetreuungsstellen konnten so den Neuankömmlingen häufig nur ein Dach über dem Kopf bereitstellen und sie manchmal nicht einmal mit dem Nötigsten versorgen. Staatliche Maurerkolonnen bauten

94 Vgl. ebenda und die Monatsberichte des LR Ansbach an den RegPräs aus den Jahren 1946/47, in: LR Ansbach, EAP 04-040.

95 Vgl. die Monatsberichte des OB Fürth an RegPräs aus den Jahren 1946/47, in: Stadtverwaltung Fürth, EAP 4.

96 Zu den Flüchtlingen in Fürth vgl. vor allem Stadtverwaltung Fürth, Nr. 4 und 460 sowie die Unterlagen im Privatbesitz von Fritz Rupprecht, der als Flüchtlingskommissar tātig war.

97 Klaus-Dietmar Henke, Der Weg nach Potsdam - Die Alliierten und die Vertreibung, in: Wolfgang Benz (Hrsg.), Die Vertreibung der Deutschen aus dem Osten. Ursachen, Ereignisse, Folgen, Frankfurt/Main 1985, S. 69 .

98 Alois Harasko, Die Vertreibung der Sudetendeutschen. Sechs Erlebnisberichte, in: Ebenda, S. $108 \mathrm{f}$.

99 Ebenda, S. 116. 
Kasernen und Baracken der Wehrmacht sowie feuchte Bunker im Eiltempo zu Flüchtlingslagern um, an den Rändern der Städte wuchsen kleine Siedlungen mit zugigen Holzbaracken aus dem Boden. Etwa die Hälfte der Flüchtlinge wurde in Lagern, die andere Hälfte bei Einheimischen einquartiert, die sich dagegen nicht selten heftig wehrten. Die lästigen evakuierten „Volksgenossen“ aus Hamburg, dem Saarland und den großen Städten des Ruhrgebiets waren kaum aus dem Haus, da kam schon die nächste Invasion von Eindringlingen. Häufig mußte sogar die Polizei bemüht werden, damit vier- oder fünfköpfige Familien endlich ein Zimmer zugewiesen bekamen.

Die Lager waren vor allem im Winter Elendsquartiere. Eine Helferin des evangelischen Hilfswerkes der Inneren Mission berichtete im Februar 1947 über das Lager Voggendorf in der Nähe von Ansbach: „Mag das Lagerleben vielleicht im Sommer erträglich sein, im Herbst und Winter aber liegt eine Atmosphäre der Trauer und des Jammers um die Baracken ... Die Baracken sind in Nebel eingehüllt und nur spärlich wird abends die Dunkelheit der Wege von einigen Lampen unterbrochen ... Fast jede Familie in den Baracken trägt ein hartes Schicksal. In einem Raum wohnen zwei Großmütter von 73 und 76 Jahren mit zwölf Enkelkindern im Alter von 2-12 Jahren. Sie sind mit den Kleinen aus Schlesien geflüchtet, während ihre Töchter, die Mütter der Kinder, in der Heimat blieben ... Ein paar Schritte weiter liegt eine junge Frau, die sich bei der Flucht einen schweren Herzschaden zugezogen hat. Sie ist fast dauernd bettlägerig und leidet unter der Unruhe des Zimmers durch die vielen Menschen sehr ... Nebenan sitzen zwei kleine Mädchen auf dem Bett, die zerrissene Kleidung tragen. Sie warten auf ihre Mutter. Sie warten schon 14 Tage auf sie, die sich meist bei Negern in Nürnberg herumtreibt. Vor wenigen Wochen hat sie in einer Fehlgeburt ein totes Negerkind zur Welt gebracht und ist nach festgestellter Gonorrhoe nach fünf Tagen ausgerückt. Die Zimmernachbarn versorgen die Kleinen notdürftig. “100

Der Herausgeber der Fränkischen Landeszeitung, Wilhelm Wiedfeld, schrieb einen aufrüttelnden Bericht über die Not in den Ansbacher Flüchtlingslagern: „In dem kleinen Saal des Vereinshauses, wohnen' 13 Familien, 68 Personen, darunter etwa 33 Kinder, sind hier untergebracht ... Der ganze Raum ist ein großes Zimmer. Aufgetürmte eiserne Militärbettstellen ringsum umgrenzen jeweils den Aufenthaltsraum einer Familie. Natürlich, man sieht durch die Bettstellen hindurch. Hier und da wird versucht, durch eine alte Decke, durch ein Kleidungsstück, durch etwas Pappe die Intimität des Wohn- und Lebensraumes zu wahren - eine verständliche, aber vergebliche Mühe. Liebe und Haß, Freude und Trauer, Hunger und Not, alles ist allen gemeinsam und sattsam bekannt. Die einen wollen in dem trostlosen Raum Licht haben, den anderen kann es nicht dunkel genug sein. Licht und Dunkel ist für alle so gleichmäßig wie die Kälte ... Ich stehe auf ein paar Quadratmetern Raum, den ein älteres Ehepaar mit acht Kindern zur Verfügung hat. Die Mutter steht vor uns. Zerfurcht, versorgt, vergrämt ... recht krank. Einige der Kleinen stehen um uns. Das Elend hat auch sie gezeichnet. Der Bub leidet am Knochenfraß, das eine Mädchen krankt an diesem, das andere an jenem ... Zudem fehlt es an allem. Die Betten ohne Bettzeug, die Menschen ohne gute Kleidung und Leibwäsche ... ,Es ist besser, wenn man nichts sagt', meint eine

${ }^{100}$ Bericht Nr. 29 vom 18. Februar 1947, in: LKA Nürnberg, Bestand: Innere Mission, Nr. 934; vgl. auch den Tätigkeitsbericht des Lagerarztes für die städtischen Flüchtlingslager in Fürth, 1. Februar 1947, in: Stadtverwaltung Fürth, EAP 460. 
verschüchtert aussehende Frau. Wer sollte uns noch helfen? Wenn schon mal ein Höherer kommt, dann macht er schleunigst, daß er hier wieder rauskommt ${ }^{\star}$... Wir gehen zur Küche. Ihr Zustand setzt aller Unfähigkeit, Nachlässigkeit, ja groben Fahrlässigkeit die Krone auf. Ein Saustall, sagt mein Begleiter. Dunkel, geschwärzt wie eine Räucherkammer, ein unsauberes Verließ. Jeder Kuhstall in Franken ist sauberer und heller. Mit einem Eimer Weißkalk hätte Abhilfe geschaffen werden können. Auch hier regnet es in Strömen. Der Boden ist eine einzige Regenpfütze. Auch der Herd steht unter Wasser. Gegenwärtig könnte kein Topf auf den Herd gestellt werden. Der Regen würde das Feuer löschen und das Essen in den Töpfen verderben. Unter diesen Umständen soll für 65 Menschen Essen gekocht werden. Aber vorerst kommen die Ärmsten hier gar nicht in Verlegenheit, denn es ist kein Stück Kohle vorhanden, weder für Heizzwecke noch für Kochzwecke."101

Besondere Sorgen bereiteten den Lagerärzten und Flüchtlingskommissaren die Kinder und Jugendlichen. „Durch die Gänge der Baracken und auf den Wegen lärmen die größeren Kinder, wenn die Schule zu Ende ist. Auch halbwüchsige, jugendliche Knaben und Mädchen balgen sich herum, gruppieren sich zu Paaren und verschwinden in der Dunkelheit. Eine Aufsichtsmöglichkeit besteht nicht, und man denkt mit großer Sorge an die wachsende Verwilderung dieser Jugend", bemerkte die schon zitierte Helferin der Inneren Mission ${ }^{102}$. Das „ungehemmte Triebleben in manchen Lagern“, so hieß es auch im Monatsbericht der Fürther Flüchtlingsbetreuung für November 1946, ,vollzieht sich ohne Scheu vor Öffentlichkeit und Umgebung. Junge Mädchen und Burschen fallen besonders auf." 103

Zu Kälte, Krankheit und Verwahrlosung kam Hunger, denn Schmalhans war Küchenmeister in den Lagern. Bei der Großküche Riedel, die die Fürther Lager belieferte, stand beispielsweise am 9. Dezember 1946 mittags Nudelsuppe und Kartoffeln und abends Erbsensuppe und Kartoffeln auf dem Speiseplan. Zur Herstellung eines Mittagessens waren für eine Person nicht mehr als $80 \mathrm{~g}$ Nährmittel, $250 \mathrm{~g}$ Kartoffeln und ganze $4 \mathrm{~g}$ Fett verwendet worden ${ }^{104}$. Sammlungen, die von Kirchen, Stadtoberhäuptern und Landräten wärmstens befürwortet wurden und deren Ergebnisse sich durchaus sehen lassen konnten, zahlreiche Gesten gutgemeinter nachbarschaftlicher Unterstützung sowie die ersten Hilfsmaßnahmen von amerikanischen Wohlfahrtsverbänden waren letztlich kaum mehr als ein Tropfen auf den heißen Stein.

Die Fragen „Wie soll es nur weitergehen?“ und „Was soll aus uns werden?" standen auf den Gesichtern. Viele, die sich während des Krieges kaum hatten einschränken müssen, litten jetzt im Frieden Hunger. Untergangsstimmung machte sich breit, nirgends zeichnete sich eine Besserung ab. Viele „blicken gespenstisch in eine Welt“, so die Fränkische Landeszeitung, ,welche die letzten Regungen ihrer Seele brutal zertreten hat. Verwesungsgeruch lastet über uns. Werden wir darunter ersticken? ${ }^{\prime 105} \mathrm{Zu}$ gleich waren es Monate des öffentlichen Räsonnements. Nicht wenige neigten dazu, die Schuld an der Misere bei der Besatzungsmacht zu suchen, ungeachtet dessen, daß die Amerikaner bereits 1946 beträchtliche Dollar-Summen in ihre Zone pumpten. In

\footnotetext{
${ }^{101}$ Fränkische Landeszeitung vom 28. Januar 1948. Vgl. auch ebenda vom 14. Februar 1948.

102 Wie Anm. 100.

${ }^{103}$ Flüchtlingsbetreuung Fürth an Stadtrat, 20. November 1946, in: Stadtverwaltung Fürth, EAP 460.

${ }^{104} \mathrm{Vgl}$. Flüchtlingsbetreuung Fürth an Stadtrat, 16. Dezember 1946, in: Ebenda.

${ }^{105}$ Fränkische Landeszeitung vom 2. November 1946.
} 
geradezu grotesker Verdrehung der Tatsachen schrieb beispielsweise der evangelische Pfarrer von Fürth-St. Michael, früher ein Anhänger deutschnationalen Gedankenguts und der NSDAP, in die Chronik seiner Gemeinde: „Sie (die Amerikaner) haben uns hungern und frieren lassen und gewalttätig behandelt ... sie (haben) auch nichts getan, um die Lasten des deutschen Volkes ... irgendwie zu erleichtern. Im Gegenteil, sie haben den deutschen Aufbauwillen behindert, wo sie konnten. Das deutsche Volk sollte nicht mehr groß werden, wenigstens nicht so rasch aus seinem Elend herauskommen.“ Weiter meinte der Pfarrer: „Der Feind saß im Land ... Er lebte im Überfluß und ließ die Bevölkerung darben, ja vernichtete seine reichlichen Speisen-Überreste und machte sie ungenießbar. Ja, er verschaffte sich, trotz seiner gegenteiligen Versprechungen, Butter und Milch, Zucker und Obst aus den deutschen Beständen, so daß die deutsche Bevölkerung nicht einmal die kärglichen Mengen, die ihr zugedacht waren, erhalten konnte. Um die Kirschen nicht pflücken zu müssen, rissen sie die Äste von den Bäumen oder sägten die Bäume ab und nahmen sie auf ihren Autos mit." ${ }^{\text {106 }}$

Der Fürther Pfarrer stand mit seiner Meinung nicht allein. Im nahen Eichstätt wurde das Gerücht ausgestreut, „die gegenwärtige Notlage der deutschen Bevölkerung werde von den alliierten Mächten absichtlich erhalten. In den Beschlüssen von Yalta und Potsdam wäre vereinbart worden, die deutsche Bevölkerung fünf Jahre hungern und frieren“ zu lassen ${ }^{107}$. An vielen Wänden hieß es damals: „Warst Du Nazi oder nicht, der Ami raubt und schont Dich nicht“ oder „Vom Nazi belogen - vom Ami betrogen." ${ }^{108}$ Und in manchen Gegenden der amerikanischen Zone erzählte man sich folgenden Witz, der das gestörte Verhältnis zwischen Besatzungsmacht und deutscher Bevölkerung treffend kennzeichnet: Ein Amerikaner fragt einen Deutschen: Glaubst Du, daß Deutschland einen dritten Krieg überleben kann? Worauf der Deutsche antwortet: Einen dritten Krieg vielleicht schon, noch eine Befreiung durch die Amerikaner aber nicht ${ }^{109}$.

Aufmerksame Beobachter stellten damals auch ein Wiederaufleben antidemokratischer Ressentiments fest. In zahlreichen Gemeinden tauchten Hakenkreuzschmierereien auf, jüdische Friedhöfe wurden geschändet, ein unverbesserlicher Nationalsozialist ließ sich sogar in SS-Uniform in einem Sarg mit Hakenkreuzinsignien bestatten ${ }^{110}$. In Freyung im Bayerischen Wald hatte ein Unbelehrbarer an eine Mauer geschrieben: „Deutsche Jugend erwache! Die deutsche Jugend vertraut noch immer auf den Führer!“ ${ }^{111}$ In Niederbayern machten Äußerungen die Runde wie: „Wenn uns noch lange die demokratische Sonne bescheint, werden wir wieder bald braun sein.“ ${ }^{112} \mathrm{Da}$ und dort gab es auch bereits kleine nazistische Gruppen. Die Militärregierung von Oberund Mittelfranken berichtete: „Eine Widerstandsgruppe bekannt als Edelweiß Marder

${ }^{106}$ Kirchenchronik des Evangelisch-Lutherischen Pfarramts Fürth-St. Michael, in: LKA Nürnberg, Bestand: Ev.-Luth. Pfarramt Fürth-St. Michael, Nr. 445.

${ }^{107}$ RegPrās an bay. Staatsregierung, 3. Oktober 1947, in: BayHStA, Reg von Mittelfranken, Berichterstattung 1947, AZ 1-64, Bd. 5.

${ }^{108}$ Weekly Intelligence Report, 30. Oktober 1946, in: NA, RG 260, 10/85-3/2.

${ }^{109}$ Weekly Intelligence Report, 6. November 1946, in: Ebenda.

${ }^{110} \mathrm{Vgl}$. Weekly Intelligence Report, 6. November 1946, in: Ebenda, sowie Weekly Intelligence Report, 1. Mai 1946, in: NA, RG 260, 10/85-3/1.

${ }^{111}$ Ebenda.

112 Weekly Intelligence Report, 6. November 1946, in: NA RG 260, 10/85-3/2. 
... soll im Entstehen begriffen sein“113. In Augsburg trat eine Gruppe „88“ (= Heil Hitler) hervor, die auch in den umliegenden Kreisen Anhänger fand ${ }^{114}$.

Zugleich begann die Demokratiebereitschaft vieler Deutscher merklich zu sinken. „Es ist immer das gleiche“, urteilte die Fürther Militärregierung, „die Leute sind nicht an der Regierung, sondern am Essen interessiert. Gerade jetzt sind sie hungrig, gerade jetzt haben sie eine demokratische Regierung. Deshalb glauben die Massen, daß die demokratische Staatsform nicht funktioniert und nicht in der Lage ist, die Probleme der Menschen zu bewältigen." ${ }^{115}$ "Demokratie ist der gleiche Schwindel wie alle anderen Regierungsformen“ - „Lieber satt und Nazischwein, als Demokrat und hungrig sein “116: In solchen Slogans drückte sich eine weitverbreitete Skepsis gegenüber dem demokratischen Neuaufbau aus.

Unzufriedenheit mit den neuen politischen Verhältnissen, Hoffnungslosigkeit und Apathie angesichts der drückenden wirtschaftlichen Misere hatten aber nur einen Teil der Bevölkerung erfaßt. Ganz offensichtlich setzten das Kriegsende und der Fall des Dritten Reiches auch neue Energien frei, die sich nicht mehr auf Volk und Führer, sondern auf privates Glück und persönliches Vorwärtskommen richteten. Nach den Jahren der strengen Reglementierung im NS-Bewirtschaftungssystem waren namentlich viele Gewerbetreibende, sofern sie sich nicht zu weit mit dem Nationalsozialismus eingelassen und deshalb Repressalien der Arbeiter oder der Besatzungsmacht zu fürchten hatten, wie befreit von einem schweren Druck und beseelt von der Hoffnung auf eine freiere unternehmerische Zukunft. Von Improvisier- und Abenteuerlust gepackt, entwickelten sich manche zu wahren Meistern des Organisierens auf dem Schwarzen Markt. Es waren - trotz allem - auch Monate und Jahre, die zu Hoffnung und Wagemut herausforderten.

\section{Die Gründerjahre des „kleinen Mannes“}

Das Fürther Gewerbeamt war schon wenige Tage nach seiner Wiedereröffnung im Mai 1945 eine gefragte Adresse. Täglich bildeten sich vor dem Schalter Schlangen von Interessenten, die vor allem eines im Sinn hatten: Herr im eigenen Geschäft zu werden. Groß war der „Ansturm auf die Selbständigkeit“ im Handwerk. „Schneider(-innen), Schuhmacher und Kraftfahrzeugmechaniker stehen hier an der Spitze mit ihren Anträgen", so Fürths Oberbürgermeister am 4. August 1945 an die Regierung in Ansbach. „Seit der Besetzung sind rund 300 Anträge auf Errichtung eines Handwerksbetriebes eingegangen.“ ${ }^{117}$ Beim Handel herrschte ein ähnliches Bild: „Trotz der herr-

\footnotetext{
${ }^{113}$ Weekly Intelligence Report, 8. Mai 1946, in: NA, RG 260, 10/85-3/1.

${ }^{114}$ Ebenda.

${ }^{115}$ Weekly Intelligence Report, 27. August 1947, in: NA, RG 260, 10/85-1/26.

${ }^{116}$ Weekly Intelligence Report, 16. Juli 1947, in: NA, RG 260, 10/85-2/13; Weekly Intelligence Report, 7. Mai 1947, in: NA, RG 260, 10/85-2/5.

${ }^{11}$ Stadtverwaltung Fürth, EAP 4. Die folgenden Ausführungen beziehen sich weitgehend auf die Wieder- und Neugründungen von Handwerksbetrieben, Handelsgeschäften und anderen Gewerbebetrieben, die weniger als zehn Beschäftigte hatten, für deren Lizenzierung nach einem Ministerialerlaß des bayerischen Wirtschaftsministerium vom 26. Februar 1946 die Oberbürgermeister und Landräte zuständig waren. Ministerialerlaß vom 26. Februar 1946, in: StA München, Reg von Oberbayern, Nr. 77 724, Gewerbe Generalia. Zum Gang des Lizenzierungsverfahrens vgl. auch eine nicht näher bezeichnete Aktennotiz vom 5. Mai 1947, in: BayHStA, MWi 13861.
} 
schenden Warenverknappung laufen sehr viele Anträge auf Zulassung zum Groß- und Einzelhandel ein."118

Der Andrang nahm in den ersten beiden Jahren nach Kriegsende kaum ab. Monat für Monat lagen Hunderte von Anträgen auf den Schreibtischen der zuständigen Beamten. Beim Landeswirtschaftsamt in München häuften sich die Klagen, daß die nachgeordneten Stellen in einer Papierflut zu ersticken drohten: „Die Anträge auf Neuzulassungen in Handel und Handwerk mehren sich in letzter Zeit derartig, daß eine Inflation schlimmster Art und Übersetzung jeder Sparte unvermeidlich ist.“ Das Landeswirtschaftsamt wußte sich deshalb nicht mehr anders zu helfen, als eine Zulassungssperre für einzelne Wirtschaftszweige zu erlassen, die teilweise bis zum Sommer 1946 in Kraft blieb ${ }^{19}$.

Die Flut der Anträge stammte von einer sehr heterogenen Personengruppe. Handwerksmeister und -gesellen, die sich während der NS-Zeit nicht selbständig machen konnten, weil die Gesetze zum Schutze des Handwerks und des Einzelhandels sehr streng gehandhabt worden waren, wollten das Versäumte nachholen. Flüchtlinge, die schon früher selbständig gewesen waren, versuchten dort wieder anzuknüpfen, wo sie in ihrer alten Heimat hatten aufhören müssen. Ehemalige Parteigenossen, die aufgrund politischer Belastungen ihre Stellungen im öffentlichen Dienst verloren hatten, erwarteten sich in der freien Wirtschaft einen beruflichen Neuanfang. Kriegsheimkehrer, die in der Wehrmacht bestimmte Qualifikationen als Fahrer oder Mechaniker erworben hatten, wollten nicht mehr in ihre früheren Berufe zurück, sondern sich mit ihren neuen Fähigkeiten auf „eigene Beine“ ${ }^{\text {stellen }}{ }^{120}$. Und schließlich hofften auch viele, die sich jetzt auf ein selbständiges Gewerbe warfen, unter dem Deckmantel der Selbständigkeit ungehindert lukrative Schwarzmarktgeschäfte treiben oder wenigstens kleinere Vorteile herausschinden zu können, die in einer Zeit der Geldentwertung und staatlich gebundener Preise und Löhne durch unselbständige Arbeit nicht zu haben waren. Das ließ etwa der Leiter des Fürther Wirtschaftsamtes anklingen, als er im Juni 1946 schrieb: „Charakteristisch ist, daß Schneiderinnen sich gerne als selbständige Gewerbetreibende niederlassen möchten ... Es ist anzunehmen, daß der Antrieb hierzu aus dem Wunsche stammt, durch überhöhte Preise oder sonstige Begünstigungen, die von der Kundschaft verlangt werden ... besondere Vorteile zu erlangen." ${ }^{\text {"21 }}$

Die Beamten im Gewerbeamt, auf deren Schreibtischen sich die „unzähligen Anträge auf Neuzulassungen “122 stapelten, klagten vor allem über die unsichere Rechtslage. Bis zum Erlaß des Gesetzes Nr. 42 über die Errichtung gewerblicher Unternehmen vom 23. September 1946 herrschte nach Meinung des Sachbearbeiters der Abteilung Handel und Gewerbe im Ansbacher Landratsamt ein „gesetzloser Zustand“ ${ }^{\text {“23. }}$

\footnotetext{
${ }^{118}$ Monatsbericht vom 22. Dezember 1945, in: Stadtverwaltung Fürth, EAP 4.

${ }^{119}$ Landeswirtschaftsamt in München an Regierungswirtschaftsämter und Landesstellen, 15. Dezember 1945, in: BayHStA, MWi 13 861; vgl. OB Fürth an RegPräs, 23. Februar 1946, in: Stadtverwaltung Fürth, EAP 4.

${ }^{120}$ Vgl. dazu OB Fürth an RegPräs, 4. August 1945, in: Stadtverwaltung Fürth, EAP 4 sowie RegPräs an bay. Staatsregierung, 17. September 1946, in: BayHStA, Reg von Mittelfranken, Berichterstattung 1946, AZ 1-64, Bd. 6.

${ }^{121}$ Wirtschaftsamt Fürth an Regierungswirtschaftsamt Fürth, 18. Juni 1946, in: NA, RG 260, 9/97-2/38.

${ }^{122}$ OB Fürth an RegPräs, 23. Februar 1946, in: Stadtverwaltung Fürth, EAP 4.

${ }^{123}$ Bericht der Abteilung Handel und Gewerbe im Landratsamt Ansbach, 8. April 1948, in: LRA Ansbach, EAP 01-016.
} 
Der bayerische Wirtschaftsminister im Kabinett Schäffer, Karl Arthur Lange, hatte zwar Anfang September 1945 verfügt: ,Jede Wiedereröffnung sowie jede Neueröffnung eines Gewerbebetriebs bedarf der Zustimmung der Militärregierung ... Von den bisherigen gewerblichen Vorschriften sind alle jene Bestimmungen ungültig, die Beschränkungen aus rassischen, religiösen oder politischen Gründen enthalten. Die übrigen gewerberechtlichen Vorschriften sind dagegen unverändert in Kraft geblieben." ${ }^{124}$ Diese Anordnung war aber anscheinend nicht bis zu den Gewerbeämtern durchgedrungen. Für die örtlichen Beamten war deshalb unklar, ob die aus der NS-Zeit stammenden Gesetze noch galten oder ob der Zusammenbruch des NS-Regimes automatisch die Rückkehr zum Gewerberecht der Weimarer Zeit bedeutete. Daraus ergab sich für die Sachbearbeiter auch die Unsicherheit, wie weit ihre eigenen Befugnisse reichten: Bei welcher Art und Größe von Betrieben konnten sie die Lizenzierung erteilen? Welche Rolle würde die Militärregierung spielen? War bei der Errichtung eines Handwerksbetriebs der 1935 als Zulassungskriterium eingeführte „Große Befähigungsnachweis" zu erbringen? Waren die Handwerkskammern bzw. IHK vor der Erteilung von Lizenzen zu hören?

Zur Klärung dieser strittigen Fragen trug die amerikanische Militärregierung zunächst wenig bei. Um sich einen Überblick über die wirtschaftliche Situation im besetzten Deutschland zu verschaffen, verlangte sie im Sommer 1945 von jedem Betriebsinhaber einen möglichst detaillierten Bericht über den Zerstörungsgrad, die Kapazität, den Arbeitskräftebedarf und die Rohstoffvorräte seines Betriebes. Um Fragen der Zulassung von Betrieben und Geschäften kümmerte sie sich recht wenig. Die verwirrenden Bestimmungen des deutschen Gewerberechts, die selbst vielen deutschen Experten Kopfzerbrechen bereiteten, waren den amerikanischen Offizieren nicht bekannt: Je größer die Zahl der Betriebe, so schien ihre Faustregel zu lauten, desto besser. Vor allem Betriebsinhaber und Geschäftsleute mit politisch weißer Weste hatten von den Amerikanern nichts zu befürchten ${ }^{125}$.

Etwas Licht in die dunkle Rechtslage brachten die Verordnung Nr. 47 der bayerischen Regierung vom 27. Januar 1946 zum Schutze der gewerblichen Wirtschaft, die auf Initiative der IHK zustandegekommen war und den bisherigen Damm gegen die „Überfremdung“126 des Wirtschaftslebens weiter aufrechterhalten sollte, und die Verfügung des bayerischen Wirtschaftsministeriums vom 26. Februar 1946, in der es hieß: „Durch die bisherige Entwicklung ist auf dem Gebiet der gewerblichen Wirtschaft eine weitgehende Rechtsunsicherheit hinsichtlich des Instanzenweges und der Funktion der nachgeordneten Behörden ... entstanden.“ Künftig waren für die Erteilung von sogenannten Anlaufgenehmigungen für Handwerks- und Handelsbetriebe mit weniger als 10 Beschäftigten, die schon vor dem 1. Mai 1945 in Bayern rechts des Rheins bestanden hatten, die Kreisbehörden zuständig. Die Vergabe von neuen Lizen-

${ }^{124}$ Schreiben des bay. Staatsministers für Wirtschaft, 4. September 1945, in: BayHStA, MWi 12556.

${ }^{125}$ Vgl. StA München, Reg von Oberbayern, RA 77 724: LRA Miesbach an Reg von Oberbayern, 10. Januar 1946 und Hans Niesner, Zwei Jahre Gewerbefreiheit, München 1951, S. 10. StA München, Reg von Oberbayern, RA 77 728: Staatsministerium für Wirtschaft an Hauptquartier der MilReg von Bayern, 5. Dezember 1946.

${ }^{126}$ Verordnung Nr. 47 zum Schutze der gewerblichen Wirtschaft vom 17. Januar 1946, in: BGVBl. 9/1946. Die Regierung folgte damit einer Bitte der wirtschaftlichen Interessenverbände, die sich für eine Schutzverordnung ausgesprochen hatten. StA München, Reg von Oberbayern, RA 77 724: Eingabe der IHK München an Wirtschaftsministerium, 7. Dezember 1945. 
zen gehörte dagegen nicht mehr zu ihrem Aufgabengebiet ${ }^{127}$, sondern oblag bei Handwerksbetrieben, kleingewerblichen und Industriebetrieben (unter 10 Beschäftigten) dem Regierungswirtschaftsamt, bei Industriebetrieben (von 10 bis 49 Beschäftigten) und Großhandelsbetrieben den Landesstellen und bei Industriebetrieben mit mehr als 50 Beschäftigten dem Wirtschaftsministerium. Die Klarheit des Ministerialerlasses bestand aber allem Anschein nach zunächst nur auf dem Papier. Die laut Erlaß zuständigen Instanzen wie die im Herbst aus der Taufe gehobenen Landesstellen und Landeswirtschaftsämter, die an die Stelle der Reichs- und Wirtschaftsgruppen der NS-Zeit getreten waren, hatten noch lange mit allen möglichen Kinderkrankheiten zu kämpfen, so daß auch weiterhin der größte Teil der Neuanträge bei den Gewerbeämtern landete ${ }^{128}$.

Als Anton Reithinger, der zuständige Referent im Wirtschaftsministerium, seine Unterschrift unter den Ministerialerlaß vom 26. Februar setzte, war ihm wohl bewußt, daß der Erlaß schon bald überholt sein würde. Schon vorher waren in seinem Ministerium erste Überlegungen für die Novellierung des Gewerberechts angestellt worden, das die größtenteils aus der NS-Zeit stammenden Regelungen ablösen sollte. Ludwig Erhard, als Nachfolger Langes neuer Wirtschaftsminister, überraschte seine Kabinettskollegen schon Anfang Januar 1946 mit einem Entwurf eines Gesetzes über die „Lizenzierung der Errichtung von Betrieben und Unternehmungen“, der bereits im Wirtschaftsausschuß des süddeutschen Länderrats in Stuttgart auf allgemeine Zustimmung getroffen war. Erhard sorgte sich damals, daß der große Drang zur Selbständigkeit die Gefahr einer Verzettelung der geringen wirtschaftlichen Ressourcen der deutschen Wirtschaft heraufbeschwöre. Restriktive Bestimmungen, so begründete er im Kabinett den Gesetzentwurf, seien „heute ... notwendiger denn je. Je kleiner das Sozialprodukt sei, desto größer sei die Anzahl der Menschen, die sich an seiner Verteilung beteiligen wollten. Man müsse dem entgegensteuern. “129 Ministerpräsident Hoegners erste Reaktion war mürrisch: das, was Erhard da vorlege, sei eine „völlige Beschränkung der Gewerbefreiheit“. In den Augen von Kultusminister Franz Fendt (SPD) brachte das Gesetz nichts anderes als eine „Privilegierung der bisherigen Besitzenden“. Diese „hätten sich bisher nicht bemüht“, so Fendt, „etwas Neues herbeizuführen, sie seien saturiert und machten nur Tauschgeschäfte“. Er sah keine Gefahr darin, daß sich „nun Leute bemühten, neu ins Geschäft zu kommen ... Man sollte keine mittelalterlichen Privilegien für die Besitzenden einführen. “130

Nach diesem offenen Schlagabtausch vertagte sich das bayerische Kabinett. Der Länderrat in Stuttgart befaßte sich auf seiner 4. Tagung am 8. Januar 1946 nur kurz mit Fragen eines neuen Gewerberechts und leitete die komplizierte Materie dann an

${ }^{127}$ Bei der Neuzulassung von Einzelhandelsgeschäften, kleingewerblichen und Industriebetrieben mit weniger als zehn Beschäftigten hatten die Gewerbeämter das Regierungswirtschaftsamt lediglich zu beraten. Vgl. Ministerialerlaß des bay. Wirtschaftsministeriums an die Landeswirtschaftsämter und Landesstellen vom 26. Februar 1946, in: StA München, Reg von Oberbayern, RA 77724.

${ }^{128} \mathrm{Vgl}$. dazu auch Schreiben des bay. Staatsministeriums für Ernährung, Landwirtschaft und Forsten an die Regierungspräsidenten, Oberbürgermeister, Landräte und Ernährungsämter vom 9. Juli 1946, in dem u.a. hervorgehoben wird, daß auch die Zuständigkeiten bei der Zulassung von Großhandelsbetrieben in der Lebensmittelbranche nicht überall klar waren, in: Archiv der IHK München, XV A-135, Bd. 1: Schutz der gewerblichen Wirtschaft gegen Übersetzung 1945-1948. Vgl. auch Notiz von Dr. Meyer-Oelschigk, 18. Dezember 1946, in: BayHStA, MWi 13861.

129 Bayerischer Ministerrat am 7. Januar 1946, in : IfZ-Archiv, ED 120/356.

130 Ebenda. 
die Ausschüsse weiter. Da die Vertreter der drei Länder aber unterschiedliche Auffassungen hinsichtlich der Einschränkungen der Gewerbefreiheit vertraten, ging man unverrichteter Dinge auseinander. Die einzelnen Länder wollten nun ihre eigenen Lizenzierungsgesetze erlassen. Ende März 1946 traf aber die Weisung der Militärregierung ein, sich erneut an einen Tisch zu setzen und binnen kurzem ein zoneneinheitliches Gesetz vorzulegen ${ }^{131}$.

Daraufhin kam Bewegung in die Gesetzgebungsmaschinerie des Stuttgarter Länderrats. Im Eiltempo entwarfen die zuständigen Referenten ein Gesetz, dem trotz völliger Preisgabe des Gedankens der Gewerbefreiheit die Vertreter aller drei Länder zustimmten. Bald wurde aber bekannt, daß die Militärregierung den Entwurf „auf keinen Fall in dieser Form durchgehen " lassen würde ${ }^{132}$. Ihre Bedenken bezogen sich nicht - wie man erwarten könnte - auf die restriktiven Bestimmungen, die den im amerikanischen Wirtschaftssystem geltenden „principles of free enterprise“, aber auch der bisherigen Großzügigkeit der örtlichen Militärregierungen zuwiderliefen. Die maßgebenden Offiziere bei OMGUS teilten damals den Standpunkt Erhards ${ }^{133}$; auch sie hielten es für ein Gebot wirtschaftlicher Klugkeit, den Kreis der Handwerker, Händler und Industriellen möglichst klein zu halten. Ihre Einwände richteten sich vielmehr auf die ungenügende Berücksichtigung der säuberungspolitischen Erfordernisse im deutschen Gesetzentwurf ${ }^{134}$. Auch in den Länderkabinetten stieß die in Stuttgart erzielte Übereinkunft auf wenig Gegenliebe; der württemberg-badische Ministerrat zögerte mit seiner Zustimmung, Hessen billigte den Stuttgarter Kompromiß mit großen Abänderungen, nur das Kabinett Hoegner stimmte $\mathbf{z u}^{135}$. Immer wieder steckenzubleiben schien das Schicksal des Gesetzentwurfs zu sein.

Die Zeit verstrich und erst im Juni 1946 einigte man sich im Hauptausschuß „Gewerbliche Wirtschaft" beim Länderrat auf eine neue Fassung des Gesetzes, mit der auch OMGUS einverstanden zu sein schien. Das bayerische Kabinett nahm den allseits gebilligten Vorschlag am 26. Juni 1946 einstimmig an ${ }^{136}$, und alles deutete darauf hin, als ob nun endlich die Weichen für ein zoneneinheitliches Gewerbelizenzierungsgesetz gestellt wären. Doch nachdem die Militärregierung nochmals kleinere Änderungswünsche angemeldet hatte ${ }^{137}$, die schnell hätten erfüllt werden können, war die Eintracht der drei Länder der US-Zone wieder dahin, so daß die neuen Gewerbelizenzierungsgesetze mit beträchtlichen zeitlichen Abständen verabschiedet wurden: Das bayerische Lizenzierungsgesetz (Gesetz Nr. 42) trat am 23. September 1946, das württemberg-badische am 5. November 1946, das hessische erst am 24. Juni 1947 in $\mathrm{Kraft}^{138}$.

Der „gesetzlose Zustand“139 war damit beendet. Das neue, nur bis zum 31. Dezem-

\footnotetext{
${ }^{131} \mathrm{Vgl}$. Aktennotiz von Schultheiß an Erhard, 9. April 1946, in: BayHStA, MWi 13861.

${ }^{132}$ Vgl. Vormerkung für Minister Erhard von Erwin Stölzl, 7. Juni 1946, in: Ebenda.

${ }^{133} \mathrm{Vgl}$. dazu etwa ein Memorandum vom 13. Januar 1948, das sich ausführlich mit den Positionen der amerikanischen MilReg befaßt. Memorandum, in: NA, RG 260, 13/82-44/19.

${ }^{134}$ So die Einschätzung des bayerischen Landeswirtschaftsamtes in einem Schreiben an das Wirtschaftsministerium, 16. April 1946, in: BayHStA, MWi 13 861. Vgl. auch OMGB an Erhard, 26. März 1946, in: Ebenda.

${ }^{135} \mathrm{Vgl}$. Vorlage vom 25. Juni 1946 für Ministerratsbesprechung, in: BayHStA, MA 6310, Bd. 3.

136 Bayerischer Ministerrat, 26. Juni 1946, in: IfZ-Archiv, ED 120/358.

${ }^{137}$ Vgl. MinPräs Hoegner an OMGB, 9. September 1946, in: BayHStA, MA 6310, Bd. 3.

${ }^{138} \mathrm{Vgl}$. Theodor Maunz, Gewerberecht, Braunschweig 1950, S. 15 und BGVBl. 20/1946.

${ }^{139}$ So der Sachbearbeiter der Abteilung Handel und Gewerbe im Ansbacher Landratsamt, 8. April 1948, in: LRA Ansbach, EAP 01-016.
} 
ber 1949 gültige Gesetz stand, wie die Fachleute urteilten, „in vollem Gegensatz zur unbeschränkten Gewerbefreiheit“140. Während der NS-Zeit, so hieß es in der Zeitschrift „Der Betriebsberater“, habe der Gesetzgeber trotz zahlreicher Einschränkungen an dem seit 1869 (Einführung der allgemeinen Gewerbefreiheit) „blaßgewordenen Gedanken der Gewerbefreiheit“ festgehalten. Die "nach dem Niederbruch entstandenen neuen Staatswesen“ setzten jetzt den „Schlußpunkt dieser Entwicklung“ und verkündeten „die Verpflichtung schlechthin, vor dem Beginn oder der Erweiterung jeder unternehmerischen Tätigkeit die Genehmigung des Staates einholen zu müssen“"141. Jeder, der einen Betrieb eröffnen wollte, mußte den Nachweis seiner persönlichen Zuverlässigkeit und fachlichen Eignung erbringen. Weiter sollte „die für die Aufrechterhaltung des Betriebes erforderliche regelmäßige Belieferung des Unternehmens mit Rohstoffen oder Waren“ gesichert sein. Und schließlich mußte ein „volkswirtschaftliches Bedürfnis für die Errichtung des Unternehmens“ vorliegen. Wer darüber zu befinden hatte, war im Gesetzgebungsverfahren heftig umstritten gewesen. Die Industrie- und Handelskammern sowie die Handwerkskammern hatten ihren ganzen Einfluß aufgeboten, um im Gesetz zu verankern, daß sie vor der Lizenzierung eines Betriebes gehört werden mußten. Das war erfolglos geblieben, die wirtschaftlichen Interessenverbände konnten, mußten aber nicht gehört werden ${ }^{142}$.

Trotz starker Einschränkungen der Gewerbefreiheit konnte das Gesetz Nr. 42 den „Drang nach Selbständigkeit im Erwerbsleben “143 allenfalls dämpfen, aber nicht stoppen. Dafür garantierten in Bayern eine Reihe von Ausnahmebestimmungen für soziale Problemfälle und auch die Flüchtlingsgesetzgebung, die großzügige Regelungen für Vertriebene vorsah und damit ein Loch in die Restriktionen der Gewerbelizenzierung riß ${ }^{144}$. Für eine Ausweitung sorgten aber auch viele Landräte und Stadtväter, die sich

${ }^{140}$ Niesner, Zwei Jahre Gewerbefreiheit, S. 11.

${ }^{141}$ Der Betriebsberater, Nr. 18, 31. Dezember 1946 (ein Exemplar findet sich in: BayHStA, MA 13 861).

${ }^{142} \mathrm{Vgl}$. IHK München an Erhard, 2. Mai 1946, in: Archiv der IHK München, XVA-135, Bd. 1: Schutz der gewerblichen Wirtschaft gegen Ubersetzung 1945-1948; IHK München an Erhard, 23. Mai 1946, in: Ebenda; IHK München an bay. Industrie- und Handelskammern, 7. Juni 1946, in: Ebenda; IHK München an Wirtschaftsministerium, 3. und 9. Juli 1946, in: Ebenda. Innerhalb des Wirtschaftsministeriums bestand aber eine Fraktion, die den Einfluß der Kammern möglichst begrenzen wollte, weil die „Erfahrung ... gezeigt (habe), daß Lizenzierungsanträge bei den IHK schweben ..., daß Aktenvorgänge nicht mehr aufzufinden sind, und eine unglaubliche Verschleppung solcher Anträge stattgefunden “ habe. Vgl. dazu Vormerkung von Dr. Meyer-Oelschigk, 2. April 1947, in: BayHStA, MWi 13 861. Diese Fraktion hatte beabsichtigt, paritätisch-besetzte Gewerbeausschüsse aus Vertretern der Wirtschaft, des Staates bzw. der Kommunen und der Gewerkschaften vor der Lizenzierung von Betrieben zu hören. Schließlich konnte sich keine der beiden Seiten durchsetzen; die Anhörung der von den Kammern leidenschaftlich abgelehnten Gewerbeausschüsse war zwar im Gesetz verankert, allem Anschein nach kam es aber nie zur Bildung der Ausschüsse. Andererseits mußten sich die Kammern damit begnügen, daß sie laut Durchführungsverordnung zum Gesetz Nr. 42 nicht gehört werden mußten, sondern nur gehört werden konnten. Vgl. vorläufige Durchführungsverordnung vom 25. Oktober 1946, in: Archiv der IHK München, XVA-135, Bd. 1: Schutz der gewerblichen Wirtschaft gegen Ubersetzung 1945-1948, und Verordnung Nr. 123 zur Durchführung des Gesetzes Nr. 42 über die Errichtung gewerblicher Unternehmen vom 23. September 1946. Verordnung Nr. 123 vom 7. Juni 1947, in: BGVBI. 11/1947.

${ }^{143}$ Jahresrückblick 1947 der Abteilung Gewerbewesen der Fürther Stadtverwaltung, in: Stadtverwaltung Fürth, EAP 26.

${ }^{144} \mathrm{Zu}$ den Ausnahmeregelungen bei Flüchtlingen vgl. Gesetz Nr. 59 über die Aufnahme und Eingliederung deutscher Flüchtlinge (Flüchtlingsgesetz) vom 19. Februar 1947 und Ausführungsbestimmungen zum Flüchtlingsgesetz vom 8. Juli 1947, in: BGVBl. 5/1947 und 12/1947. Vgl. auch Schreiben des bay. Wirtschaftsministeriums an die Regierungspräsidenten, 2. Juli 1947, in dem es hieß, daß die Eingliederung von Ausgewiesenen nicht an „einer kleinlichen Konkurrenzangst der alteingesessenen Betriebsinhaber scheitern“ dürfe. Schreiben vom 2. Juli 1947, in: StA München, Reg von Oberbayern, RA 77 728, Gewerbe Generalia. 
von den neuen Selbständigen beträchtliche Steuereinnahmen zur Entlastung der strapazierten Sozialetats versprachen und deshalb die restriktiven Bestimmungen nicht allzu engherzig auslegten.

Überall setzte sich diese Neigung freilich nicht durch. In den beiden Städten Ansbach und Fürth blockte man Lizenzbewerber nicht selten mit allen zu Gebote stehenden Mitteln ab. Ansbach hatte nach Kriegsende noch immer den Ruf einer ruhigen Beamtenstadt, die im 19. Jahrhundert den Anschluß an die „neue Zeit“" verpaßt hatte. Lange vor der Jahrhundertwende hatten die Schuckert-Werke Ansbach als Standort auserkoren; die Niederlassung war aber am Nein der Ansbacher Stadträte gescheitert, Schuckert hatte sich deshalb in Nürnberg angesiedelt. Die industrielle Entwicklung verlief so in "geruhsamen Bahnen“ und ohne den „Rahmen des Althergebrachten“ zu sprengen ${ }^{145}$. 1945 litt Ansbach noch immer unter den damaligen Versäumnissen. Nach Kriegsende beherbergte die Stadt, die nun schon weit über 30000 Einwohner hatte, lediglich neun Betriebe, die mehr als 100 Personen beschäftigten; darunter die Fleischwerke Schafft, die Druckerei von Justizrat Bayer, drei größere Bauunternehmungen, die Firma für Präzisionsteile von Matthias Oechsler und Sohn und die Kinderwagenfabrik von Louis Schmetzer. Zwölf Betriebe hatten über 50 Beschäftigte, 35 über zwanzig, die übrigen waren Klein- und Kleinstbetriebe ${ }^{146}$. Ganz leicht ließ sich die wirtschaftliche Rückständigkeit auch nicht wettmachen, denn, so Oberbürgermeister Körner, die „im Tal der Rezat liegende Stadt (hat) nahezu keine Ausdehnungsmöglichkeit mehr ... und der Baugrund (ist) außerordentlich knapp geworden “147.

Man ließ es allerdings auch nicht auf einen Versuch ankommen. Die neuen Herren im Ansbacher Rathaus waren nach 1945 nicht ganz frei von jener bedächtig-vorsichtigen Mentalität ihrer Vorväter, zuallererst den Besitzstand der eingesessenen Geschäftsleute zu wahren. Sie verschanzten sich deshalb oft hinter der Behauptung, eine großzügige Lizenzierung führe nur zu einem weiteren Anwachsen des Schwarzen Marktes. „Der Stadtrat vertritt die Auffassung“, so hieß es in der Sitzung vom 25. Februar 1947, „daß bei Vergebung gewerblicher Räume und vor allem bei Neuzulassung von Handelsgeschäften ein strenger Maßstab anzulegen ist, da keinerlei Interesse an Handelsgeschäften besteht, sondern nur solche Unternehmungen gefördert werden sollten, die produktive Arbeit leisten. ${ }^{\text {"148 }}$ Diese Devise wurde dann auch strengstens befolgt.

Als am 3. März 1947 um 17.00 Uhr im Amtszimmer des Oberbürgermeisters der Industrieausschuß, der das entscheidende Wort bei allen Lizenzierungs- und Neuansiedlungsanträgen sprach, zusammen mit einigen Experten zu tagen begann, war Ansbachs honorig-konservative Geschäftswelt gleichsam unter sich: ein Malermeister, ein Wäschereibesitzer, einige Kaufleute und der Druckereibesitzer, Justizrat Dr. Bayer, der seinen ganzen Einfluß als graue Eminenz der Stadt geltend machte, um die alte Wirtschaftsstruktur Ansbachs zu bewahren. Sieben Stadträte saßen im Industrieausschuß, fast alle gehörten den bürgerlichen Parteien CSU und FDP an ${ }^{149}$. Daß die Ansbacher

\footnotetext{
145 Fränkische Landeszeitung vom 13. November 1948.

146 Ebenda.

${ }^{147} \mathrm{OB}$ Ansbach an MilReg, Stimmungsbericht vom 25. Februar 1947, in: Stadtverwaltung Ansbach, EAP 022-95/19.

${ }^{148}$ Ausschnitt aus der Niederschrift der Stadtratssitzung vom 25. Februar 1947, in: Stadtarchiv Ansbach, ABc $\mathrm{T} / 10 / 25$.

${ }^{149}$ Niederschrift der Ausschußsitzung vom 3. März 1947, in: Stadtarchiv Ansbach, ABc T/3/17.
} 
Führungsschicht entschlossen war, wenigstens in ihrer Heimatstadt die industrielle Entwicklung aufzuhalten, mußte auch das bekannte Werk Saba erfahren, als es über seinen Generalvertreter für Nordbayern anfragen ließ, ob Ansbach ein größeres Zweigwerk aufnehmen wolle. Der Stadtrat schien zunächst nicht abgeneigt, seine Stellungnahme vom 29. August 1947 lautete: „Die Firma Saba fertigt Rundfunkgeräte und Telefonapparate. Sie hat ihren Sitz in Villingen in der französischen Zone, möchte aber den Betrieb in die amerikanische Zone verlegen, weil die Gefahr der Abmontierung besteht. Ein Teil der Maschinen soll sich bereits in der amerikanischen Zone befinden. Beschäftigt können bis zu 300 Personen werden, darunter auch viele Frauen. Die Niederlassung dieser Firma wäre für Ansbach zweifellos von großer Bedeutung. "

Im Industrieausschuß war man aber ganz anderer Meinung. Die alteingesessenen Gewerbetreibenden fürchteten die Konkurrenz, und vor allem sorgte man sich um das niedrige Lohnniveau in den einheimischen Betrieben, das ein so großes Werk wie Saba womöglich ins Wanken gebracht hätte. So lautete der Beschluß wie in den meisten anderen Fällen auch: Der Antrag wird abgelehnt ${ }^{151}$.

Wie sehr sich das alte mittelständische Gewerbe auf seine Vertreter im Industrieausschuß verlassen konnte, zeigte sich auch, als Anfang 1947 der Ingenieur Robert Lindner den Ansbacher Stadträten gleich einen ganzen Gewerbezweig aus dem ehemaligen Sudetengau offerierte. Lindner schickte am 1. März 1947 einen Brief an den Oberbürgermeister, in dem er seine Firma, die Strickwaren, Klöppelspitzen und Lederhandschuhe herstellen sollte, ausführlich vorstellte. Die „Strickwarenfirma beschäftigte im Sudetengau ca. 60 Personen im Betriebe und eine weitaus größere Zahl in Heimarbeit ... Beabsichtigt ist folgendes Erzeugungsprogramm: Herstellung gestrickter und gewirkter Oberbekleidung für Kinder und Erwachsene, Ausführung von Reparaturen und Umarbeitungen von gebrauchten Strick- und Wirkwaren. Hierzu sind die für den Anfang erforderlichen Maschinen vorhanden und in Auftrag gegeben, deren Lieferung bereits zugesagt ist. Gleichzeitig sollen in Heimarbeit handgestrickte Pullover, Westen, Strümpfe, Handschuhe etc. hergestellt werden für Export und stehen wir bereits mit Exportfirmen in Verbindung, die Material für 3-4000 Heimarbeiterinnen liefern würden. “ Ủber die Aussichten der Klöppelspitzen- und Lederhandschuhindustrie hieß es in Lindners Brief weiter: „Nachdem im Sudetengau der Hauptsitz der Klöppelspitzenindustrie auch gleichzeitig der Hauptsitz der Handschuhindustrie war, sind in den Familien zumeist beide Berufsarten vertreten, weshalb die Firma, genau so wie sie es im Sudetengau hatte, beide Industrien in einem Ort (evtl. kleinen Umkreis) ansiedeln will ... Es sind auch für diese beiden Industrien alle Vorbereitungen in Bezug auf tech. Einrichtungen getroffen und könnte auch die Handschuherzeugung in kurzer Zeit anlaufen. Kleine Mengen Leder wurden von der Landesstelle in Aussicht gestellt. Nachdem Verwandte, die seit vielen Jahren in Amerika ansässig sind und sich dort u.a. mit dem Vertrieb von Lederhandschuhen befassen, bereits Schritte eingeleitet haben, um größere Mengen Rohmaterial zur Verarbeitung senden zu können, bestehen außergewöhnlich günstige Aussichten, daß die Firma rasch aufblühen wird. Für die Spitzen- und Handschuherzeugung wäre vorläufig die Ansiedlung von ca. 20 Familien (60-70 Personen) notwendig ...“ 
Obwohl sich im Stadtgebiet kein vergleichbarer Betrieb befand, war der Industrieausschuß alles andere als begeistert: „Anfertigungsbetriebe in Lederhandschuhen befinden sich zwei im Stadtbezirk. Eine weitere Firma hat einen Betrieb in Herrieden aufgezogen. Dieser Betrieb beschäftigt ca. 20 Leute. Die Rohmaterialfrage in der Anfertigung von Handschuhen ist prekär und bestehen auch keine Aussichten auf Besserung, da auch die Ziegen- und Schaffelle der Bewirtschaftung unterliegen." ${ }^{152}$ Wieder plädierte der Industrieausschuß für Ablehnung des Antrags ${ }^{153}$. Chance um Chance, die kleingewerbliche Basis der Ansbacher Wirtschaft etwas zu verbreitern, wurde so vertan. Einmal nahm man im Industrieausschuß die seit 1946 bestehende Zuzugssperre zum Vorwand, um ein Industrieunternehmen fernzuhalten, ein andermal stand der Zulassung eines neuen Gewerbes der Mangel an geeigneten Räumen in der Stadt entgegen. In Wahrheit scheute man eine zu schnelle wirtschaftliche Veränderung innerhalb der Stadtmauern und vor allem unliebsame Konkurrenz.

Die Vertreter des alteingesessenen Ansbacher Gewerbes waren freilich nicht allmächtig. Das zeigte sich am Beispiel des Lizenzierungsantrages von Josef Kempf. Der robuste ehemalige Fahnenjunker der Wehrmacht, der den Polen-, Frankreich- und Rußlandfeldzug mitgemacht hatte und schließlich in Italien schwer verwundet worden war, hatte sich noch während des Krieges geschworen: „Wenn ich hier heil rauskomme, will ich nie mehr etwas wissen von Gehorsam und Dienen, ich mache meinen eigenen Laden auf und mit 50 Jahren will ich vor meiner eigenen Fabrik stehen.“ Als der gebürtige Unterfranke, der seit den dreißiger Jahren in Ansbach lebte, im Sommer 1945 in seine Wahlheimat zurückkehrte, trug er sich mit dem Gedanken, eine Elektrogroßhandlung zu eröffnen. Als er aber einen Lizenzierungsantrag stellte, gab es zunächst eine glatte Absage. In den Augen der Stadträte war kein Bedürfnis für eine Elektrogroßhandlung vorhanden. Auch die IHK lehnte ab, weil Kempf, der Kaufmann gelernt hatte, nicht die beruflichen Voraussetzungen erfüllte. Die Innung winkte ab, weil die tonangebenden Elektrogrossisten aus Nürnberg ihre Absatzgebiete im Ansbacher Raum gefährdet sahen. Kempf ließ aber deshalb den Mut nicht sinken. Woche für Woche, jeweils am Freitagnachmittag, lief er zur Regierung von Mittelfranken und brachte dort sein Anliegen vor. Der Beamte, der den dickschädligen Kempf bereits kannte, wies ihn aber jedesmal mit dem Hinweis auf einen Aktenbock voller Lizenzierungsanträge ab. „Mein hinhaltender Widerstand“, so Kempf später, „scheint dem Beamten aber imponiert zu haben.“ Am 18. Januar 1946 hielt er jedenfalls eine Lizenz für den Handel mit „Elektroartikeln und Artikeln des täglichen Bedarfs“ in Händen ${ }^{154}$. Bald darauf eröffnete er in einem früheren NSKK-Lehrsaal, der vorübergehend vom Roten Kreuz benützt worden war, seinen kleinen Laden.

Auch den Fürther Ratsherren kam die Verschärfung der gewerberechtlichen Bestimmungen nach Kriegsende nicht ungelegen. Die Wirtschaft der Stadt steckte seit den dreißiger Jahren in einer tiefgreifenden Strukturkrise. Traditionelle Branchen wie die Spiegel- oder die Spielwarenindustrie, deren Leistungsfähigkeit die Stadt ihren Ruf verdankte, waren nicht ausgelastet; viele kleine und mittlere Betriebe hatten schließen müssen, andere schrieben rote Zahlen. Neue Zweige wie die Elektroindustrie, die im Krieg einen enormen Aufschwung genommen hatte, mußten sich erst noch fest eta-

\footnotetext{
152 Protokoll vom 12. März 1947, wie auch das Schreiben von Lindner, in: Ebenda.

${ }^{153}$ Beschluß vom 18. April 1947, in: Ebenda.

${ }^{154}$ Mündliche Mitteilung von Josef Kempf vom 21. Juli 1983.
} 
blieren. In dieser unsicheren Situation entschloß sich die sozialdemokratische, eng mit dem Gewerbe verbundene Stadtregierung, die angeschlagene einheimische Wirtschaft vor weiterer Konkurrenz abzuschirmen.

Wie schwer es war, in der wegen ihrer wirtschaftlichen Freizügigkeit einst sprichwörtlich bekannten Stadt (,Fürther Freiheit") ein Gewerbe zu eröffnen, erfuhr beispielsweise ein Textilfabrikant aus dem ehemaligen Sudetenland, der in seiner alten Heimat in einer Weberei mit angeschlossenem Appretur- und Konfektionsbetrieb 300 Arbeitskräfte beschäftigt hatte. Als er 1946 die Genehmigung seines Betriebes beantragte, mußte er "unzählige Wege“ beschreiten, „bis die örtlichen Stellen mit den Münchner Zentralstellen ... auf einen Nenner gebracht werden konnten “155. Eine besonders unrühmliche Rolle spielte dabei das Fürther Arbeitsamt, das dem Antragsteller immer neue Steine in den Weg legte und ihn sogar als „Arbeitsscheuen“ einstufte. Als sein Antrag schließlich unter Hinweis auf die herrschenden Engpässe bei der Rohstoffversorgung abgelehnt wurde, stand für den Textilfabrikanten fest, daß „alle diese Maßnahmen nur zum Schutze und Ausbau der ansässigen heimischen Industrie“ ergriffen worden seien. „Es muß“, so schrieb er verbittert an den Hauptausschuß für Flüchtlingswesen in München, „scheinbar der letzte Webstuhl und die letzte Dorfbrettsäge vorerst laufen, bevor einem Flüchtlingsunternehmer eine Existenzmöglichkeit gegeben wird." ${ }^{156}$

Ähnliche Erfahrungen mußten namentlich nach dem Erlaß des Gewerbegesetzes vom September 1946 viele machen. In Fürth ging die Zahl der neuzugelassenen Betriebe und Geschäfte, die vor Erlaß des Gesetzes monatlich zwischen 50 und 121 geschwankt hatte, drastisch zurück: im ersten Jahr auf durchschnittlich 37 pro Monat ${ }^{157}$. Die Zahl der neueröffneten Handwerksbetriebe, die vor dem Wirksamwerden des Gesetzes bei durchschnittlich 35 pro Monat gelegen hatte, sank auf 12 pro Monat ${ }^{158}$. Für die Lizenzbewerber in Fürth und Ansbach erwies sich mithin die Zeit der „Ungesetzlichkeit" vor Erlaß des neuen Gesetzes, als die Gewerbeämter und Landesstellen dazu neigten, die restriktiven Bestimmungen der NS-Zeit nicht mehr buchstabengetreu zu befolgen, als weitaus günstiger als die seit September 1946 entstandene Situation. Der Ansturm auf die Selbständigkeit ließ sich allerdings auch in Ansbach und Fürth nicht ganz stoppen; in beiden Städten nahm die Zahl der Selbständigen an der Gesamtbevölkerung weiterhin zu.

Wesentlich bessere Startbedingungen fanden die Lizenzbewerber in der industriell wenig entwickelten Umgebung von Ansbach und Fürth vor. Der Landkreis Ansbach war vor 1945 ein „rein bäuerliches Hinterland“ der Kreisstadt gewesen. Kleinere und mittlere Bauernhöfe bestimmten das Bild, die etwa 1800 meist winzigen Gewerbebetriebe trugen zur wirtschaftlichen Entwicklung des Landkreises wenig bei. Nach 1945 begannen die "neuen Herren“ im Landratsamt und in den Rathäusern vor allem unter dem Druck der auf dem Lande untergebrachten Flüchtlingsmassen eine relativ großzügige Gewerbelizenzierungspolitik zu betreiben und damit einen "gewissen Um-

\footnotetext{
${ }^{155}$ Vgl. Franz J. Bauer, Flüchtlinge und Flüchtlingspolitik in Bayern 1945-1950, Stuttgart 1982, S. 410.

${ }^{156}$ Ebenda, S. 412.

157 Vgl. Monatsberichte des OB Fürth an RegPräs aus den Jahren 1946/47, in: Stadtverwaltung Fürth, EAP 4.

${ }^{158}$ Ebenda.
} 
schwung" einzuleiten ${ }^{159}$. Sie waren sich klar darüber, daß die durch die Fürsorgezahlungen für mittellose Flüchtlinge erschöpften Gemeindefinanzen sich auf längere Sicht nur erholen würden, wenn es gelang, finanzkräftige Betriebe in ihren Gemeinden anzusiedeln. Viele Bürgermeister erkannten auch, daß die "große Zahl ehemals selbständiger Handwerker und Gewerbetreibender" unter den Flüchtlingen „volkswirtschaftlich gesehen ein Gewinn für den Landkreis“ werden könnte. „Erst eine gesunde Mischung von Agrar- und Industriewirtschaft", so die Devise des Landrats, „dürfte zu einer Milderung der wirtschaftlichen Not der Flüchtlinge führen und damit zu einer Entlastung der öffentlichen Fürsorge." ${ }^{160}$

Der Erfolg blieb nicht aus: Bereits 1948 hatten sich im Landkreis Ansbach 600 neue Betriebe niedergelassen, mehr als die Hälfte stammte von Flüchtlingen. Allem Anschein nach kam es bei dieser beginnenden „Industrialisierung“ des bäuerlichen Hinterlandes kaum zu schwerwiegenden Konflikten zwischen Einheimischen und Flüchtlingen. Die Flüchtlinge füllten manche der durch den Krieg entstandenen Lükken im kleingewerblichen Fertigungsbereich (z. B. Schuhmacherei, Schneiderei) und waren darüber hinaus maßgeblich an der Gründung von Industriebetrieben beteiligt. Das alte bodenständige Handwerk blieb dagegen in einheimischer Hand. Unter den 147 Metzgern und Brandmetzgern des Landkreises fand sich nur ein Flüchtling, alle 58 Bäckereien waren im Besitz von Einheimischen ${ }^{161}$.

Einer der ländlichen Orte, in denen nach 1945 eine rapide wirtschaftliche Entwicklung begann, war das fünfzehn Kilometer westlich von Ansbach gelegene Städtchen Leutershausen, das 1939 etwa 1500 Einwohner zählte. Der neue Bürgermeister Fritz Schultheiß, ein Landwirt und ehemaliger Ortsbauernführer, war ein gutmütiger Mann, der es allen recht machen wollte. Er bereitete den unternehmungsfreudigen Flüchtlingen keine Schwierigkeiten, in einigen Fällen setzte er sich sogar nachdrücklich dafür ein, um Flüchtlingsbetriebe in sein ebenso traditionsreiches wie wirtschaftlich ,verhocktes" Städtchen zu holen. Besondere Verdienste erwarb er sich, als 1947 die Familie Hanel aus dem ostsudetendeutschen Großkunzendorf/Altvatergebirge einen Antrag auf Lizenzierung eines Steinmetzbetriebes stellte.

Die Hanels, die schon in ihrer alten Heimat ein Steinwerk betrieben hatten, waren durch einen Zufall nach Leutershausen gekommen. Ein Schwager, der sich in der Wehrmacht mit einigen Leutershausenern angefreundet hatte, ließ sich aus der Kriegsgefangenschaft zu seinen mittelfränkischen Freunden entlassen; in seine Heimat konnte er nicht zurück, denn dort war die Vertreibung der Deutschen bereits im Gange. Uber den Suchdienst des Roten Kreuzes kam 1946 die Mutter Hanel mit zwei Kindern nach. 1947, als Vater Josef aus englischer Kriegsgefangenschaft zurückgekehrt war und Sohn Leonhard aus französischer Kriegsgefangenschaft hatte fliehen können, war die Familie komplett. Der Familienrat beschloß, daß man sich schnellstens wieder selbständig machen wolle. Aber der Stadtrat von Leutershausen, dem neben einigen Kaufleuten und Bauern auch ein Maurermeister angehörte, der bisher Grabsteine verkauft hatte, wollte den Lizenzierungsantrag nicht befürworten: Es be-

\footnotetext{
${ }^{159}$ Amts- und Mitteilungsblatt des Landkreises Ansbach, 20. Februar 1952.

${ }^{160}$ Bericht der Abteilung Handel und Gewerbe im Landratsamt Ansbach, 8. April 1948, in: LRA Ansbach, EAP 01-016.

${ }^{161}$ Ebenda.
} 
stehe kein Bedürfnis, so hieß es. Die Hanels wandten sich daraufhin an den Landrat ins Ansbach, stießen aber auch dort auf taube Ohren. Schließlich suchten sie Bürgermeister Schultheiß privat auf, trugen ihm ihre Sorgen vor und überzeugten ihn davon, daß die ablehnende Haltung des Stadtrats wohl in erster Linie auf Konkurrenzangst beruhte. Schultheiß schlug deshalb von sich aus vor, den Stadtrat vor vollendete Tatsachen zu stellen. Die Hanels reichten einen zweiten Antrag ein, Schultheiß gab - ohne die Ratsherren zu informieren - grünes Licht, das Landratsamt folgte der Empfehlung des Bürgermeisters, und wenig später eröffnete die Firma Hanel in einer ärmlichen Hütte ihren Betrieb ${ }^{162}$.

Bereits 1946 hatte sich in Leutershausen die aus Haslau im westlichen Sudetenland stammende Strick- und Wirkwarenfabrik Biedermann - heute der zweitgrößte Betrieb der Stadt - angesiedelt. Biedermann, in dessen Firma in Haslau zeitweise fast 100 Leute beschäftigt gewesen waren, hatte im Sommer 1945 erkannt, daß er als Deutscher im Sudetenland einen schweren Stand haben würde. Er hatte deshalb sein Werk in das jenseits der Grenze gelegene Oberfranken verlagert. Viel hatte er aber nicht retten können, er brachte nur einige Maschinen mit, als er im Dezember 1945 in Selb eintraf. Dort nahm er sofort seine alten geschäftlichen Verbindungen wieder auf. Im Frühjahr 1946 machte er auf einer Geschäftsreise nach Stuttgart in Ansbach Station und lernte dort den späteren Abgeordneten der CSU im Landtag, Georg Mack, kennen, der uns schon als Motor der CSU im Landkreis Ansbach begegnet ist. Mack, ein unweit von Leutershausen ansässiger Landwirt, wurde hellhörig, als er erfuhr, daß Biedermann einen neuen Standort für seinen Betrieb suchte. Er schlug Leutershausen vor und versprach, sich bei den - wie er wohl wußte - reservierten Stadträten für Biedermann zu verwenden. Auch Bürgermeister Schultheiß setzte sich für Biedermann ein und verschaffte ihm eine Unterkunft in einer Schmiede in Jochsberg, die sich aber bald als zu eng erwies. Als Biedermann daraufhin das leerstehende Lutherheim anmieten wollte, wurde deutlich, daß sich Schultheiß mit seiner Politik der Industrieansiedlung viele Feinde gemacht hatte. Einige Leutershausener taten sich zu einer Bürgerinitiative zusammen und sammelten Unterschriften gegen die Pläne ihres Bürgermeisters, der - um die Ruhe im Städtchen wieder herzustellen - schließlich von seinen Plänen abrückte und Biedermann einige Nebenräume des Gasthofes zur Neuen Post zuwies $^{163}$.

Biedermann sorgte dafür, daß auch seine frühere Kundschaft - der Färbereibetrieb Hans Hausner aus Asch im Sudetenland - in Leutershausen ansässig werden konnte. Die Hausners, die ihre kleine Fabrik erst 1922 gegründet hatten, waren 1945 ausgewiesen worden und hatten zunächst in Hessen eine Bleibe gefunden. Biedermann erfuhr davon und überredete Hausner, der etwas zögerte, ob er im Alter von 47 Jahren nochmals von vorne anfangen sollte, nach Leutershausen zu kommen und wieder für ihn zu färben. Im Gegensatz zu Biedermann hatte Hausner weder Maschinen noch Rohstoffe aus der alten Heimat mitnehmen können. So fing man mit primitivsten Mitteln an: Gefärbt wurde in einem heute noch vor der Hausnerschen Fabrik stehenden Kupferkessel, den der Firmenchef von einem hessischen Bauern erhalten hatte,

${ }^{162}$ Mündliche Mitteilung von Leonhard Hanel vom 27. Juli 1983.

${ }^{163}$ Mündliche Mitteilung von Adi Biedermann vom 29. Juli 1983. 
der den Kessel als Viehtränke benutzt hatte. Untergebracht war die Färberei, die heute mehr als 350 Leute beschäftigt, in einem kleinen Keller der Brauerei Krone ${ }^{164}$.

1949 - die Einwohnerzahl war mittlerweile auf 2300 gestiegen - hatten sich bereits über 30 Handwerksbetriebe (= ein Drittel aller Handwerksbetriebe der Stadt) und zwei größere Fabriken von Flüchtlingen in Leutershausen niedergelassen. Die Fränkische Landeszeitung berichtete im Januar 1949 über die „kleine Stadt mit großem Eifer“: „Es klingt unwahrscheinlich, wie sich diese Menschen emporarbeiten."

Während in Leutershausen mit der Ansiedlung neuer Industrie- und Gewerbebetriebe eine neue Zeit einzog, begann man sich in den obersten Stäben der Militärregierung und auf deutscher Seite erste Gedanken über eine neue gesetzliche Regelung des Gewerberechts nach Ablauf der 1946/47 beschlossenen Ländergesetze zu machen - unterschiedliche Gedanken, wie sich bald herausstellte, die zu einer der heftigsten Kontroversen zwischen Militärregierung und deutschen Regierungen in der Geschichte der amerikanischen Besatzungsherrschaft in Deutschland führten. Innerhalb der Militärregierung schien 1947/48 eine Fraktion immer größeren Einfluß zu gewinnen, die eine radikale Abkehr von den restriktiven Gewerbegesetzen forderte. Die deutsche Wirtschaft habe sich inzwischen soweit erholt, daß die „extraordinary measures $^{\text {"166 }}$, die 1946 angebracht gewesen seien, einer weiteren wirtschaftlichen Erholung nur im Wege stünden. „Es ist notwendig, daß OMGUS die Tatsache nicht in Vergessenheit geraten läßt, die Amerikas Industrie groß gemacht hat", hieß es in einem amerikanischen Memorandum vom 13. Januar 1948. „Diese Tatsache kann zusammengefaßt werden, in dem man sagt, es ist ein Grundprinzip der amerikanischen Wirtschaftsdemokratie, daß jedermann frei ist, sich auf jedes Wagnis einzulassen, auch wenn er dabei bankrott gehen sollte. ${ }^{\text {167 }} \mathrm{Daß}$ die liberale Fraktion die Oberhand gewonnen hatte, zeigte sich im März 1948, als OMGUS erstmals auf eine grundlegende Revision der bisherigen Gewerbepolitik drängte ${ }^{168}$. Namentlich nach dem Abbau der Zwangswirtschaft im Zuge der Währungsreform schien die Umgestaltung des restriktiven Zulassungswesens unabdingbar.

In München, Stuttgart und Wiesbaden schien man der Wende von OMGUS keine größere Bedeutung beizumessen. Die Länderregierungen - obwohl von den Amerikanern beauftragt, Vorschläge für liberale Gesetze zu erarbeiten - warteten ab und verlieBen sich auf eine Gesetzesinitiative des Wirtschaftsrates des Vereinigten Wirtschaftsgebietes, der am 9. Juli 1948 tatsächlich ein Gewerbezulassungsgesetz verabschiedete, das aber im Länderrat scheiterte. Nachdem der Einspruch der Länder Mitte August 1948 zurückgewiesen worden war, verweigerte die Militärregierung die Zustimmung, weil sie einer späteren Zuständigkeitsregelung durch die neue deutsche Regierung nicht vorgreifen wollte ${ }^{169}$. Die Sache zog sich Monat für Monat hin: Wirtschaftsrat,

\footnotetext{
${ }^{164}$ Mündliche Mitteilung von Herbert Hausner vom 27. Juli 1983. Vgl. auch Fränkische Landeszeitung vom 29. Januar 1949 und Hermann Schreiber, Leutershausen, Leutershausen 1975, S. 276.

${ }^{165}$ Fränkische Landeszeitung vom 29. Januar 1949.

${ }^{166}$ Memorandum vom 13. Januar 1948, in: NA, RG 260, 13/82-44/19.

167 Ebenda.

${ }^{168}$ Monthly Report of the Military Governor, U.S. Zone, Nr. 33: März 1948, hrsg. von Office of Military Government for Germany (U.S.), S. 4.

${ }^{169}$ Vgl. dazu Tilman Pünder, Das bizonale Interregnum. Die Geschichte des Vereinigten Wirtschaftsgebiets 1946-1949, Köln 1966, S. 229 f. Vgl. auch AVBRD, Bd. 4, S. 858-860, 1011-1013, 1025-1027.
} 
Länderrat und Parlamentarischer Rat berieten über bundesstaatliche Kompetenzen und einzelne Paragraphen des Gewerberechts. Dabei zeichnete sich eine Regelung ab, die zwar zu einer allgemeinen Lockerung der restriktiven Bestimmungen führen, aber die ,gewerbliche Tradition der Prüfung von Bedürfnis, Sachkunde und persönlicher Zuverlässigkeit“ eines Antragstellers wahren sollte ${ }^{170}$.

Wieder lehnte die Militärregierung ab, die jetzt mehr und mehr zu erkennen gab, daß sie - wie von ihrem liberalen Flügel gefordert - auf die Einführung der „bedingungslosen“ Gewerbefreiheit abzielte. Den Amerikanern war nicht verborgen geblieben, daß die Privatwirtschaft über Handwerkskammern und Handelsgremien einen entscheidenden Einfluß auf die Vergabe von Lizenzen ausübte; sie „hielten diese an die Zünfte erinnernden Verfahren für schädlich"171. Außerdem hatten sie den Eindruck gewonnen, den Deutschen sei überhaupt nicht an einer neuen gesetzlichen Regelung gelegen - jedenfalls nicht vor Ablauf der Besatzungszeit, da sie sich nicht auf einen Kompromiß mit der Militärregierung einlassen wollten. Verärgert, daß es ihnen nicht gelungen war, die Länderchefs und Abgeordneten des Wirtschaftsrates von den Vorteilen des Prinzips des freien Handels und Gewerbes zu überzeugen, oktroyierten die Amerikaner deshalb am 29. November 1948 die "radikale“ Gewerbefreiheit ${ }^{172}$.

Auf deutscher Seite weckten sie damit die lebhafteste Besorgnis. Überall kam es zu Kundgebungen und Demonstrationen. Das oberfränkische Handwerk veranstaltete in der Adventszeit des Jahres 1948 eine Aktionswoche mit acht Großkundgebungen in verschiedenen Städten ${ }^{173}$. Im Onoldiasaal von Ansbach trafen sich am 14. Dezember 1948 empörte Handwerker der umliegenden Landkreise und verabschiedeten eine Resolution, in der es hieß: „Gewerbefreiheit ... bedeutet, daß dem Pfuschertum, dem Schieber- und Freibeutertum Tür und Tor geöffnet wird.“ Besorgt über die Abschaffung des Großen Befähigungsnachweises, forderten sie die bayerische Regierung und die Handwerkskammer auf, ,alles zu tun, um eine Durchführung der in Aussicht gestellten Maßnahmen abzuwenden“174. Reinhold Maier, der Ministerpräsident des „Handwerkerlandes“ Württemberg-Baden, machte sich zu einem der lautstärksten Wortführer der gewerblichen Opposition. Vom Feuer der eigenen Rede wie vom Beifall der versammelten Handwerker mitgerissen, tönte er kurz nach dem Bekanntwerden des amerikanischen Diktats in einer Versammlung: „Wir rufen den Amerikanern zu: Hört auf mit der Bevormundung! Wir verstehen von diesen Dingen auch etwas, vom deutschen Handwerk verstehen wir bestimmt mehr als ihr! Haltet uns nicht für dümmer, als wir sind, und euch nicht für gescheiter, nicht überlegener, als ihr seid!"175 Das nützte aber alles nichts. Die Amerikaner hielten an ihrer Politik fest. Als wäre eine Schleuse geöffnet worden, brach jetzt eine zweite Welle von Zulassungsanträgen

\footnotetext{
${ }^{170}$ AVBRD, Bd. 5, S. 24.

${ }^{171}$ Gimbel, Amerikanische Besatzungspolitik in Deutschland, S. 307.

${ }^{172}$ AVBRD, Bd. 4, S. 1011-1013, 1025 1027.

${ }^{173} \mathrm{Vgl}$. Mitteilungsblatt der Handwerkskammer für Oberfranken (Bayreuth), 3. Jg., Nr. 1, Januar 1949, S. 1; vgl. auch Bayerische Handwerkerzeitung, 1. Jg., Nr. 1, 1. Februar 1949.

${ }^{174}$ Resolution, in: BayHStA, Bayerische Staatskanzlei (1976), AZ 6310. Vgl. auch Fränkische Landeszeitung vom 16. Dezember 1948, die über eine Kundgebung des mittelfränkischen Handwerks berichtet in der der Handwerkskammer-Präsident von Mittelfranken Dirscherl aus Protest gegen das von den Amerikanern oktroyierte Gesetz ausrief: „Wir sind kein Kolonialvolk.“

${ }^{175}$ Reinhold Maier, Erinnerungen 1948-1953, Tübingen 1966, S.127; vgl. auch Dorn, Inspektionsreisen, S. $129 \mathrm{f}$.
} 
auf die staatlichen Stellen herein. Hatte die Zahl der Gewerbebetriebsanmeldungen beispielsweise in München 1948 nur 7000 betragen, so lag sie 1949 bei über 27000 , 1950 noch bei über 15000 . Auch in Fürth stieg die Zahl der Gewerbebetriebe zwischen Weihnachten 1948 und Weihnachten 1949 von 6200 auf $7580^{176}$.

In vielen Regionen Bayerns begann in der Besatzungszeit die verspätete Industrialisierung, die erst in den fünfziger und sechziger Jahren voll zum Tragen kam und sich im deutlichen Anstieg der in Industrie und Handel beschäftigten Personen und in der Abnahme der selbständigen Existenzen äußerte. Während der Besatzungszeit, als manche Grundsteine hierfür schon gelegt wurden, war die Bedeutung dieses Umschichtungsprozesses erst ansatzweise zu erkennen. Damals dominierte unter den Neuzulassungen noch der kleine Gewerbebetrieb, häufig der Ein-Mann-Betrieb. Die Besatzungszeit war also, trotz einer Reihe von wirksamen Defensivmaßnahmen der alteingesessenen Geschäftswelt vor allem in den Städten, eine Art von Gründerzeit; der Anteil der selbständigen Erwerbspersonen nahm - industriegeschichtlich atypisch - gegenüber 1939 deutlich $\mathbf{z u}^{177}$. Mochten viele neugegründeten „Kümmerbetriebe“ auch schnell bankrott gehen und zu einer wirtschaftlichen Strukturveränderung wenig beitragen, eines blieb doch haften: Die Jahre unter amerikanischer Besatzung bahnten eine neue Beweglichkeit und größere Freiheit im Erwerbsleben an. Die wirtschaftliche Privatinitiative fühlte sich ermuntert, der einzelne war nicht mehr eingespannt in zahlreiche ideologisch-politische und behördliche $Z$ wänge, sondern konnte sich auf sein wirtschaftliches Fortkommen besinnen.

Einige der „neuen“ Händler und Handwerker unterschieden sich beträchtlich vom Typ des sorgsam kalkulierenden seriösen Unternehmers. Sie kümmerten sich kaum um bürokratische Dienstwege, die im Zeichen einer totalen Bewirtschaftung besonders lang waren und häufig nicht zum Ziel führten, sondern beschritten oftmals völlig neue Wege. Über ein solches Beispiel von Findigkeit und Wagemut berichtete der Elektrowarengroßhändler Josef Kempf, der sich 1945/46 - wie wir gesehen haben sehr schwer getan hatte, die Lizenz für sein Gewerbe zu erhalten. Kempf, der frühere Offizier, war ein Neuling in der Branche, der sich seine Geschäftsverbindungen zu den Elektroartikellieferanten erst aufbauen mußte. Überall wurde er skeptisch aufgenommen. Die Lieferanten wußten ja nicht, so Kempf, ,ist der Kempf eine Eintagsfliege oder ein seriöser Geschäftsmann“. Die Firma Busch und Jäger in Lüdenscheid behandelte ihn zunächst mit Reserve und wollte mit ihm erst ins Geschäft kommen, als er versprach, die leitenden Herren mit Kartoffeln zu versorgen. Kempf sicherte das zu und kaufte mit Hilfe seines Schwiegervaters, der in Ansbach und Umgebung ein angesehener Mann war, etwa 20 Zentner Kartoffeln zusammen. Wie aber sollte er sie nach Lüdenscheid bringen? Mit seinem alten DKW jedenfalls nicht. Das Problem schien sich wie von selbst zu lösen, als Kempf eines Tages in der Ansbacher Innenstadt einen Lastwagen aus Westfalen entdeckte, der sich auf der Rückfahrt zu seinem Heimatstandort befand. Die zwanzig Säcke mit Kartoffeln waren schnell aufgeladen. Kompliziert wurde es erst, als der Chauffeur für seine Hilfe 400,- RM und vier Packungen

${ }^{176}$ Vgl. Niesner, Zwei Jahre Gewerbefreiheit, S. 27 und 29. Vgl. Fürth 1946-1955. Wiederaufbau eines Gemeinwesens - Entwicklung zur Großstadt, Fürth 1956, S.62 f. Vgl. auch OB Fürth an Reg von Mittelfranken, 10. Januar 1950, in: BayHStA, MWi 12574.

${ }^{177}$ Klaus Schreyer, Bayern - ein Industriestaat. Die importierte Industrialisierung, München/Wien 1969, S. 293. 
amerikanische Zigaretten haben wollte. Kempf hatte nur eine Packung parat und so mußte er einen Angestellten in die Uzstraße schicken, der dort auf dem Schwarzmarkt die restlichen drei Packungen kaufen sollte. Er selbst wollte nicht gehen, für einen Elektrogroßhändler, so glaubte er, schicke sich das nicht. Als der Chauffeur zufriedengestellt war, konnte Kempf für eine Weile glauben, Busch und Jäger in Lüdenscheid als ersten wichtigen Lieferanten gewonnen zu haben. Der Kartoffeltransport wurde aber in Würzburg von der Polizei gestoppt, die Ladung Kartoffeln beschlagnahmt und Kempf mit einem Bußgeld von 100.- RM bestraft. Die Geschäftsverbindung mit der Lüdenscheider Firma kam aber dann doch noch zustande, denn Kempf machte sich sofort auf den Weg nach Westfalen und lag dort dem Prokuristen von Busch und Jäger solange in den Ohren, bis dieser die abenteuerliche Geschichte von den beschlagnahmten Kartoffeln glaubte und Kempf mit Schaltern, Kabeln und Steckern versorgte $^{178}$.

Auch den Alteingesessenen blieben die „dunklen“ Wege zum Erfolg nicht verborgen. Der Ansbacher Eisenwaren- und Kohlenhändler Friedrich Laubinger, Inhaber der 1901 gegründeten Firma Moritz Eckart am Martin-Luther-Platz, mußte seine bäuerliche Kundschaft aus dem Umland nach Kriegsende immer wieder vertrösten, wenn sie Hufbeschläge bei ihm verlangte. Zwei, drei Jahre waren im Rahmen der Bewirtschaftung schon keine Hufeisen mehr zu haben gewesen. Die Landwirtschaft arbeitete damals noch überwiegend mit Pferden, die schließlich, so Laubinger, „nicht barfuß laufen“ konnten. Er zögerte deshalb nicht lange, als ihm 1946 eine recht originelle Transaktion vorgeschlagen wurde, die Linderung für die bäuerlichen Nöte und für ihn selbst - ein einträgliches Geschäft versprach. Die Kesselofenfabrik Lang aus Barmen, die vor dem Krieg ein kleineres Zweigwerk in Ansbach errichtet hatte, wollte dieses nach 1945 wieder in das Ruhrgebiet zurückverlegen. Dazu brauchte man aber eine Genehmigung der Militärregierung, die nur zu erlangen war, wenn die für den Transport erforderlichen Lastwagen nicht leer nach Ansbach zurückfahren mußten. Die Kesselofenfabrik suchte also einen Partner, und sie fand ihn in Laubinger, der sich daran erinnerte, daß er während des Krieges Hufbeschläge in Barmen bzw. Wuppertal bestellt hatte, die aber ausgeblieben waren. Mit den alten Bestellscheinen in der Tasche machte er sich also im Troß von Lang auf den Weg in die britische Zone.

Nichts war ungewisser als der Erfolg seiner Mission. Die Werke standen noch, sie waren aber geschlossen. Nur das Pförtnerhäuschen und die Chefetagen waren besetzt. Laubinger sah mit einem Blick, daß sich in den Lagerhallen fand, was er begehrte: Hufbeschlag, Pflugscharen, Türschlösser. Laubinger brauchte seinen früheren Lieferanten nicht lange an die guten alten Geschäftsbeziehungen zu erinnern, dies umso weniger, als er in seinem Gepäck Kartoffeln und Dosenfleisch mitführte, die auch in den Chefetagen rar geworden waren. Wieder in Ansbach zurück, riß man ihm die Hufeisen und Pflüge förmlich aus der Hand. „Was war ich blöd“, so Laubinger später, „daß ich diese Schätze für schlechtes Geld verkauft habe. Aber wir waren halt damals so." 179

Was sich mit Einfallsreichtum alles machen ließ, bewies auch der uns schon bekannte Steinmetzbetrieb Hanel aus Leutershausen. Seit seiner Gründung kurz vor der

${ }^{178}$ Mündliche Mitteilung von Josef Kempf vom 21. Juli 1983.

${ }^{179}$ Mündliche Mitteilung von Friedrich Laubinger vom 21. Juli 1983. 
Währungsreform litt der Familienbetrieb an Rohstoffmangel. Quarz- oder Granitblöcke für Grabsteine waren nirgends aufzutreiben. Durch Zufall erfuhr Leonhard Hanel von einem verfallenen Friedhof im etwa $10 \mathrm{~km}$ entfernten Obersulzbach. Viele alte Gräber waren von Gras überwuchert, die Steine umgefallen und beschädigt. Für billiges Geld kaufte Hanel die alten Steine und arbeitete sie in seinem Betrieb völlig um. Nun eigneten sich aber die weichen fränkischen Sandsteine nicht besonders gut für Grabinschriften, über kurz oder lang wusch der Regen die Buchstaben aus. Für Hanel war das aber kein Hindernis. Er holte härtere Juraplatten aus dem im Altmühltal gelegenen Solnhofen, montierte sie auf die Sandsteine, und neue Grabsteine waren fertig $^{180}$.

Viele Unternehmer und Handwerker ließen sich auch nicht entmutigen, wenn ihre Wünsche nach Rohstoffen von den heimischen Wirtschaftsämtern nicht erfüllt werden konnten, sondern klapperten die übergeordneten Stellen solange ab, bis sie schließlich doch irgendwo fündig wurden. Ein Beispiel dafür lieferte der Kohlen- und Eisenwarenhändler Friedrich Laubinger aus Ansbach. Sein Kohlenkontor war 1946 so gut wie leer. Nachschub gab es schon seit längerem nicht mehr, die Kohlenbezugsscheine drohten zu verfallen. Nachfragen beim städtischen Wirtschaftsamt und beim Regierungswirtschaftsamt in Fürth fruchteten nichts. Also fuhr Laubinger selbst zur Kohlenauslieferungsstelle nach Mannheim. Um dort wirkungsvoll auftreten zu können, hatte er einen Koffer voller Geschirr mitgenommen, das er den zuständigen Beamten zusteckte. Wenig später waren in Ansbach wieder Kohlen zu haben ${ }^{181}$.

Die Wirtschaftsämter beobachteten das anarchische Treiben der Privatwirtschaft mit gemischten Gefühlen. Der Oberbürgermeister von Fürth beispielsweise, der sich seit Monaten wegen der knappen Brotvorräte sorgte, konnte im April 1946 aufatmend feststellen: „Der Privatinitiative verschiedener Bäckereien ist es gelungen, immer wieder Bezugsquellen bei früheren Lieferanten (Mühlen) zu erschließen, so daß die Brotversorgung im großen und ganzen bisher aufrechterhalten werden konnte. “182 Auch das Wirtschaftsamt der Stadt lobte im Juni 1946 die vorbildliche Unternehmerinitiative: „Die Firma Schmelz hat es zustande gebracht, einen Kaufvertrag über 1000 Wassereimer abzuschließen. Sie bringt damit den Beweis, daß die Privatinitiative mehr Ware heranzuschaffen vermag. " ${ }^{183}$

Manchem Leiter eines Wirtschaftsamtes bereiteten die zweifelhaften Geschäfte aber auch erhebliches Kopfzerbrechen. „Die unkontrollierbaren Kompensationsgeschäfte haben ein Ausmaß angenommen, daß wirksame Schritte unternommen werden müssen ... Die Wirtschaftskontrollstellen verlieren sonst jede Autorität und haben mit Rücksicht auf den grundsätzlich vorhandenen grauen Markt keine Möglichkeit wirksam einzugreifen. Es steht also die Autorität auf dem Spiel!"184 Regierungspräsident Schregle war vor allem die Verwilderung der Geschäftspraktiken ein Dorn im Auge: „Die wirtschaftliche Betätigung der Unternehmer entfernt sich immer mehr vom vorsichtigen kaufmännischen Rechnen und Abschätzen der Käuferwünsche und artet vielfach in ein wüstes Rennen um den Warennachschub aus, wobei leider Rücksichts-

\footnotetext{
${ }^{180}$ Mündliche Mitteilung von Leonhard Hanel vom 27. Juli 1983.

${ }^{181}$ Mündliche Mitteilung von Friedrich Laubinger vom 21. Juli 1983.

${ }^{182}$ OB Fürth an RegPräs, 24. April 1946, in: Stadtverwaltung Fürth, EAP 4.

${ }^{183}$ Monatsbericht des Wirtschaftsamtes der Stadt Fürth vom 18. Juni 1946, in: Ebenda.

${ }^{184}$ Monatsbericht des Wirtschaftsamts Ansbach, 20. September 1947, in: Stadtarchiv Ansbach, ABc T/5/90.
} 
losigkeit und Skrupellosigkeit oft den größeren Erfolg aufweisen als solides Geschäftsgebaren - eine Entwicklung, die bei längerem Andauern zu volkswirtschaftlich äußerst bedenklichen Auswirkungen und geradezu zu einer Balkanisierung führen muß." 185 Die heftige Kritik gegen Kompensationsgeschäfte und unlautere Geschäftspraktiken blieb aber ohne Konsequenzen. Die Kritiker wußten ja selbst nur zu gut, daß das Bewirtschaftungssystem allein nicht in der Lage war, die Versorgung von Bevölkerung und Industrie zu gewährleisten.

$\mathrm{Zu}$ diesem neuen Typus des einfallsreich-hemdsärmligen Händlers, Handwerkers und Unternehmers, der sich nach Kriegsende herausbildete, gehörte auch der spätere Konzernchef Max Grundig aus Fürth - allerdings nur cum grano salis, denn Grundig blickte 1945 bereits auf eine steile Karriere zurück, die ihm neben einigem Ansehen auch das „große Geld“ eingebracht hatte.

\section{Lehrjahre eines Konzernchefs: Max Grundig 1945-1948}

Max Grundig, der Sohn eines Magaziners bei den Nürnberger Herkules-Werken, hätte sich, als er 1930 in der Fürther Sternstraße Nr. 4 einen kleinen Laden mietete, wohl kaum träumen lassen, daß er bei Kriegsende über ein Vermögen von 17,5 Millionen Reichsmark verfügen würde. In dem Laden waren früher Hüte und Stöcke verkauft worden, jetzt (1930) eröffnete Grundig dort zusammen mit seinem Freund Karl Wurzer ein Radio-Fachgeschäft, das er zunächst Radio-Centrale Fürth, wenig später RadioVertrieb Fürth nannte. Im Protokoll des Amtsgericht-Registergericht Fürth hieß es damals: „Wir betreiben ab 15. Nov. 1930 ... den Handel mit Radio-Geräten und verwandten Artikeln in offener Handelsgesellschaft, sowie die Installation von elektrischen Einrichtungen ... Unser Betriebskapital beträgt 3500,- RM, wovon jeder Gesellschafter zur Hälfte beteiligt ist. Kaufmännische Buchführung ist vorhanden. "186 Grundig hatte in Nürnberg die Volksschule besucht, danach eine dreijährige Lehre als kaufmännischer Angestellter bei der Installationsfirma Jean Hilpert absolviert. Dabei hatte er sich so geschickt angestellt, daß er sofort nach der Lehre eine gutgehende Filiale in Fürth übernehmen konnte ${ }^{187}$, in der er die nötigen Erfahrungen für einen eigenen Laden sammelte.

Die Geschäfte in der Sternstraße liefen nicht schlecht. Grundig, seit seiner frühesten Jugend ein besessener Radiobastler, bot gute Qualität und verstand es mit der Kundschaft umzugehen. Bereits 1934 wurde es in der Sternstraße zu eng. Ein größeres Geschäft in der Schwabacherstraße 1/Ecke Schirmstraße kam hinzu, und auch hier brauchte Grundig nicht über schleppenden Geschäftsgang zu klagen. Die gesamte Rundfunkbranche stand seit 1923, als erstmals in Deutschland im Vox-Haus in Berlin die neue, aus Amerika kommende Sendetechnik vorgeführt worden war, unter einem

${ }^{185}$ RegPräs an bay. Staatsregierung, 3. Oktober 1947, in: BayHStA, Reg von Mittelfranken, Berichterstattung 1947, AZ 1-64, Bd. 5.

${ }^{186}$ Prot. des Amtsgericht-Registergericht Fürth vom 12. November 1930, in: Amtsgericht Fürth, RG, HRA 2 123: Radio Vertrieb Fürth: Max Grundig. Am 14. November 1930 ānderten Grundig und Co. den Namen, weil die Stadt Einspruch erhoben hatte. „Die übrigen Radiogeschāftsinhaber würden Einspruch erheben wegen des Wortes Centrale, da solches den Anschein erweckt, als wären die hiesigen Radiohändler centralisiert." Ebenda.

${ }^{187}$ Vgl. Fein, Sieben Tage Grundig, S. 9-37 und 83-143. 
guten Stern. Wer es sich irgendwie leisten konnte, kaufte sich eines der drahtlosen Empfangsgeräte mit Kopfhörer. Zwischen 1924 und 1939 stieg die Zahl der Rundfunkteilnehmer von $\mathbf{4 7 6}$ auf etwa 11 Millionen. Getragen von dieser anhaltend guten Konjunktur ging es stetig aufwärts mit Grundig. Der Regimewechsel 1933 hatte für den unpolitischen Händler und sein Radiogeschäft zunächst keine Bedeutung. Schon bald nachdem er den Laden in der Schwabacherstraße hinzugemietet hatte, begnügte er sich nicht mehr damit, Radios zu verkaufen. Er spezialisierte sich darauf, defekte Transformatoren zu reparieren; das war gerade im Raum Nürnberg/Fürth ein lohnendes Geschäft, denn Nürnberg verfügte damals über Wechselstrom, Fürth dagegen über Gleichstrom und jeder, der von der einen in die andere Stadt umzog und den Radioapparat an den „ungewohnten“ Strom anschloß, machte die gleiche Erfahrung: Nach einem lauten Knacken gab der Apparat keinen Ton mehr von sich - ein Fall für Grundig $^{188}$.

Die Reparatur von Transformatoren war aber nur der Anfang. Bald baute der RadioVertrieb Fürth selbst Transformatoren: 1938 schon 30000 Stück ${ }^{189}$. Grundig beschäftigte inzwischen zwei Monteure, fünf, sechs Frauen, die an den Wickelmaschinen arbeiteten, einen Buchhalter, eine Schreibkraft und einen Lehrling. Außerdem standen seine drei Schwestern fast immer im Laden. Noch vor Kriegsbeginn war Grundig Umsatzmillionär. Bald gehörte auch die Wehrmacht zu seinem Kundenkreis. Man schätzte die gute Arbeit und vor allem die Zuverlässigkeit von Grundig. Daß der "Chef“" selbst 1941 in Bayreuth einrücken mußte, störte die guten Geschäfte wenig. Es bedurfte keines weitblickenden, sich um alles sorgenden Betriebsleiters mehr, denn nach und nach nahmen die "Großen“ der Rüstungsindustrie dem Radio-Vertrieb Fürth die geschäftlichen Fäden aus der Hand. AEG und Siemens hießen jetzt die Auftraggeber, die wöchentlich Hunderte von defekten Transformatoren anfahren ließen.

Grundig brauchte erneut zusätzliche Räume und fand sie in zwei Wirtshäusern im kleinen Fürther Vorort Vach, wo er sich im unbenutzten Tanzsaal des Gasthauses „Linde“ und in der Kegelbahn des „Roten Ochsen“190 einquartierte. „Mit höchster Dringlichkeitsstufe versehen“, so Grundig später in einem Interview, erhielt „ich binnen zweier Monate an die hundert Wickelmaschinen aus Berlin"191. Dazu kamen hochspezialisierte Ingenieure von AEG und Siemens, etwa 100 bis 200 ukrainische Fremdarbeiterinnen, die zusammen mit den Wickelmaschinen „angeliefert“ wurden, und weitere Aufträge für die Kriegsproduktion. Der nun nicht mehr so kleine Fürther Gewerbebetrieb baute Steuerungsgeräte für die V 1- und V 2-Raketen und, nachdem die Körting-Werke in Leipzig ausgebombt worden waren, elektrische Zünder für Panzerabwehrwaffen. Die 300 Wickelmaschinen im Tanzsaal und in der Kegelbahn standen bald nicht mehr still. „Bei Kriegsende“, so erinnerte sich Grundig, „hatten wir in Vach draußen so um 600 Leute gehabt." 192

Am 19. April 1945 war in Fürth der Krieg zu Ende und auch die erste Karriere des Max Grundig als Zulieferer für die Rüstungsindustrie. Wenige Tage danach kreuzte in

\footnotetext{
${ }^{188}$ Vgl. ebenda, S. $107 \mathrm{f}$.

${ }^{189} \mathrm{Vgl}$. Industriefragebogen der amerikanischen Militärregierung vom August 1945, in: Firmenarchiv Grundig.

190 Vgl. Fein, Sieben Tage Grundig, S. 129.

${ }^{191}$ Interview mit Max Grundig, zu dessen 70. Geburtstag, in: Funkschau 50 (1978), Nr. 10, S. 443.

192 Ebenda. Vgl. auch Meldebogen für das Reichswirtschaftsministerium, in: BA Koblenz, R 13 V/148 und Fein, Sieben Tage Grundig, S.134.
} 
Vach ein Jeep auf. Ein amerikanischer Leutnant erkundigte sich nach Grundig und nahm ihn mit, nachdem er ihn im ersten Stock des Gasthauses „Linde“ ausfindig gemacht hatte. Bei den anschließenden Verhören im Fürther Rathaus, dem Sitz der Militärregierung, verstand es Grundig, allen Fragen nach seiner Verwicklung in die deutsche Kriegsproduktion auszuweichen; er mußte deshalb nach drei Tagen im Gewahrsam der Military Police in der Nürnbergerstraße wieder auf freien Fuß gesetzt wer$\operatorname{den}^{193}$.

Die drei Tage Haft warfen keinen Schatten auf die glänzende Ausgangslage Grundigs. Er hatte sich durch die Aufträge der Wehrmacht eine goldene Nase verdient, war dabei aber weder in den Vordergrund gerückt, noch hatte er sich mit dem NS-Regime mehr als nötig eingelassen. Er war also politisch unbelastet, außerdem hatte er viel Geld: 17,5 Millionen Reichsmark, davon 10 Millionen Reichsmark offene Forderungen bei Siemens und $\mathrm{AEG}^{194}$. Zudem waren die Maschinen und Meßgeräte intakt ${ }^{195}$, der Laden in der Schwabacherstraße war unbeschädigt und schließlich konnte er auch seine gesamten Rohstoffvorräte über die Wirren der letzten Kriegstage retten. „Ich hatte viel Material“, erzählte Grundig später. „Da kamen dann die Großhändler, alle die bekannten, mit Lastwagen, etwa aus Köln der Kleine-Erfkamp und aus Ulm der Dieseldorf"196. Allmählich fand sich auch der alte Stamm von Experten von AEG und Siemens wieder zusammen, der im Laufe der Jahre durch jüngere leistungsbereite Kräfte ergänzt wurde, die anderswo keine geeignete Betätigungsmöglichkeit gefunden hatten oder denen die alte Radioindustrie zu schwerfällig war. Die Weichen für die zweite Karriere waren also gestellt.

Trotzdem zögerte Grundig zunächst. So sehr war er noch in der Mentalität des Radiohändlers befangen, daß er nicht mehr richtig weiter wußte, als nun plötzlich die „Großen“ fehlten, denen er seine bisherigen Erfolge hauptsächlich verdankte. Den ganzen Mai über war er damit beschäftigt, zusammen mit seinen Leuten die Maschinen und Rohstoffe von Vach nach Fürth zurückzubringen. Einige Wochen war es freilich höchst zweifelhaft gewesen, ob Grundig die Rohstoffe und Maschinen würde behalten können. Captain Carl Barker von Special Branch, ein „Deutschenhasser, Berufssoldat, bullig und unfreundlich“, hielt Grundig für einen Nutznießer des NS-Regimes, der nicht ungestraft davonkommen sollte. Erst auf Drängen der deutschen Angestellten von Special Branch - alles Sozialdemokraten -, die glaubten, es sei im Interesse der Stadt Fürth, wenn Grundig sobald als möglich die Fabrikation wiederaufnehmen könne, willigte Barker ein, Grundig die Rohstoffe zu überlassen ${ }^{197}$.

Nachdem Grundig diese vielleicht schwierigste Klippe nach Kriegsende überwunden hatte, mietete er im Rückgebäude der Jakobinenstraße 24 ein kleines Haus, das dem Spielwarenfabrikanten Christian Götz gehörte, der seinen Laden zugemacht hatte, weil er für Spielwaren keine Zukunft mehr sah. Im Juni 1945 begann mit 11 Männern und 31 Frauen die Fabrikation. Grundig, nun auf sich allein gestellt, knüpfte dort wieder an, wo er im April 1945 aufgehört hatte: Er produzierte Allzweck-Trans-

\footnotetext{
${ }^{193}$ Vgl. Fein, Sieben Tage Grundig, S. $140 \mathrm{ff}$.

${ }^{194} \mathrm{Vgl}$. ebenda, S. 142 und $155 \mathrm{f}$.

${ }^{195}$ Vgl. u. a. Konstantin Prinz von Bayern, Die großen Namen. Begegnungen mit bedeutenden Deutschen unserer Zeit, München 1956, S. 202 f.

196 Funkschau 50 (1978), Nr. 10, S. 443.

${ }^{197}$ Mündliche Mitteilung von Otto Gellinger vom 29. Januar und 10. Februar 1983.
} 
formatoren, die sich zum Stückpreis von 37,- Reichsmark gut verkauften. Bald waren 80 Personen, hauptsächlich ungelernte Frauen, auf den 400 qm Fabrikfläche in der Jakobinenstraße beschäftigt. Engpässe bei der Rohstoffversorgung - die Geißel fast aller übrigen Betriebe - kannte man bei Grundig nicht. Man hatte in Vach, was man brauchte. Außerdem zahlten AEG und Siemens ihre Schulden etwa zur Hälfte in Materialien, so daß Grundig 200 Tonnen Bleche für Transformatoren und tonnenweise Kupferdrahtrollen bekam.

Das Geschäft mit den Transformatoren stieß aber bald an seine Grenzen. Von Januar bis Oktober 1946 fiel die Zahl der produzierten Trafos von etwa 2700 auf $190^{198}$. Grundig war auf diesen Einbruch vorbereitet gewesen und hatte frühzeitig mit dem Bau von elektrischen Meß- und Prüfgeräten „Novatest“ und „Tubatest“ begonnen, die anfangs ebenfalls reißenden Absatz fanden. Jeder Kunde war zugleich auch Lieferant. Um einen "Novatest" zu erwerben, mußte der Kunde in Rohmaterialien wie Kupfer, Schrauben und Drähten „zahlen“. Grundig, der auf wahren Schätzen von Rohstoffen saß, fühlte aber trotz guten Geschäftsgangs, daß er eigentlich auf der Stelle trat. In dieser etwas unbefriedigenden Situation kam ihm der Zufall zu Hilfe. Eines Tages besuchte ihn Hans Eckstein, ein exzellenter Radiofachmann, der schon 1933 bei Lumophon in Nürnberg Rundfunkempfänger entwickelt und später bei Telefunken gearbeitet hatte ${ }^{199}$. „Es wäre doch eine einmalige Chance, jetzt Rundfunkgeräte zu bauen!", schlug er Grundig vor, der sich aber nicht so recht für diese Idee erwärmen konnte. Er scheute das Risiko. Nach einiger Zeit, so glaubte er, würden die Großen der Rundfunkbranche wieder zu Kräften kommen und ihn, den Neuling, schnell verdrängen ${ }^{200}$.

Ecksteins Vorschlag hatte es aber in sich. Zigtausende von Rundfunkgeräten waren während des Krieges kaputtgegangen oder mußten nach Kriegsende an die Besatzungsmacht abgeliefert werden. Ersatz war nicht zu haben - und das in einer Zeit, da sich viele nach der Eintopfkost aus dem Volksempfänger nach der "großen Welt“ des Rundfunks sehnten. Wie groß dieses Bedürfnis war, zeigt allein ein Blick auf die trotz beträchtlicher Lieferschwierigkeiten - emporschnellende Zahl der Rundfunkgenehmigungen zwischen 1946 und 1950. 1946 waren in Bayern auf 1000 Einwohner 112 Rundfunkgenehmigungen gekommen, 1950 waren es bereits $152^{201}$. Die führenden Hersteller hatten ihren Stammsitz in Berlin oder in der sowjetisch besetzten Zone und waren damit vom Westen fast völlig abgeschnitten. Außerdem hatten sie durch „Kriegseinwirkungen und Demontagen durchweg acht Zehntel und mehr ihrer Kapazität" verloren ${ }^{202}$. Das größte westdeutsche Rundfunkwerk Saba in Villingen befand sich fest in der Hand der französischen Besatzungsmacht. So bestand eine enorme Marktlücke ${ }^{203}$ „ „Die Firmen Blaupunkt, Atlas, Telefunken, Padora, Siemens, Seibt, haben in der Zeit vom 15. 1. 1946 bis 15. 1. 1947 die Gesamtzahl von 2917 Rundfunkgeräten ausgeliefert“, so schilderten die Nürnberger Nachrichten am 30. April 1947

\footnotetext{
${ }^{198} \mathrm{Vgl}$. monatliche Industrieberichte an das Bayerische Statistische Landesamt und an das bayerische Staatsministerium für Wirtschaft aus den Jahren 1946 und 1947, in: Firmenarchiv Grundig.

${ }^{199}$ Vgl. auch den Briefwechsel zwischen Grundig und Eckstein, in: Firmenarchiv Grundig.

${ }^{200}$ Vgl. Der Spiegel vom 15. Januar 1958 und Fein, Sieben Tage Grundig, S. $168 \mathrm{f}$.

201 Vgl. Statistisches Jahrbuch für Bayern 1952, S. 410.

${ }^{202}$ Anton Zischka, War es ein Wunder? Zwei Jahrzehnte deutschen Wiederaufstiegs, Hamburg 1966, S. 481 f.

${ }^{203}$ Vgl. Der Spiegel vom 15. Januar 1958.
} 
die Flaute in der Radiobranche. „Davon entfielen auf politisch und rassisch Verfolgte: 630, auf die Militärregierung in Bayern: 114, als Firmenanteil für Lieferverträge und Materialbeschaffung: 645, als Kontingent für die außerbayerischen Länder der USZone: 488, als Hilfskontingent für Heime, Lager und Schwerstversehrte: 411, für Blinde: 168 und als Dienst- und Behördenkontingent einschließlich Presse: 437 Stück.“

Schließlich gab Grundig sein Zögern auf und beauftragte Eckstein mit der Konstruktion eines einfachen Rundfunkgeräts, das sich möglichst „breit“ aus vorhandenen Restbeständen bestücken ließ ${ }^{204}$. Das war aber leichter gesagt als getan, denn zum einen waren Radios streng bewirtschaftet und zum anderen ihre Herzstücke, die Röhren, nur noch auf dem Schwarzen Markt zu haben. Schwierigkeiten über Schwierigkeiten also, denen sich Eckstein und Grundig gegenübersahen. Die rettende Idee kam, so will es jedenfalls die Firmenlegende, Max Grundig beim Mittagessen. Nach der Suppe sprang er plötzlich auf und murmelte: „Mir ist was eingefallen, ich komm gleich wieder." Dann ward er 24 Stunden nicht mehr gesehen. Als er wieder in den Kreis der Familie zurückkehrte, war ihm klar, wie sich die Schwierigkeiten ausräumen ließen. Grundig dachte daran, einen Radiobaukasten zu konstruieren, den selbst der technisch unbegabteste Käufer mühelos zusammenbasteln konnte - ein Spielzeug also, das keine Röhren enthielt und so nicht der Bewirtschaftung unterlag. Der Baukasten sollte den Namen „Heinzelmann“ tragen, weil Grundig, wie die Heinzelmännchen, den Menschen heimlich half ${ }^{205}$.

Am 10. August 1946 erteilte die Landesstelle Eisen und Metalle in München der Firma Max Grundig eine vorläufige Arbeitserlaubnis für die Herstellung von Werkstatt-, Meß- und Prüfgeräten, Kleintransformatoren und Rundfunkgeräte-Baukästen $^{206}$. Zwei Monate später lief die Produktion der unvollendeten Radioapparate bereits auf Hochtouren. Zuerst wurden monatlich 75 Exemplare hergestellt, im April 1947 schon über 1000. Zwischen 100 und 120 Leute arbeiteten nun in den engen Räumen der Jakobinenstraße. „Was bis zum Abend fertig war, ging noch am selben Tag raus“, so erzählte Grundig später über seine aufregende Pionierzeit. „Viele Händler holten die Baukästen selber ab. Da wurde bar bezahlt, und an manchen Tagen hatten wir so viel Geld eingenommen, daß wir es abends gar nicht mehr zählen konnten.“207 Daß der Baukasten keine Röhren enthielt, war in der fünfzehn Seiten langen Gebrauchsanweisung so erklärt: „Für das Gerät sind nur zwei Empfangsröhren erforderlich, die im Baukasten nicht enthalten sind. Bedingt jedoch durch die Vielzahl der verwendbaren Röhren wird ihr Rundfunkhändler in der Lage sein - und er hat die freiwillige Verpflichtung hierzu durch den Verkauf des RVF-Baukastens übernommen - dieselben aus vorhandenen Beständen mitzuliefern.“208 Durch diesen geschickten Einfall entzog sich Grundig der Kontrolle der Wirtschaftsämter. Der „Heinzelmann“ wurde mit über 100000 verkauften Exemplaren ein Renner, der Grundig rund 22,5 Millionen Mark einbrachte ${ }^{209}$.

\footnotetext{
${ }^{204}$ Vgl. Fein, Sieben Tage Grundig, S. 168-172.

${ }^{205}$ Ebenda, S. 168.

${ }^{206}$ Ebenda, S. 173. Zum Heinzelmann vgl. auch ein technisches Gutachten, in: BayHStA, MWi 9811.

${ }^{207}$ Fein, Sieben Tage Grundig, S. 177 f.

${ }^{208}$ Ebenda, S. 183.

${ }^{209}$ Vgl. Der Spiegel vom 15. Januar 1958.
} 
Durch die Produktion der „Heinzelmänner“ erschöpften sich natürlich die Rohstoffvorräte aus dem Zweiten Weltkrieg. Wie alle übrigen Firmen mußte sich nun auch der RVF etwas einfallen lassen - und er tat es. Angespornt durch seine imponierenden Erfolge bei der Herstellung des „Heinzelmann“ entdeckte Grundig nun mehr und mehr seine Fähigkeiten, die ihn später berühmt machten: Einfallsreichtum bei der Überwindung von Schwierigkeiten und die Vorliebe, unkonventionelle Wege zu gehen. Die ersten Jahre nach Kriegsende waren wohl so etwas wie die Lehrjahre für Max Grundig, in denen er endgültig zum großen Unternehmer wurde.

Er selbst war in Fürth und Umgebung ununterbrochen unterwegs und „organisierte“. Sein Vertreter-Ring, der sich mittlerweile zumeist aus alten AEG- und Siemens-Leuten gebildet hatte, bestand fast durchweg aus Spezialisten des Schwarzen und Grauen Marktes, die über ihre früheren Verbindungen immer wieder an Rohstoffe kamen. Erich Rüsing aus Wuppertal behauptete Jahre später: „Ich allein habe Grundig damals 170000 Röhren besorgt. "210 Wie abenteuerlich-verwickelt diese Geschäfte oft waren, zeigte sich, als Grundig 3000 seiner „Heinzelmänner“ an die französische Militärregierung verkaufte, die nicht bar, sondern in Tabak bezahlte: 30 Millionen Zigaretten und 5000 Kisten Zigarren. Grundig brauchte aber keine Zigaretten, gefragt war vor allem Zement, da der Neubau der ersten Fabrik gerade begonnen hatte. Also tauschte er seine Zigaretten gegen 30 Waggons Kohle, die auf dem Rangierbahnhof Nürnberg angeliefert wurden. Um in den Besitz der Kohle zu gelangen, mußten allerdings erst die örtlichen Behörden besänftigt werden. Dabei entstanden so große „Reibungsverluste“, daß für Grundig letztlich nur noch zehn Waggons übrigblieben, die er sofort an eine Zementfabrik in Marktheidenfeld weiterleitete. Aus Marktheidenfeld trafen wenig später tatsächlich die verabredeten zehn Waggons Zement ein; einen Teil beanspruchte der Fürther Bauhof, dessen Chef dafür versprach, Stillschweigen über die Schiebergeschäfte Grundigs zu bewahren ${ }^{211}$.

Bei so viel Findigkeit florierten die Geschäfte. Ende 1947 erzielte Grundig, der nun fast 300 Arbeiter und Angestellte beschäftigte, einen Umsatz von vier Millionen Reichsmark. Diese Findigkeit hätte aber wohl nicht ausgereicht, den Erfolg seines Unternehmens zu begründen, wenn Max Grundig nicht zugleich bereit gewesen wäre, die erzielten Gewinne sofort wieder in sein Werk zu stecken. So wie er die Einnahmen aus der Transformatorenfertigung in die Produktion des „Heinzelmann“ investierte, so flossen auch die beträchtlichen Gewinne aus dem „Heinzelmann“-Geschäft unverzüglich in den Betrieb zurück. Noch 1946, als gerade die ersten „Heinzelmänner“ die kleinen Fertigungsstuben in der Jakobinenstraße verließen, hatte er bei Eckstein ein Nachfolgemodell bestellt, das er ab 1947 unter dem Namen „Weltklang“ produzierte. Anfang 1947 begann er mit dem Bau einer neuen Fabrikanlage aus sechs Steinbarakken in der Kurgartenstraße, die am 17. September 1947 fertig war. Grundig und seine Mitarbeiter hatten selbst Hand angelegt - nicht nur die ungelernten Kräfte, sondern auch die Techniker und Laborleiter. Sie schienen tatsächlich von so etwas wie Pioniergeist durchdrungen und waren so auch zu außerordentlichen Leistungen bereit. Kein Wunder: Ringsum wurde die wirtschaftliche Lage immer trostloser, nur bei Grundig 
überschlugen sich die Erfolge. Noch vor der Währungsreform hatte sich Grundig auf dem Radiomarkt seinen Anteil erobert. „Er gehörte dazu“, so schrieb die Süddeutsche Zeitung später, „als wäre es nie anders gewesen.“ ${ }^{\text {212 }}$

\section{Am Vorabend der Währungsreform: Schwarzmarkt und Horten}

Die glänzenden Erfolge Grundigs schon vor der Währungsreform im Jahre 1948 blieben in der Region um Ansbach und Fürth eine Ausnahme. Während der Kohlebergbau und die Eisen- und Stahlindustrie der britischen Zone im Laufe des Jahres 1947 so „bedeutende Fortschritte“ erzielten, daß der Index der industriellen Produktion der Bizone gegenüber 34 im Jahre 1946 auf $44(1936=100)$ anstieg $^{213}$, ließ in Mittelfranken ein entscheidender Durchbruch zu einer wirtschaftlichen Erholung auf sich warten. „Die mangelnde Energieversorgung, die überaus hohen Unkosten in der Warenbeschaffung und die nicht genügend ausgenützte Produktionskapazität“, so faßte Regierungspräsident Schregle im Dezember 1947 die nach wie vor düstere Lage zusammen, „machen die gesamte Industrie unrentabel und stellen ihren Fortbestand weiterhin in Frage.“214 Im Baugewerbe, in der optischen und Metallindustrie ging es zwar etwas aufwärts ${ }^{215}$, diese kleinen Fortschritte wurden aber durch die verschiedensten Hemmnisse immer wieder zunichte gemacht, wie etwa das Beispiel der Fürther Spielwarenindustrie zeigte: „Die Beschäftigung dieser Industrie scheitert nicht daran“, so der Bericht des Oberbürgermeisters vom 22. Oktober 1947, „daß die Exportmärkte für diese Erzeugnisse nicht aufnahmefähig wären. Sie scheitert nicht einmal daran, daß es an Rohstoffen mangelt. Im Gegensatz zu Beginn dieses Jahres hat sich die Versorgung mit Blechen, Buntmetall und Federbandstahl sehr befriedigend entwickelt. Es fehlt heute allein an Verpackungsmaterial und zwar an Pappe, von der $70 \mathrm{t}$ in Frankreich gekauft, aber leider noch nicht geliefert wurden. " 16 Außerdem war die leichte wirtschaftliche Besserung vor allem im Produktions- und Investitionsgüterbereich, nicht aber im Nahrungs- und Genußmittelbereich bzw. bei Textilien und Schuhen zu spüren, wo in der zweiten Hälfte von 1947 der Index der Produktion in Bayern erst 33,6 bzw. 30 und $41(1936=100)$ betrug $^{217}$. Die Schaufenster und Läden blieben deshalb weitgehend leer, zwei Jahre nach Kriegsende zeichnete sich für die Verbraucher noch immer keine Wende zum Besseren ab.

Eine Änderung war vor der Beseitigung des finanziellen Erbes des Dritten Reiches, das in einer inflationär aufgeblähten Geldmenge und in einem kärglichen Warenangebot bestand, nicht zu erwarten. Die Folgen dieser Geldvermehrung hatten während der NS-Zeit durch den Lohn- und Preisstop notdürftig verschleiert werden können, nach Kriegsende war der Ruin der deutschen Währung offenkundig. Die alliierten

\footnotetext{
212 Süddeutsche Zeitung vom 1. Juli 1958.

${ }^{213}$ Werner Abelshauser, Wiederaufbau vor dem Marshall-Plan, in: VfZ 29 (1981), S. $564 \mathrm{f}$.

${ }^{214}$ RegPräs an bay. Staatsregierung, 4. Dezember 1947, in: BayHStA, Reg von Mittelfranken, Berichterstattung 1947, AZ 1-64, Bd. 5.

${ }^{215}$ Vgl. OB Fürth an RegPräs, 22. August 1947, in: Stadtverwaltung Fürth, EAP 4.

216 In: Ebenda.

${ }^{217} \mathrm{Vgl}$. Statistisches Jahrbuch für Bayern 1952, S.176f.
} 
Siegermächte vertrauten zwar weiterhin auf das aus der NS-Zeit stammende staatliche Bewirtschaftungssystem und hielten auch den Lohn- und Preisstop aufrecht. Der Erfolg war aber bescheiden, das Netz der Verordnungen und Gesetze hatte schon während der NS-Zeit, als Verstöße gegen die Kriegswirtschaftsordnung mit drastischen Strafen bedroht gewesen waren, nur notdürftig gehalten. Nun wurde es trotz vieler neuer Maßnahmen immer löchriger, so daß der offizielle Markt des Bewirtschaftungsund Rationierungssystems mehr und mehr in den Hintergrund trat. Deutschland, dem die britische Militärregierung noch 1945 nachgerühmt hatte, das einzige Land ohne Schwarzen Markt zu sein, verwandelte sich binnen kurzem zu einem einzigen großen Schwarzen Markt ${ }^{218}$, auf dem für Zigaretten und Wertsachen und zu weit überhöhten Reichsmarkpreisen alles das zu haben war, was in den Auslagen der Läden und Kaufhäuser schon lange fehlte. „Keine Ware wird mehr um des Geldes Willen abgegeben“, berichtete der Landrat von Ansbach im September 1947, „keine Dienstleistung mehr um des Geldes Willen ausgeführt, wie es doch sein sollte ... man sucht sich durch Kompensationsgeschäfte aller Art, angefangen vom Pfund Kartoffeln bis zum Millionengeschäft, schadlos zu halten.“219 Mit dieser „desorganisierten Wirtschaft" schien, wie es etwa in bayerischen Wirtschaftskreisen treffend hieß, „die niedrigste Stufe des Handels aus dem frühen Mittelalter erreicht“220.

Millionengeschäfte waren auf dem Ansbacher und Fürther Schwarzmarkt meist nicht zu machen. Was sich im Areal der Baugenossenschaft „Eigenes Heim“ am Finkenschlag in Fürth und in der Ansbacher Innenstadt abspielte, war kleine Münze im Vergleich zu den Geschäften in den Münchener oder Frankfurter Schwarzmarktzentren, wo Schieber und Spekulanten ohne nennenswerte Mühe zu raschem Wohlstand kamen. Gelegentlich erhielt freilich auch die Bevölkerung der mittelfränkischen Provinz eine Ahnung von den riesigen Dimensionen der Geschäfte auf dem Schwarzen Markt; so etwa im Herbst 1947, als die Fürther Kriminalpolizei eine kleine Gruppe internationaler Schieber auffliegen ließ. 3500 Flaschen Sliwowitz und Likör, 20000 bulgarische Zigaretten und $100 \mathrm{~kg}$ feinster Gänseleberpastete wurden beschlagnahmt, drei Personen - allesamt Auswärtige - in Haft genommen. „Die Schiebergesellschaft“, schrieb der Lokalredakteur der Fürther Ausgabe der Nürnberger Nachrichten, „wurde anscheinend gerade im richtigen Augenblick geschnappt, als sie ihre dunklen Geschäfte auch auf Nürnberg - Fürther Firmen ausdehnen wollte." Mit kaum verhohlenem Staunen über das Ausmaß der Geschäfte und die korrupte Arbeitsweise von Großschiebern berichtete die Presse, daß der Hauptschuldige versucht habe, die Kriminalpolizei zu bestechen. Wenn man ihn laufen lasse, so habe er angeboten, wolle er die Waren im Wert von 1,5 Millionen Reichsmark der Polizei überlassen: „Ich gehe eben dann zurück nach Berlin und sage: Wir haben in Fürth Pech gehabt! Die Gegenstände sind verloren! ${ }^{\text {2221 }}$

Die Masse der Schieber- und Schwarzmarktgeschäfte aber war kleineren Kalibers. Im Zentrum des Ansbacher Schwarzmarktes, in den engen Gassen der Uzstraße und im schäbigen Gasthof „Zur Butte“, lungerten von früh bis spät kleine Schieber herum.

\footnotetext{
${ }^{218} \mathrm{Vgl}$. Werner Abelshauser, Wirtschaft in Westdeutschland, S. 54.

219 Bericht des LR Ansbach, 17. September 1947, in: NA, RG 260, 9/144-2/2.

${ }^{220}$ Fränkische Landeszeitung vom 26. Mai 1948.

${ }^{221}$ Nürnberger Nachrichten, Fürther Ausgabe, vom 25. Oktober 1947.
} 
Wenn eine Polizeistreife auftauchte, zerstreuten sich die kleinen Gruppen, die sich aber sogleich wieder bildeten, wenn die Polizisten außer Sichtweite waren. Es war ein dauerndes Kommen und Gehen. In den düsteren Hausfluren wechselten Zigaretten und Lebensmittel die Besitzer ${ }^{222}$; im Oktober 1947 mußte man für ein Kilo Nescafé 500,- RM, für ein Kilo Zucker 180,- RM und für ein Kilo Butter 360,- RM hinblättern $^{223}$. Wer mitbieten konnte, gehörte zum Kundenkreis des Schwarzen Marktes. Es waren aber anscheinend fast immer Angehörige gesellschaftlicher Randgruppen, die das Geschehen auf dem Fürther Finkenschlag oder in der Ansbacher Uzstraße bestimmten: Juden, die im KZ überlebt hatten, aus der Bahn geworfene Jugendliche und vor allem polnische DP's, die von der Besatzungsmacht großzügige Lebensmittelrationen erhielten und damit einen schwungvollen Handel treiben konnten ${ }^{224}$.

Eine besondere Rolle unter den Schiebern spielten die Angehörigen der amerikanischen Streitkräfte. Sie hatten Zigaretten, Kaffee und Alkoholika im Uberfluß; einige Gl's verstanden es auch, Medikamente und Treibstoff von den offiziellen Armeebeständen abzuzweigen und damit große Gewinne zu machen. „Der Schwarze Markt gedieh zügellos", schrieb General Clay in seinen Memoiren. Aus der Disziplin des Krieges entlassen, waren die schlachterprobten GI's nicht immer bereit, sich der „strengen

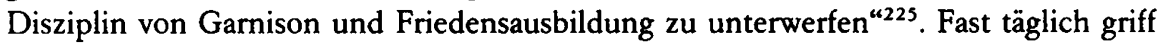
die amerikanische Militärpolizei bei Razzien zahlreiche eigene Landsleute auf, die unter die Schwarzhändler gegangen waren; an einem Februartag des Jahres 1947 allein in

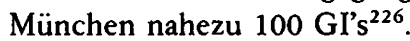

In Ansbach gediehen diese krummen Geschäfte ganz in der Nähe der amerikanischen Unterkünfte in der Bleidorn-Kaserne. Die GI's hatten es vor allem auf Uhren abgesehen. Einige trugen zwei, drei oder gar vier Uhren am Arm; je mehr, desto gröBer war das Ansehen vor allem unter den farbigen Soldaten. Auch Nazi-Embleme standen unter den Besatzungssoldaten hoch im Kurs. Eine Parteifahne brachte zehn Stangen Zigaretten, ein Parteiabzeichen noch zwei oder drei Stangen ein. Für Deutsche waren diese Geschäfte nicht ungefährlich ${ }^{227}$. Ein Ansbacher beispielsweise, der sechs Packungen Zigaretten gegen seinen Wecker eintauschte, ließ sich dabei von der Militärpolizei erwischen, die ihn wegen unrechtmäßigen Besitzes alliierten Eigentums ins Gefängnis steckte - eine drakonische Strafe für ein kaum nennenswertes Vergehen, die den Landrat, dem eine ganze Reihe ähnlicher Fälle zu Ohren gekommen war, zu einer Beschwerde bei der Militärregierung veranlaßte: „Mir ist durchaus bekannt, daß die in Deutschland geltenden Bestimmungen über die Verhaftung für die MP Polizei keine Anwendung finden können. Ich darf aber vielleicht doch darauf hinweisen, daß nach den deutschen Bestimmungen, die wenigstens als Vergleichsmaßstab dienen können, Verhaftungen, selbst bei Verbrechen, auf denen mehrere Jahre Gefängnis steht, nur dann vorgenommen werden, wenn Fluchtgefahr oder Gefahr einer Verdunklung des Tatbestandes besteht.“228

\footnotetext{
${ }^{222}$ Mündliche Mitteilungen von Willibald Kornburger und Karl-Heinz Sening vom 13. Juni 1983.

${ }^{223}$ Vgl. Quarterly Hist. Rep., Det. Ansbach, 27. Januar 1948, in: NA, RG 260, 10/80-3/6.

${ }^{22}$ Mündliche Mitteilung von Willibald Kornburger vom 13. Juni 1983.

${ }^{225}$ Clay, Entscheidung, S. $79 \mathrm{f}$.

${ }^{226} \mathrm{Vgl}$. Süddeutsche Zeitung vom 15. Februar 1947.

${ }^{227}$ Mündliche Mitteilung von Willibald Kornburger vom 13. Juni 1983.

${ }^{228}$ LR Ansbach an MilReg, 31. Oktober 1946, in: LRA Ansbach, EAP 04-040.
} 
Ein ehrbarer Kaufmann, ein Bauer oder ein Beamter der Stadtverwaltung war dagegen als aktiver Schwarzhändler kaum denkbar. Wenn es sich nicht vermeiden ließ, frequentierten auch sie den öffentlichen Schwarzen Markt, im allgemeinen aber hielten sich ihre illegalen Geschäfte im Rahmen von nachbarschaftlichen, verwandtschaftoder bekanntschaftlichen Beziehungen. Zu dieser Art von Geschäften gehörten beispielsweise das Schwarzschlachten, der Tausch eines Kaffeeservices gegen etwas Eßbares und der Verkauf von Fleisch an einen Nachbarn, obwohl in der Auslage längst das Schild „Kein Fleisch“ hing. Am riskantesten war dabei das Schwarzschlachten, das die amerikanische Militärregierung mit drastischen Strafen bedrohte. Doch auch da wußten sich die Deutschen zu helfen. Sie griffen einfach auf einen Trick zurück, der sich schon im Dritten Reich bewährt hatte: Ein Bauer, der im Rahmen der bestehenden Regelungen ein Schwein geschlachtet hatte, ließ sich von einem Nachbarn die Sau stehlen - natürlich nicht ohne vorher vereinbart zu haben, daß man nach dem gelungenen Diebstahl die Beute redlich teilen werde. Beide profitierten davon. Der Nachbar kam zu einem halben Schwein und hatte für die nächste Zeit die „Magenfrage“ gelöst. Der Bauer selbst hatte die andere Hälfte und keine Kommission konnte ihm vorschreiben, was er mit dem Fleisch machen sollte. Im Bedarfsfall ließ sich diese Vorgehensweise mit umgekehrter Besetzung leicht wiederholen ${ }^{229}$.

An den Wochenenden blieb es in den städtischen Schwarzmarktzentren meist ruhig. Die „Kunden“ zog es nämlich zu Hamsterfahrten aufs Land. Schlecht bezahlte Arbeiter, die sich weder von wertvollen Teppichen und Ölgemälden, noch von gediegenem Familiensilber trennen mußten, durften sich von den anstrengenden Landpartien aber nur dann etwas versprechen, wenn sie zur neuen, in Naturalien entlohnten „Arbeiteraristokratie“ gehörten, die die Produkte ihrer Werke zum Tausch gegen Lebensmittel anbieten konnten. Der Landpolizei-Posten im oberfränkischen Mühlhausen, der zwei Fürther Frauen - beide Näherinnen bei der Firma Quelle - aufgegriffen hatte, berichtete im August 1946 über eine dieser Hamsterfahrten: „Am 29.8.1946 gegen 16.00 Uhr wurden während eines Dienstganges auf der Straße von Horbach nach Sinnersdorf zwei Frauen mit bepackten Rucksäcken und vollen Taschen einer Kontrolle unterzogen ... Bei der Durchsicht des Gepäcks wurde festgestellt, daß die Schaue 55 Eier, 1/4 Pfund Fett, 1/4 Pfund Rauchfleisch und 7 Pfund Mehl bei sich hatte. Die Regel hatte 39 Eier, 1 Pfund Butter, 11/2 Pfund Rauchfleisch, 11 Pfund Mehl und $1 \frac{1}{2}$ Laib Brot bei sich. Beide Frauen hatten je drei Rollen Garn, wie es in den Spinnereien verarbeitet wird, als Tauschmittel bei sich. Auf Vorhalt gaben die Beschuldigten an, sie seien am 29.8. früh gegen $6.00 \mathrm{Uhr}$ von Fürth bis nach Mühlhausen/Ofr. gefahren. Von dort seien sie in mehrere Ortschaften in der Nähe von Mühlhausen gegangen und hätten sich die Lebensmittel gekauft bzw. gegen das Garn eingetauscht ... Wie die einzelnen Ortschaften und Bauern hießen, wo sie die Lebensmittel erhielten, wollen sie nicht mehr wissen." ${ }^{230}$

Die größeren und kleineren Geschäfte auf nachbarschaftlicher, verwandt- und bekanntschaftlicher Basis folgten anderen Gesetzen als die großen Schiebereien. Da man einander seit Jahren kannte, mußte man wohl oder übel Rücksicht nehmen, um Stammkunden nicht zu verprellen oder nicht denunziert zu werden. Das dämpfte die

${ }^{229}$ Mündliche Mitteilung von Willibald Kornburger vom 13. Juni 1983.

${ }^{230}$ Landpolizei-Posten Mühlhausen an Bezirksinspektion der Landpolizei in Höchstadt a.d. Aisch, 29. August 1946, in: Stadtarchiv Fürth, Bestand Ernährungsamt, Nr. 4 c. 
Profitgier mancher Geschäftsleute, außerdem wirkten diese Rücksichtnahmen und Beziehungen wohl auch dem Gefühl entgegen, dem zunehmend schlechter funktionierenden Bewirtschaftungs- und Rationierungssystem restlos ausgeliefert $\mathrm{zu}$ sein. Und schließlich: Nicht einer allein verstieß gegen geltende Gesetze, sondern die Bewohner ganzer Straßen und Häuserblocks. Die Häufigkeit, ja bald Alltäglichkeit der kollektiven Vergehen erleichterte es vielen ehrlichen Menschen, die sich viel darauf zu gute hielten, noch nie mit dem Gesetz in Konflikt gekommen zu sein, illegale Geschäfte zu machen und aufkommendes Unrechtsbewußtsein schnell zu unterdrücken.

Dies umso eher, als die „Autoritäten“ in den Dörfern und Städten bei den kleinen Schwarzmarktgeschäften und Schiebereien beide Augen zudrückten. Der Bürgermeister von Seukendorf beispielsweise, der im April 1947 erfahren hatte, daß ein einheimischer Bauer von einem durchreisenden Schwarzhändler übers Ohr gehauen worden war, reagierte darauf nicht, wie zu erwarten gewesen wäre, mit einer allgemeinen Warnung vor Schwarzmarktgeschäften, sondern mit folgendem Aushang in der Gemeindekanzlei: „Bei der allgemeinen Knappheit an Lebensmitteln ist es verständlich, daß der Bauer von dem Angebot verlockt wurde und Schinken, Butter, Eier, Mehl, Geflügel, Schnaps hergab. Unverständlich ist es jedoch, daß er auf die schönen Versprechungen hereinfiel und auf das bloße Versprechen, die Ware in acht Tagen zu liefern, die guten Sachen hergab, ohne sich auch nur einen Ausweis zeigen zu lassen." 231

Viel Verständnis für die läßlichen „Sünden“ zeigte auch die Kirche. Die Ansbacher und Fürther Pfarrer dachten wohl ganz ähnlich wie der Kölner Erzbischof Joseph Kardinal Frings, der in seiner Silvesterpredigt 1946 gesagt hatte: „Wir leben in Zeiten, $\mathrm{da}$ in der Not auch der einzelne das wird nehmen dürfen, was er zur Erhaltung seines Lebens und seiner Gesundheit notwendig hat, wenn er es auf andere Weise, durch seine Arbeit oder durch Bitten nicht erlangen kann." ${ }^{\text {"232 }}$ So offen konnten Polizei und Justiz ihr Verständnis nicht bekunden. Sie taten es eher indirekt, in dem sie das breite Spektrum von scharfen Strafen, das ihnen beispielsweise mit dem Kontrollratsgesetz Nr. 50 vom 7. April 1947 zur Verfügung stand („Bestrafung der Entwendung und des rechtswidrigen Gebrauchs von zwangsbewirtschafteten Nahrungsmitteln und Gütern und von Urkunden, die sich auf Zwangsbewirtschaftung beziehen") nicht ausschöpften. Auch die örtlichen Parteien meinten es mit ihren Forderungen nach Sofortmaßnahmen gegen Schieber und Schwarzhändler ${ }^{233}$ nicht ganz ernst; ausgenommen vielleicht einige Sozialdemokraten, die sich selbst um keinen Preis der dunklen Schwarzmarktwege bedient hätten. Sie erblickten in den fortgesetzten Verstößen gegen geltendes Recht nicht nur eine Antwort auf die „gegenwärtige Notzeit“, sondern vor allem ein Indiz dafür, „daß die Moral des deutschen Volkes durch die lange Dauer des Krieges, wie bei allen derartigen Ereignissen, zwangsläufig zu tiefst gesunken ist und zu einem totalen Absturz führte durch die bewußte und planmäßige Erziehung desselben zur Unmoral in den letzten 12 Jahren nationalsozialistischer Herrschaft ${ }^{\text {“234 }}$.

So gut die Kleinformen des Schwarzen Marktes in den Dörfern und Städten auch funktionierten, im Laufe der Zeit wurde der Kundenkreis in der Ansbacher Uzstraße

${ }^{231}$ Nürnberger Nachrichten, Fürther Ausgabe, vom 3. April 1947.

${ }^{232}$ Silvesterpredigt des Kölner Kardinals, Köln 1947, S. $11 \mathrm{f}$.

${ }^{233}$ Vgl. Nürnberger Nachrichten, Fürther Ausgabe, vom 3. Mai 1947.

${ }^{234}$ OB Ansbach an MilReg, Stimmungsbericht vom 18. September 1946, in: Stadtverwaltung Ansbach, EAP $022-95 / 19$. 
und am Fürther Finkenschlag immer kleiner. Ein großer Teil der Bevölkerung hatte einfach nichts mehr anzubieten. Die Ersparnisse waren aufgebraucht, die Wertsachen schon längst zu Lebensmitteln „gemacht" worden und die regelmäßigen Einkünfte zu gering, um auf dem Schwarzen Markt mitbieten zu können. Die 111 Beschäftigten bei Grundig beispielsweise, die noch zu den Besserverdienenden zählten, fanden im Dezember 1946 im Durchschnitt 158,79 Reichsmark in der Lohntüte vor, ein ungelernter Arbeiter meist keine 100 Reichsmark ${ }^{235}$; dafür hätte er auf dem Fürther Finkenschlag gerade $200 \mathrm{~g}$ Nescafé kaufen können. Viele waren nun einzig auf die offiziellen Zuteilungen angewiesen, die im Februar 1948 für einen Normalverbraucher täglich etwa 1.300 Kalorien betrugen, darunter eine kaum nennenswerte Menge Fett von nicht einmal drei Kalorien und etwa 44 Kalorien Fleisch - „Hungerrationen“, nannte es Ansbachs Oberbürgermeister, „zum Leben zu wenig und zum Sterben zu viel“236. „Es fehlt an allem“, bemerkte der Fürther Landrat, „so daß die Verelendung der Bevölkerung weiter fortschreitet.“237

Im Frühjahr 1948 mußten die Lebensmittelzuteilungen erneut gekürzt werden. Viele Hausfrauen rätselten, wie sie ihre Familie über die Runden bringen sollten. Ärzte zögerten Operationen hinaus, weil sich ihre Patienten in beklagenswert schlechtem körperlichen Zustand befanden. Arbeitende Menschen brachen aus Entkräftung an den Arbeitsplätzen zusammen. „In den letzten Tagen“, schrieb Ansbachs Oberbürgermeister am 26. Mai an die Militärregierung, ,ist eine erhebliche Beunruhigung vor allen Dingen unter der arbeitenden Bevölkerung zu bemerken, die dadurch hervorgerufen worden ist, daß die Schwerarbeiterkarten mit Fleisch nicht mehr beliefert werden. Durch diese Maßnahme ist selbst der schwerarbeitende Mensch auf die minimale Ration von $100 \mathrm{~g}$ Fleisch in vier Wochen angewiesen.“238

Es herrschte eine diffuse Aufgeregtheit und Gereiztheit, die sich zuweilen spontan entlud. Schon im Januar 1948 hatten in allen größeren Städten Warnstreiks stattgefunden, die von den Gewerkschaften nicht unter Kontrolle gehalten werden konnten. Die „Ernährungskrise ... wirft alle guten Ratschläge über den Haufen“, so charakterisierte ein kommunistischer Gewerkschaftsfunktionär aus Nürnberg im Februar 1948 die Lage in Bayern. „Sie fragt nicht nach Programm und Partei, sondern geht ihren eigenen Weg, wenn eine Führung fehlt, wie bei uns, und das kam auch in dieser Hungeraktion zum Ausdruck. Die beiden Arbeiterparteien waren unbeteiligt bei den Bewegungen, die seit November 1947 in den verschiedenen Städten einsetzten. Die Bundesleitung tat alles, um die einzelnen Streiks in den Betrieben zu unterbinden. Vergebens! Die Betriebsräte waren außerstande, die Belegschaften zurückzuhalten ..."239

In den folgenden Wochen flackerten überall Tumulte auf. Da und dort brachen Hungerrevolten aus, die sich gegen alle richteten, die an der lausigen Lebensmittelversorgung Schuld haben konnten. Die Landräte und Oberbürgermeister Ober- und Mittelfrankens, die im Mai 1948 im oberfränkischen Kronach zu ihrer monatlichen Be-

${ }^{235} \mathrm{Vgl}$. Fein, Sieben Tage Grundig, S. 178.

${ }^{236} \mathrm{OB}$ Ansbach an MilReg, Stimmungsbericht vom 21. Januar 1948, in: Stadtverwaltung Anșbach, EAP 022-95/19 und Schreyer, Bayem - ein Industriestaat, S. 167.

${ }^{237}$ Monatsbericht vom Februar 1948, in: NA, RG 260, 9/97-1/1.

${ }^{238}$ In: Stadtverwaltung Ansbach, EAP 022-95/19.

${ }^{239}$ Zit. nach Grebing, Lehrstücke in Solidarität, S. 209. 
sprechung zusammenkamen, trafen nach ihren Beratungen auf protestierende Frauen und Kinder. „Die Demonstranten“, berichtete die Fränkische Landeszeitung, „nahmen eine bedrohliche Haltung gegenüber den anwesenden Behördenvertretern ein und verlangten die Verteilung von Lebensmitteln, da sie und ihre Kinder seit 2 Tagen nichts mehr zu essen hätten." 240 Beamte, die die aufgebrachte Menge zu besänftigen suchten, ernteten nur Spott und beißende Ablehnung.

In Ansbach riefen wenig später zahlreiche Mütter zu einer Demonstration auf. Ehefrauen von Beamten und Angestellten, Witwen von kleinen Gewerbetreibenden und Händlern zogen zusammen mit Müttern aus dem proletarischen Milieu durch die Straßen der alten Residenzstadt. Es war die zweite Demonstration innerhalb von drei Jahren; im April 1945 hatten sich die Ansbacher Frauen ebenfalls zu einer solchen Aktion entschlossen, als ihre Stadt gefährdet schien. Auf Flugblättern hieß es jetzt: „Ansbacher Mütter mit Eueren Kindern!

Erscheint alle am Freitag, den 28.5.1948 um 18 Uhr zu einer

Demonstration gegen den Hunger unserer Kinder

und die Korruption unserer deutschen Behörden

vor dem Ratbaus!

Wir fragen unseren Herrn Oberbürgermeister und den Regierungspräsidenten, was sie zu tun beabsichtigen,

um uns und unsere Kinder vor dem Verhungern zu schützen.

$\operatorname{Schlu} \beta$ mit allen leeren Versprechungen, denn davon werden wir nicht satt!!

Ansbacher Mütter, kommt ebenso geschlossen, wie damals im April 45

als wir vor dem Kreisleiter um den Schutz der Stadt demonstrierten.

Bringt Euere bungernden Kinder mit.!

Ansbacher Mütter, die zum Äußersten gezwungen sind!«241

Der Volkszorn, der den Landräten und Oberbürgermeistern nicht nur in Ansbach und Kronach entgegenschlug, wurde weiter angestachelt. In jeder Zeitung war zu lesen, daß die Wirtschaft der Bizone seit Frühjahr 1947 einen merklichen Aufschwung erlebte: „Langsame Frühjahrsbelebung“, hieß es in der Süddeutschen Zeitung vom 26. April; in der Ausgabe vom 17. Mai stand: „Textilprämie fördert Spinnereiproduktion“ und am 9. August meldete dieselbe Zeitung: „Steigender bayerischer Export“. Die Verbraucher bemerkten davon aber wenig, weil ein beträchtlicher Teil der produzierten Güter in dunkle Kanäle floß bzw. gehortet wurde. Wahrscheinlich vollzog sich die „Hälfte des gewerblichen Umsatzes durch Tausch und Schwarzmarkt außerhalb der Bewirtschaftung“242. Das zwang den Wirtschaftsrat der Bizone ein eigenes „Enthortungsgesetz“ zu verabschieden, das die haarsträubenden Mißbräuche unterbinden sollte. War das nicht Beweis genug, daß wieder die „Kleinen“ die Dummen waren, während die „Großen“, koste es, was es wolle, auf ansehnliche Profite nach der Währungsreform spekulierten?

Die Verantwortlichen in der Verwaltung für Wirtschaft, die das Enthortungsgesetz am liebsten verhindert hätten, waren über die Warenhortung nicht unglücklich. Ihr Konzept einer Währungsreform ließ sich nur verwirklichen, wenn nach dem Tag X

\footnotetext{
${ }^{240}$ Fränkische Landeszeitung vom 12. Mai 1948.

241 Flugblatt, in: NA, RG 260, 9/124-3/18.

${ }^{242}$ Eschenburg, Jahre der Besatzung, S. 267.
} 
eine große Menge Güter auf den Markt geworfen werden konnte, um die erwartete erste Kaufwelle aufzufangen. Ludwig Erhard brachte das in seiner Rede vor dem Plenum des Wirtschaftsrates vom 21. April 1948 deutlich zum Ausdruck, als er seine Bedenken „gegen eine über das volkswirtschaftlich berechtigte Maß hinausreichende Entleerung der Läger und gegen die Preisgabe unserer letzten volkswirtschaftlichen Güterreserve“ anmeldete ${ }^{243}$.

Im Frühjahr 1948 mehrten sich die Zeiten, daß die immer wieder diskutierte Geldumstellung nur noch eine Frage von Tagen, höchstens weniger Wochen war. Nachdem die Verhandlungen im Alliierten Kontrollrat über eine gesamtdeutsche Währungsreform lange verschleppt worden waren, gaben die Regierungen Frankreichs, Großbritanniens und der Vereinigten Staaten Ende Mai 1948 bekannt, daß sie übereingekommen seien, in ihren Besatzungszonen eine Währungsreform durchzuführen $^{244}$. Tagtäglich wurde nun in der Presse wie an den Stammtischen über die bevorstehenden Ereignisse debattiert. Ein humorvoller Redakteur der Nürnberger Nachrichten reimte Anfang Juni:

„Was bewegt uns heut enorm?

Tag und Nacht?! - Währungsreform!

Kommt sie heute, kommt sie morgen?

Jeder macht sich seine Sorgen.

Manchem Mann ist davor bange,

Manchem währt es viel zu lange.“245

Die evangelische Kirche bereitete sich ebenfalls auf den Währungsschnitt vor. Wenn der Termin am Wochenanfang bekanntgegeben werden sollte, wollte man noch unter der Woche einen Sonder-Gottesdienst abhalten, um die „öffentliche und allgemeine Not schnellstens in das Licht des Wortes Gottes“ rücken zu können. Es sei damit zu rechnen, meinte der Nürnberger Kreisdekan, „daß der Eintritt des Ereignisses ... eine starke Schockwirkung ausübt ... Viel Selbstmordversuchung!“. Gleichwohl legte die Kirchenleitung den Pfarrern nahe, sich in den Predigten vor ungerechter „Schwarzweiß-Malerei“ zu hüten: „Keine billige Entrüstung über die ,Zustände`! Die Schuld und Mitschuld an ihnen nicht abschieben auf einzelne Sündenböcke! Nicht schelten über das Dritte Reich, die Amerikaner, die Regierung, die Parteien - auch nicht in pharisäischer Selbstgerechtigkeit über Schieber und Schwarzhändler!“ Statt eines klaren Wortes, daß die Geldentwertung nicht von der Besatzungsmacht und von den Parteien, sondern einzig von den Nationalsozialisten verursacht worden war, empfahl das Kreisdekanat, auf die „,verborgene Hand' hinzuweisen, die im Hintergrund alles Geschehens, gerade auch des unbegreiflichen und bedrückenden, waltet und auch heute die Gestalten auf der Bühne der Weltpolitik und der Weltwirtschaft wie Marionetten an den Fingern hat“246.

In den Morgenstunden des 16. Juni 1948 fuhr ein schwerer Lastwagen an der Fürther Zweigstelle der Reichsbank in der Moststraße vor ${ }^{247}$. Einige Passanten beobachte-

\footnotetext{
${ }^{243}$ Erhard in der 14. Vollversammlung des Wirtschaftsrats des VWG, in: Wörtliche Berichte und Drucksachen des Wirtschaftsrates des Vereinigten Wirtschaftsgebietes 1947-1949, München/Wien 1977, S. 440.

${ }^{244} \mathrm{Vgl}$. Süddeutsche Zeitung vom 25. Mai 1948.

${ }^{245}$ Nürnberger Nachrichten, Fürther Ausgabe, vom 9. Juni 1948.

${ }^{246}$ Zur Predigt am Sonntag nach Bekanntgabe der Währungsreform, in: LKA Nürnberg, Bestand: Kreisdekan Nürnberg, 14-522, Bd. 6.

${ }^{247}$ Vgl. Nürnberger Nachrichten, Fürther Ausgabe, vom 19. Juni 1948.
} 
ten diesen Vorgang und wußten sofort: Das neue Geld ist da, in den nächsten Tagen wird die Währung umgestellt. Diese erregende Nachricht breitete sich wie ein Lauffeuer in der Stadt aus. In den Straßen bildeten sich kleine Gruppen von diskutierenden Menschen. Vor den großen Geschäften in der Innenstadt staute sich eine lärmende Menschenmenge. Die Gespräche kreisten um eine Frage: Was sollte man mit dem alten Geld tun? Einige meinten, auf der Sparkasse liege das Geld am sichersten. Die meisten aber rieten: Kaufen und nochmals kaufen, damit man nicht auf der alten Reichsmark sitzenblieb ${ }^{248}$

Die Läden wurden förmlich belagert, es gab eine „Hochsaison der Angsteinkäufe“. „In letzter Minute tätigte jeder noch irgendwelche ,Transaktionen““, so beschrieb die Fränkische Landeszeitung die Ereignisse in Ansbach. „Friseure hatten von morgens bis abends Hochbetrieb.“ Besonders stark waren „Parfüm, Kunstgewerbe, Brot, Zahnpasta, Blumentöpfe, Vaseline und alle Arten von Talmi-Schmuck gefragt“. Jeder wollte seine Reichsmark „krisenfest“ anlegen und so kam es zuweilen auch zu grotesken Erscheinungen: „70jährige kauften Baby-Sauger ... und die Oma von nebenan erwarb sieben Lippenstifte ... Der Schlachtruf der krisenschwachen Zeitgenossen ertönte in jeder Gasse: Kauft, Leute, wer weiß, was morgen kommt! “249 Vor den Postämtern und Banken bildeten sich lange Schlangen, selbst kleinste Schulden und Rechnungen wollte man noch schnell begleichen. Ein Reporter der Fränkischen Landeszeitung beobachtete vor dem Schalter der Ansbacher Stadtsparkasse einen Mann, der behauptete, noch etwas bezahlen zu müssen: „Der Beamte wühlte in allen Büchern herum, in großen und kleinen - umsonst - keine unbeglichene Rechnung ließ sich finden. Der Mann vor dem Schalter schüttelte enttäuscht den Kopf. Ein anderer kam und wollte eine Rechnung zum zweiten Male erledigen ... Ist längst erledigt! triumphierte der Mann hinter dem Schalter."250

Den Handwerkern, Händlern und Geschäftsleuten kam dieser Ansturm sehr ungelegen. Sie wollten ihre Ware heil über den Tag X retten und erst danach wieder für gutes Geld verkaufen. Verärgerte Kunden, die auf längst überfällige Lieferungen warteten, sprachen von Produzentenstreik. „Ladentüren waren plötzlich verrammelt“, berichtete die Fränkische Landeszeitung ${ }^{251}$. In den Schaufenstern hingen Schilder wie „Ausverkauft“, „Inventur“ und „Betriebsferien“. Die Käufer fühlten sich betrogen und wollten sich die besonders geschäftstüchtigen Händler merken, um sie später zu boykottieren.

\section{Die Währungsreform}

Wer am Abend des 18. Juni 1948 das Radiogerät laufen hatte, erfuhr den Termin und die Einzelheiten der Währungsreform. Die gemeinsame Proklamation der drei Westmächte lautete: „Das erste Gesetz zur Neuordnung des deutschen Geldwesens ist von den Militärregierungen Großbritanniens, der Vereinigten Staaten und Frankreichs verkündet worden und tritt am 20. Juni in Kraft. Die bisher gültige deutsche Währung

248 Ebenda.

249 Fränkische Landeszeitung vom 19. Juni 1948.

250 Fränkische Landeszeitung vom 23. Juni 1948.

${ }^{251}$ Ebenda. 
wird durch dieses Gesetz aus dem Verkehr gezogen. Das neue Geld heißt, Deutsche

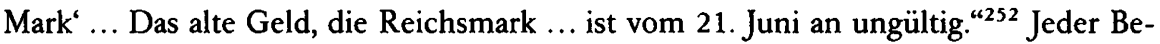
wohner der Westzonen erhielt am ersten großen Zahltag, am Sonntag den 20. Juni, einen Kopfbetrag von 40,- DM im Umtausch gegen 40,- RM Altgeld. Alle Gewerbetreibenden und Firmeninhaber bekamen einen ersten Geschäftsbetrag von $60,-\mathrm{DM}$ je beschäftigtem Arbeitnehmer. Zugleich gaben die Lebensmittelkartenstellen Formulare aus, „auf denen das übrige Altgeld sowie die Bank- und Sparguthaben angemeldet werden mußten. Alles Altgeld, das nicht bis zum Freitag, dem 26. Juni, abgeliefert und deklariert war, verfiel."

In diesen Tagen vor und zwischen den „Gezeiten der Währungsumstellung“253 fielen zwei weitere Entscheidungen, auf die die deutsche Öffentlichkeit schon lange gewartet hatte und die man als Nutzanwendung aus der Währungsreform ${ }^{254}$ verstand. Nach einer erregten Nachtsitzung verabschiedete der Wirtschaftsrat in seiner 13. Vollversammlung am 18. Juni 1948 gegen die Stimmen von Sozialdemokraten und Kommunisten das „Gesetz über die wirtschaftspolitischen Leitsätze nach der Währungsreform", das den Abbau der staatlichen Zwangs- und Befehlswirtschaft sowie die Rückkehr zur wettbewerbsorientierten Marktwirtschaft einleitete. Der Wirtschaftsrat sprach sich dabei grundsätzlich für die Aufhebung der Bewirtschaftung und des Preisstops aus. Lediglich die Hauptnahrungsmittel und die wichtigsten Rohstoffe sollten auch weiterhin bewirtschaftet werden und dem Preisstop unterliegen. Drei Tage später dekretierten die Militärregierungen der Westzonen das „Gesetz zur vorläufigen Neuordnung der Steuern“, das eine drastische Senkung der Steuersätze der Kontrollratsgesetze aus dem Jahre 1946 mit sich brachte, die schon von mittleren Einkommen die Hälfte und mehr abgeschöpft hatten.

Nach der Radiomeldung vom 18. Juni konnte niemand ahnen, wie ihn der Währungseinschnitt treffen würde. Für viele kam das böse Erwachen am 26. Juni 1948 mit der Verkündung des 3. Gesetzes zur Neuordnung des Geldwesens, in dessen Präambel es hieß: „Im allgemeinen wird das Altgeld im Verhältnis von zehn zu eins gegen neue Deutsche Mark eingetauscht. Das heißt, je 10 Mark Altgeld werden auf eine Deutsche Mark zusammengelegt. Die eine Hälfte dieses Neugeldes kommt auf ein sogenanntes Freikonto, die andere wird auf einem sogenannten Festkonto gutgeschrieben, das heißt, sie wird blockiert.“ Ausgenommen davon waren alle regelmäßig wiederkehrenden Leistungen wie etwa Löhne, Gehälter und Mieten ${ }^{255}$.

Dieses Umstellungsverhältnis ließ das Eigentum an Grund und Boden, an Produktionsmitteln und Waren unberührt ${ }^{256}$, während es zugleich massenhaft privaten Wohlstand vernichtete. Am härtesten traf es die Sparer; ehemalige Selbständige wie Rechtsanwälte und Apotheker, Freiberufler wie Künstler und Gelehrte, die es nach

\footnotetext{
${ }^{252}$ Zit. nach Hans Roeper, Die D-Mark. Vom Besatzungskind zum Weltstar, Frankfurt/Main 1978, S. 20.

${ }^{253}$ Ebenda, S. 23.

${ }^{254}$ Vgl. Fränkische Landeszeitung vom 19. Juni 1948.

253 Uber das blockierte Geld sollte innerhalb von 90 Tagen entschieden werden. Das sogenannte Festkontengesetz vom 7. Oktober 1948 bestimmte, daß die blockierten Gelder nicht in vollem Umfang freigegeben wurden, sondern daß davon nochmals 70 Prozent gestrichen wurden. Alle Bank- und Sparguthaben wurden also letztlich nicht 10:1, sondern 10:0,65 umgestellt. Wer 100 RM auf einem Konto hatte, erhielt dafür noch ganze 6,50 DM. Vgl. Roeper, D-Mark, S. $24 \mathrm{f}$.

${ }^{256}$ Vgl. Wolfgang Benz, Wirtschaftspolitik zwischen Demontage und Währungsreform, in: Westdeutschlands Weg zur Bundesrepublik, S.83.
} 
der Erfahrung der ersten Inflation von 1922/23 nochmals gewagt hatten, für ihre Altersversorgung oder zur Sicherung der Familie Geld zurückzulegen, mußten nun erleben, wie mit einem erbarmungslosen Federstrich ihre ehrlich ersparten Notgroschen ihren Wert verloren. Das Gefühl, betrogen worden zu sein, breitete sich aus. „Es wird in verschiedenen Berichten hervorgehoben“, so hieß es im Monatsbericht des Regierungspräsidenten für Ober- und Mittelfranken an die bayerische Staatsregierung in München vom 9. Juli 1948, daß dieses Gesetz ,innerhalb der Bevölkerung mit großer Enttäuschung aufgenommen“ wurde. „Insbesondere herrscht große Erbitterung darüber“, so fuhr der Regierungspräsident fort, „daß jene Bevölkerungskreise, die bislang von ihren sauer und ehrlich verdienten Ersparnissen gelebt hatten, nun vor dem Nichts stünden ... Man habe für kleine Sparguthaben eine Sonderregelung gegenüber dem Unternehmertum und jenen Geschäftsleuten, die im Hinblick auf die Warenhortungen viel besser abschneiden würden, erwartet ... Es ginge nicht an, daß eine Unzahl von Menschen durch die Währungsreform völlig verarme, während andere als Nutznießer aus ihr hervorgingen.“257

Am 21. Juni 1948, dem ersten Tag nach der Währungsreform, war Sommeranfang. Es regnete in Strömen, dunkle, graue Wolken zogen über den Himmel. Das unfreundlich düstere Wetter lud nicht gerade zum Verweilen vor den Läden und Geschäften ein, die sich völlig verändert präsentierten. „Auf dem Markt und in den Läden werden erhebliche Mengen von Gemüse und Salat angeboten“, berichtete ein Reporter der Nürnberger Nachrichten, „Gurken, um die man sich noch vor einer Woche gerauft hätte, warten seelenruhig im Korb auf Käufer. Sogar Kirschen tauchen da und dort auf. Die Textilschaufenster haben plötzlich ein reichhaltiges Gesicht bekommen." 258 Von heute auf morgen hörten die Kompensations- und Tauschgeschäfte auf. Das Geld übernahm wieder seine gewohnte Funktion, der Schwarze Markt verschwand fast ganz. Während im April oder Mai noch das Gespenst einer Ernährungskatastrophe umgegangen war, hieß es nun: „Schlagartig mit dem Inkrafttreten des Währungsgesetzes begann am 21.6. die Anfuhr von großen Mengen Qualitätserzeugnissen. Es gab Kohlrabi, Karotten, Frühwirsing, Gurken, Rettiche, Zwiebeln, Blumenkohl und neue Kartoffeln. “259 Bereits Ende Juni kündigte die Fränkische Landeszeitung eine „Lebensmittelschwemme“ an $^{260}$, und Mitte Juli stand in der Zeitung: „Die 1800-Grenze überschritten. Zum erstenmal seit Kriegsende sind jetzt in der 116. Periode die lang ersehnten und oft versprochenen 1800 täglichen Kalorien erreicht.“261 Außerdem schienen die Ladenbesitzer und Gewerbetreibenden nach demTag X die Höflichkeit wiederentdeckt zu haben. So mancher Geschäftsmann, der vorher durch sein aufgeblasenes Benehmen aufgefallen war, hielt sich jetzt wieder an das alte Motto: „Der Kunde ist König. “262

\footnotetext{
${ }^{237}$ In: BayHStA, Reg von Ober- und Mittelfranken, Berichterstattung 1947, 1948. Vgl. auch Landpolizei Oberund Mittelfranken, Bezirksinspektion Ansbach an Landpolizei Bayern, 2. Juli 1948, in dem es u. a. hieß: Der arbeitenden Bevölkerung "wird dadurch der letzte Notpfennig, den sie sich durch jahrelange mühsame Arbeit erspart hat, genommen “. LRA Ansbach, EAP 04-040.

${ }^{258}$ Nürnberger Nachrichten, Fürther Ausgabe, vom 26. Juni 1948.

${ }^{259} \mathrm{OB}$ Fürth an RegPrās, 2. Juli 1948, in: Stadtverwaltung Fürth, EAP 4.

${ }^{260}$ Fränkische Landeszeitung vom 26. Juni 1948.

${ }^{261}$ Nürnberger Nachrichten, Fürther Ausgabe, vom 17. Juli 1948

${ }^{262}$ Fränkische Landeszeitung vom 23. Juni 1948.
} 
Angesichts der vollen Schaufenster setzte sich die vor dem 20. Juni beobachtete Kaufwut fort. Auf fast geheimnisvolle Weise tauchten plötzlich Waren in großen Mengen auf, die seit Beginn des Krieges nur noch selten oder überhaupt nicht mehr angeboten worden waren. Also kaufte man. In den Textilhäusern, Lebensmittel- und Gebrauchtwarengeschäften klingelten die Kassen wie lange nicht mehr. „Schuhe, Textilien, Haushaltswaren einschließlich Glas und Porzellan", so der Direktor des Kaufhauses „Weißer Turm“ in Fürth, aber auch „unnötige Sachen“ wie Handtaschen, Sekt und Pralinen waren im $\mathrm{Nu}$ ausverkauft ${ }^{263}$. Der Reiz dieser lange entbehrten Artikel war groß und oft auch trotz fast leerer Brieftaschen nicht zu unterdrücken. Wer wußte denn, ob das neue Geld nicht bald erneut seinen Wert verlieren würde, wie es Pessimisten schon prophezeiten. Verkäuferinnen berichteten, „daß Kunden schwanken, ob sie Teller kaufen sollen oder Blumenvasen und sich dann für die letzteren entscheiden; oder andere interessieren sich für einen Sessel um 60,- DM und eine gleichteure Lederhandtasche und wählen diese mit der Begründung, daß der alte Stuhl zu Hause seinen Zweck noch erfülle, aber die Tasche so gut zum neuen Kleid passe. Dies sind keine Einzelfälle, sondern typische Beispiele für das Kaufgebaren vieler." ${ }^{264}$

Während sich die Lebensmittel- und Textilbranche über mangelnde Nachfrage nicht beklagen konnte, brach in anderen Branchen nach der Währungsreform das Geschäft fast zusammen. Die 40,- DM waren schnell ausgegeben. Nachdem sich der Ansturm der ersten Tage gelegt hatte, spürte „man bei jeder Gelegenheit“, so die Militärregierung, , wie knapp das Geld nun geworden ist ... Der ungewöhnlich starke Andrang der ersten Tage nach der Währungsreform hat inzwischen erheblich nachgelassen. Während man in den ersten Tagen noch ... ohne Bedenken ein Kaffeeservice für 55,- DM kaufte, überlegt es sich heute mancher, ob er eine einzelne Tasse für 55 Pfennige erstehen soll, wenn sie in einem anderen Schaufenster für 53 Pfennige angeboten wird. Man achtet wieder genau auf den Preis und ist sehr wählerisch. “265

Man mußte wieder mit dem Pfennig rechnen, was vorher leicht zu haben gewesen war, war jetzt unerschwinglich. Schwere Einbußen hatten beispielsweise die Besitzer von Tanz- und Kaffeehäusern zu beklagen. Der Chef des Cafés „Fürther Kleeblatt“ in der Hirschenstraße - bis zur Währungsreform als der Treffpunkt der Fürther Gesellschaft eine wahre Goldgrube - hatte geglaubt, es werde nach dem Tag X nicht so schlimm kommen, weil er hoffte, „daß die Ausländer, die bei uns verkehren, nach wie vor Geld haben und verbrauchen werden“. Schon eine Woche nach der Währungsreform mußte er sich aber eingestehen, daß seine Hoffnungen getrogen hatten. „Er sieht nur noch schwarz in schwarz und verspricht sich nichts Gutes für die nächste Zeit" ${ }^{266}$, notierte die Militärregierung bei einer Umfrage. Auch der Non-Stop-Vergnügungsschau in Fürth half es wenig, daß sie ihre Preise deutlich gesenkt hatte und durch originelle Reklamekarawanen in den Straßen auf sich aufmerksam machte. „Die ,tolle Lola“ biete sich gar schon für 50 Pfennig an“, so hieß es in der Zeitung ${ }^{267}$, und war dennoch nicht mehr so begehrt wie früher.

${ }^{263}$ ID -Research Branch - Munich Brief No. 132 -Auswirkungen der Währungsreform, 4. Bericht vom 20. Juli 1948, in: NA, RG 260, 10/70-1/15.

264 Ebenda.

${ }^{265}$ Ebenda.

266 Ebenda.

${ }^{267}$ Nürnberger Nachrichten, Fürther Ausgabe, vom 26. Juni 1948. 
Den Theatern ging es nicht besser. In vielen Privattheatern und Kleinkunstbühnen Münchens, Frankfurts und Stuttgarts, die nach Kriegsende mit aggressiven und frechamüsanten Stücken Furore gemacht hatten und Abend für Abend ausverkauft gewesen waren, blieben jetzt die Zuschauerräume leer. Sogar das Interesse an ausländischem Theater, das zeitweise kaum zu stillen gewesen war, erlahmte; ungebrochen war lediglich der Erfolg von Zuckmayers „Des Teufels General“ und von Wolfgang Borcherts „Draußen vor der Tür “268. Der Jahresbericht des Kulturreferats der Stadt Ansbach vom 24. Dezember 1948 weist auf diese auch in der Provinz herrschenden Probleme hin: „Auch auf dem Kultursektor hat die Wäbrungsreform einschneidende Veränderungen hervorgerufen und das Jahr 1948 in zwei ungleichartige Hälften geteilt. Das erste Halbjahr stand im Zeichen einer Überfülle kultureller Darbietungen, wobei die Mittelmäßigkeit und die anspruchslose Unterhaltung einen breiten Raum einnahmen. Der Geldüberhang verschleierte diese Scheinblüte und verschaffte auch den zahlreichen zweitrangigen Unternehmungen recht ergiebige Einnahmequellen. Der Andrang der Angebote war groß, vielfach kam es zu Terminüberschneidungen und zu unerquicklichen Auseinandersetzungen zwischen den einzelnen Unternehmern unter sich und dem Publikum ... Die Währungsreform hat dann die ungesunde inflationsartig angewachsene Fülle mit einem Schlag beendet. Im Zeichen der Geldknappheit ist das Publikum zur Zeit ein Faktor, der regulierend und auslesend im Kulturleben auftritt. Seitdem hat sich in der Praxis ein gewisser echter Bedarf kultureller Veranstaltungen auf verschiedenen Gebieten herausgebildet, denen man das Prädikat ,wenig, aber gut' zugestehen darf. Mittelmäßige Unternehmungen haben im Augenblick kaum Aussicht auf Erfolg. “269

Selbst bei den Zeitungs-, Zeitschriften- und Buchhändlern, die nach 1945, als jeder wissen wollte, was in der Welt vor sich ging, Umsatzrekorde verzeichnet hatten, ließ das Geschäft merklich nach. Zeitschriften waren fast nicht mehr gefragt. Eine Ausnahme bildete der „Sportkurier“, der im fußballbegeisterten Fürth sogar ein leichtes Plus verzeichnete. Tageszeitungen verkauften sich dagegen noch relativ gut, die Auflage der Fränkischen Landeszeitung blieb nach der Währungsreform fast stabil. „Unsere Auflage“, so erklärte man sich dieses Phänomen, „hat vor der Geldumstellung nicht annähernd ausgereicht, um der starken Nachfrage zu genügen. Wir waren nicht in der Lage, Zeitungen im Straßenverkauf anzubieten. So stand also eine gewisse ,Reservearmee' von Interessenten bereit, die bis jetzt keine Zeitung erhalten konnten. Sie ist sofort in die Lücke gesprungen", die entstanden war, da vor allem finanzschwache Rentner und Flüchtlinge als Abonnenten ausschieden ${ }^{270}$.

In den Chefetagen der Industriebetriebe dagegen hellten sich die Mienen bald auf. Im monatlichen Bulletin des bayerischen Arbeitsministeriums vom September 1948 hieß es: „Die Industrieproduktion hat ... auch in Bayern zugenommen, und zwar im Juli um 12 Prozent und im August um weitere 10 Prozent. Gemessen an der Produktion des Jahres 1936 lag der Index der bayerischen Industrieproduktion im August bei 72 v. H. Für September kann mit einer weiteren Erhöhung gerechnet werden. “271 Aus

\footnotetext{
${ }^{268}$ Vgl. dazu Henning Rischbieter, Theater, in: Benz, Bundesrepublik Deutschland, Bd. 3, S. 78.

${ }^{269}$ Stadtverwaltung Ansbach, EAP 022-95/20.

${ }^{270}$ Fränkische Landeszeitung vom 21. Juli 1948.

${ }^{271}$ Bayerisches Staatsministerium für Arbeit und soziale Fürsorge, Monatsbericht über „Arbeit und Wirtschaft in Bayern im September 1948“, in: BayHStA, Berichte des Landesarbeitsamtes, Bayern 1948. Zur Problematisierung der zeitgenössischen Daten vgl. Abelshauser, Wirtschaft in Westdeutschland, S. 51 ff.
} 
der britischen Zone trafen ebenfalls Meldungen ein, die zum Optimismus rieten: Die Steinkohlenförderung und die Stahlerzeugung erreichten im Juli 1948 einen neuen Höchststand seit Kriegsende. Bis November 1948 nahm die Förderleistung unter Tage stetig zu („Neuer Förderrekord an der Ruhr“). Auch die Eisen- und Stahlerzeugung stieg weiter an. An der Ruhr schien man endgültig über dem Berg zu sein ${ }^{272}$.

Bei Grundig, der mittlerweile 400 Personen beschäftigte und damit bereits zu einem der wichtigsten Industriebetriebe von Fürth zählte, begann nach dem 20. Juni der eigentliche Aufstieg zum Weltkonzern. Auf den Tag X war Grundig, wie fast jeder Kaufmann oder Industrielle, vorbereitet gewesen. Bereits Ende 1947 hatte er den Verkauf der „Heinzelmänner“ gedrosselt, um zum Zeitpunkt des Währungsschnitts volle Lager zu haben. Auch den „Weltklang“, dessen Produktion im Februar 1948 angelaufen war, brachte Grundig zunächst nicht auf den Markt, obwohl er das in Fachkreisen als mustergültig bezeichnete Gerät schon im März auf der dritten Leipziger Frühjahrsmesse nach dem Krieg der Öffentlichkeit vorgestellt hatte ${ }^{273}$. Am Tag nach der Währungsreform standen „Heinzelmänner“ und rund 1300 „Weltklang“ bei allen Händlern bereit und fanden zum Stückpreis von etwa 220,- DM bzw. 500,- DM reißenden $\mathrm{Absatz}^{274}$. Grundig verfügte so schon kurz nach der Währungsreform über ein beträchtliches DM-Kapital, das er sofort wieder in den Bau von „Weltklang“ investierte. Nach diesem glänzenden Start ging es Schlag auf Schlag. Bis zum Ende des Jahres 1948 wurden über 15000 Exemplare des „Weltklang“ fertiggestellt. Im Februar 1949 feierten Grundig und seine nun schon 800 Beschäftigten ein kleines Jubiläum: Das 100000 ste Radio verließ die Werkshallen in der Kurgartenstraße. Grundig war damit die Nummer 1 unter allen deutschen Rundfunkherstellern, sein Marktanteil betrug etwa 20 Prozent. „In einem geradezu amerikanisch anmutenden Tempo wurden nach Kriegsende die Grundig-Werke aufgebaut", hieß es in einem Pressebericht vom März $1949^{275}$.

Die allgemeine wirtschaftliche Belebung nach der Währungsreform reichte aber nicht aus, um die stürmische Nachfrage zu befriedigen. Die Folge war, daß die Preise höher und höher kletterten - angetrieben nicht zuletzt durch die Spekulationen erfahrener Horter, die ihre Waren nun erneut zurückhielten ${ }^{276}$. Vor allem die Preise für Textilien und Porzellan zogen kräftig an, Steigerungsraten von 100-200 Prozent waren keine Seltenheit ${ }^{277}$. Da die Löhne noch immer dem Lohnstop aus der NS-Zeit unterlagen, fiel die Lohnentwicklung im Wettlauf mit den galoppierenden Preisen immer weiter zurück. „Ernsthafteste Sorge bereitet die seit der Währungsreform eingetretene ungeheure Preissteigerung“, so berichtete Ansbachs Oberbürgermeister Ernst Körner im September 1948 an die Militärregierung. „Wenn hier nicht in absehbarer Zeit eine Änderung in der Form Platz greift, daß entweder eine rapide Senkung der Preise oder entsprechende große Lohnerhöhungen folgen, ist der soziale Friede auf

\footnotetext{
${ }^{272} \mathrm{Vgl}$. Süddeutsche Zeitung vom 10. August, 4. September, 12. Oktober, 19. Oktober, 6. November, 23. und 28. Dezember 1948.

${ }^{273} \mathrm{Vgl}$. Fein, Sieben Tage Grundig, S. 200.

${ }^{274}$ Vgl. ebenda, S. 206 und Anton Zischka, War es ein Wunder?, S. 482.

${ }^{275}$ Zit. nach Fein, Sieben Tage Grundig, S. 214.

${ }^{276}$ Vgl. dazu Frankfurter Hefte, 4 (1949), S. 75.

${ }^{277}$ Vgl. RegPräs an bay. Staatsregierung, 8. September 1948, in: BayHStA, Reg von Ober- und Mittelfranken, Berichterstattung 1947, 1948.
} 
das ernsthafteste bedroht. ${ }^{\text {278 }}$ Die finanziellen Mittel der Arbeiter reichten zwar gerade, um die noch immer bewirtschafteten Grundnahrungsmittel zu bezahlen. Von vielen nichtbewirtschafteten Gütern des täglichen Bedarfs konnten sie aber nur träumen. Hemden, Schuhe und Kindersachen waren für die breite Masse der Bevölkerung unerschwinglich. Eine Reihe lebensnotwendiger Gebrauchsartikel war überhaupt vom Markt verschwunden.

Der Lebensstandard vieler Arbeiter sank jetzt sogar noch tiefer als vor der Währungsreform, weil nun auch noch die Arbeitslosigkeit sprunghaft anstieg. In Nordthein-Westfalen nahm die Zahl der Arbeitslosen vom 20. Juni bis Ende Juli 1948 um 25 Prozent, in Hamburg um 110 Prozent und in Schleswig-Holstein sogar um über 200 Prozent zu. Das Münchener Arbeitsamt hatte kurz vor der Währungsreform rund 14000 Arbeitslose registriert, Ende Juli 1948 waren in der bayerischen Landeshauptstadt fast 21000 Menschen ohne Arbeit - Zaungäste des wirtschaftlichen Lebens, wie die Süddeutsche Zeitung am 5. März 1949 meinte $^{279}$.

Arbeitslosigkeit in Ansbach und Fürth in Prozent ${ }^{280}$

\begin{tabular}{lrcr}
\hline \multicolumn{1}{l}{ Arbeitsamtsbezirk Ansbach } & Stadt- und Landkreis Fürth & Bayern \\
\hline Juni 1948 & 5,9 & 4,5 & 5,6 \\
Juli & - & 7 & 9,1 \\
August & 12,7 & 8,5 & 10,2 \\
Sept. & - & 8,5 & 10,1 \\
Okt. & 12,2 & 7,5 & 8,8 \\
Nov. & 10,7 & 6,5 & 7,9
\end{tabular}

Nach dem 20. Juni vollzog sich nämlich eine Strukturveränderung der Wirtschaft, ein "gesunder Reinigungsproze $\beta^{\text {“281 }}$, wie es das Landesarbeitsamt Nordbayern nannte, der die Arbeitslosenzahlen beträchtlich anschwellen ließ. Sog. Konjunkturkarnickel, d.h. Betriebsinhaber, die sich im Zeichen der gelockerten Gewerbelizenzierungspolitik der Vorwährungszeit selbständig gemacht hatten, mußten ihre Geschäfte schließen

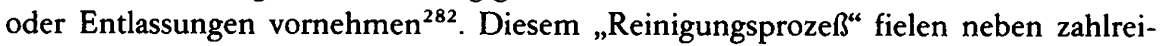
chen Kümmerexistenzen vor allem viele erst im Aufbau befindliche Betriebe, insbesondere Flüchtlingsbetriebe zum Opfer, „die nur über eine ungenügende technische Ausrüstung, keine absatzfähigen Warenvorräte, kein ausreichendes Betriebskapital und keine Sicherheiten für Kredite“ verfügten ${ }^{283}$. Außerdem erhielten die Arbeitsäm-

${ }^{278}$ OB Ansbach an MilReg, Stimmungsbericht vom 1. September 1948, in: Stadtverwaltung Ansbach, EAP 022-95/19.

${ }^{279}$ Vgl. Der Spiegel vom 14. August und 16. Oktober 1948 sowie Süddeutsche Zeitung vom 31. Juli 1948.

${ }^{280} \mathrm{Zu}$ den Zahlen für den Arbeitsamtsbezirk Ansbach vgl. Monatsberichte des bayerischen Staatsministeriums für Arbeit und soziale Fürsorge über „Arbeit und Wirtschaft in Bayern“, in: BayHStA, Berichte des Landesarbeitsamtes, Bayern 1948. Die Zahlen für den Stadt- und Landkreis Fürth beruhen z. T. auf Schätzungen auf der Basis der nicht sehr detaillierten Monatsberichte des OB Fürth an den RegPräs. Monatsberichte in: Stadtverwaltung Fürth, EAP 4. Zu den Zahlen für Bayern vgl. Statistisches Jahrbuch für Bayern 1952, S. 89.

${ }^{281}$ Lagebericht für Januar 1949, 2. Februar 1949, in: BayHStA, Landesarbeitsamt Nordbayern, Lageberichte 1949.

${ }^{282} \mathrm{Vgl}$. Monatsbericht des bay. Staatsministeriums für Arbeit und soziale Fürsorge über den bay. Arbeitsmarkt am 20. Juli 1948, in: BayHStA, Berichte des Landesarbeitsamtes, Bayern 1948.

${ }^{283}$ Ebenda, Bericht über Arbeit und Wirtschaft in Bayern im Juni 1948. 
ter jetzt auch ganz neue Kundschaft, die bisher meist keinen Sinn darin gesehen hatte, sich registrieren zu lassen, weil sie nicht vermittelt werden konnte oder wollte. „Hausfrauen, Haustöchter, Studenten und Rentner, weiterhin Personen, die seither aufgrund einer Krankheit nicht oder nur sehr beschränkt arbeitsfähig waren, oder die seither vom ,Schwarzen Markt' und von Schwarzarbeit gelebt hatten “284, vermehrten jetzt das Arbeitslosenheer. Der stellvertretende Leiter des Ansbacher Arbeitsamtes bezog sich in einem Gespräch mit der Fränkischen Landeszeitung auf einen weiteren Grund: „Gleich in den ersten Tagen nach der Währungsreform kam ein großer Teil der notorischen Arbeitsverweigerer und bat um Einweisung in Arbeitsstellen ... Selbst vor der schwersten Arbeit wurde nicht zurückgeschreckt.“285 Außerdem wurde nach der Währungsreform auch bei der Besatzungsmacht - mit einem Anteil von etwa 15 Prozent aller Arbeiter und Angestellten einer der größten Arbeitgeber der Region - das Geld knapper, so daß auch sie Entlassungen nicht vermeiden konnte ${ }^{286}$.

1949 schnellte die Arbeitslosenquote noch einmal in die Höhe, erreichte im Herbst 1949 und Winter 1949/50 den Höhepunkt und flachte erst dann langsam wieder ab. Im vorwiegend ländlich strukturierten Arbeitsamtsbezirk Ansbach gingen zeitweise mehr als 20 Prozent der Arbeitsfähigen stempeln. In Fürth nahm die Entwicklung, wie auch in den anderen Städten Bayerns, einen etwas günstigeren Verlauf.

Arbeitslosigkeit im Stadt- und Landkreis Fürth 1949 in Prozent ${ }^{287}$

$\begin{array}{lr}\text { Januar } & 6,0 \\ \text { Februar } & 7,4 \\ \text { März } & 8,5 \\ \text { April } & 10,5 \\ \text { Mai } & 11,3 \\ \text { Juni } & 11,1 \\ \text { Juli } & 11,9 \\ \text { August } & 12,4 \\ \text { September } & 13,0\end{array}$

Arbeitslosigkeit und leere Kassen bei Arbeitern und Angestellten sorgten fast schlagartig für eine Verbesserung der seit 1945 immer wieder beklagten „Arbeitsmoral“. Regierungspräsident Schregle hatte in den Jahren 1945 bis 1948 fast keinen Bericht an die Staatsregierung nach München gesandt, ohne auf das „Absinken der Arbeitsmoral“ hinzuweisen. In seinem Monatsbericht vom 18. Oktober 1946 hatte es beispielsweise geheißen: „Der Ausfall an Arbeitsstunden ist im übrigen beträchtlich, weil die Arbeiter vielfach aufs Land gehen, um zusätzliche Nahrungsmittel sich zu beschaffen. Andere bleiben der Arbeit fern, weil sie so schlechte Schuhe haben, daß sie damit nicht arbeiten können. Zu diesen der Not der Zeit entspringenden Arbeitsver-

\footnotetext{
${ }^{284}$ Der bayerische Arbeitsmarkt am 3. August 1948, in: BayHStA, Berichte des Landesarbeitsamtes, Bayern 1948.

${ }^{285}$ Fränkische Landeszeitung vom 30. Juni 1948.

${ }^{286} \mathrm{Vgl}$. dazu Landpolizei Ober- und Mittelfranken an Landpolizei Bayern, 1. August 1948, in: LRA Ansbach, EAP 04-040; OB Fürth an RegPrās, 1. Oktober 1948, in: Stadtverwaltung Fürth, EAP 4.

${ }^{287} \mathrm{Vgl}$. OB Fürth an RegPräs, Monatsberichte für 1949, in: Stadtverwaltung Fürth, EAP 4.
} 
säumnissen kommt noch das echte Bummelantentum, das besonders häufig bei Frauen auftritt, die oft wochenlang unentschuldigt von der Arbeit fernbleiben. “288 „Dazu kommt noch“, so der Monatsbericht vom 2. Juli 1947, „daß den Arbeitern infolge des Fehlens von Wohnraum am Ort des Betriebssitzes mehrstündige An- und Abmarschwege zugemutet werden. Dies ist schon in normalen Zeiten untragbar, unter den heutigen Verhältnissen macht dies eine geregelte Arbeit unmöglich.“ ${ }^{289}$

Nach der Währungsreform waren ein sicherer Arbeitsplatz und ein sicheres Einkommen wieder sehr geschätzt. Kaum jemand wollte sie durch „Blaumachen“ gefährden. Krankheit war nun in den Betrieben ein Fremdwort. Und schließlich schien auch der „Mangel an Arbeitskleidung“, der häufig als Grund für das Fernbleiben von der Arbeit angegeben worden war, „plötzlich behoben“, wie das bayerische Arbeitsministerium im Juli 1948 etwas spitz kommentierte ${ }^{290}$. Wie drastisch sich die Zeiten änderten, zeigt auch die Arbeitszeitstatistik: Ein Facharbeiter in der metallverarbeitenden Industrie, der bis zur Währungsreform in der Regel keine 40 Stunden pro Woche gearbeitet hatte, war nun bis zu 50 Stunden im Betrieb ${ }^{291}$. In der Stadtverwaltung Fürth erhöhte sich, wie der Stadtrat in seinem Monatsbericht vom 2. November 1948 feststellte, die Zahl der geleisteten Arbeitsstunden seit der Währungsreform allein aufgrund der höheren Anwesenheitsrate um 25,3 Prozent ${ }^{292}$. Unter dem „Zwang zur Arbeit" fanden sich nun auch für weniger attraktive Stellen, die bis dahin vergeblich ausgeschrieben worden waren, zahlreiche Interessenten. Ein Arbeitsbummler aus Ansbach scheute sich jetzt nicht, im $15 \mathrm{~km}$ entfernten Neuendettelsau eine Stelle anzunehmen. „,Er könne ja mit dem Fahrrad fahren', sagte er. ,Die Zeit der schwarzen Geschäfte ist vorbei, geben sie mir ehrliche Arbeit, sagte ein anderer.“293

Angesichts der gewandelten Lage begann nun in den Betrieben ein schärferer Wind zu wehen. Vor dem 20. Juni hatten viele Betriebsinhaber das häufige „Blaumachen“ ihrer Arbeiter und Angestellten nicht verhindern können. Gewerkschaften und Betriebsräte hatten in den Betrieben den Ton angegeben, oft sogar die Betriebsinteressen gegenüber der Besatzungsmacht vertreten und über Einstellung und Entlassung von Personal entschieden. „Damals war ich eigentlich Unternehmer“, „die Gewerkschaft kann einfach alles“, solche Äußerungen von Betriebsräten aus dem Ruhrgebiet zeugen vom Selbtbewußtsein der organisierten Arbeiterschaft in den Industrieregionen ${ }^{294}$. Auch im eher kleingewerblich strukturierten Mittelfranken mit seinen vielen patriarchalisch geführten Gewerbebetrieben, wo die Stellung der Unternehmer nicht so angeschlagen war, hatten sich viele Betriebsinhaber von Entnazifizierungsverfahren, resoluten Betriebsräten und der bloßen Anwesenheit der Militärregierung einschüchtern lassen. Sie waren deshalb oder auch aus Verständnis für die mißliche Lage ihrer Arbei-

\footnotetext{
${ }^{288}$ In: BayHStA, Reg von Mittelfranken, Berichterstattung 1946, AZ 1-64, Bd. 6.

${ }^{289}$ Ebenda, Bd. 5.

${ }^{290}$ BayHStA, Berichte des Landesarbeitsamtes, Bayern 1948.

${ }^{291}$ Vgl. Statistisches Jahrbuch für Bayern 1952, S. 266 f. Vgl. dazu auch Mitteilungen der Abteilung Statistik und Wirtschaftsbeobachtung des wirtschaftswissenschaftlichen Instituts der Gewerkschaften, Minden 1948, Nr. 1, S. 36-38.

${ }^{292} \mathrm{Vgl}$. OB Fürth an RegPräs, 2. November 1948, in: Stadtverwaltung Fürth, EAP 4.

${ }^{293}$ Fränkische Landeszeitung vom 30. Juni 1948.

${ }^{294}$ Alexander von Plato, Nachkriegssieger. Sozialdemokratische Betriebsräte im Ruhrgebiet - Eine lebensgeschichtliche Untersuchung, in: Lutz Niethammer (Hrsg.). „Hinterher merkt man, daß es richtig war, daß es schiefgegangen ist." Nachkriegs-Erfahrungen im Ruhrgebiet, Berlin/Bonn 1983, S. 326, 330.
} 
ter häufig zu Kompromissen mit der Belegschaft bereit gewesen. „Unter Hinweis auf die gegenwärtige Ernährungslage“, so der Regierungspräsident in seinem Monatsbericht für Juli 1947, habe man ,in einer größeren Anzahl von Betrieben aufgrund von Vereinbarungen mit den örtlichen Gewerkschaften die wöchentliche Arbeitszeit auf 40 Stunden“ herabgesetzt, und „zwar im allgemeinen unter Beibehaltung des bisherigen Lohnes“295. Zugleich waren auch „allerlei Vergünstigungen neben dem Tariflohn“, zusätzliche Urlaubstage und eine großzügige Ausstattung der Belegschaft mit Kompensationsware an der Tagesordnung gewesen.

Nach der Währungsreform zerbröckelte die Macht der Gewerkschaften und Betriebsräte selbst in den Industriezentren. Die Unternehmerschaft erhielt durch die Währungsumstellung und die marktwirtschaftlich orientierte Politik Erhards wieder Auftrieb. Die sozialen Spannungen in den Betrieben verschärften sich, wie der Leiter der Zweigstelle Ansbach des Arbeitsgerichtes Nürnberg betonte: „Während beispielsweise vor der Geldneuordnung im Bereich des Arbeitsgerichts Nürnberg auf etwa 900 Beschäftigte ein arbeitsgerichtlicher Streitfall entfiel, kommt nunmehr bereits auf 114 Beschättigte ein Arbeitsprozeß.“296 Im gesamten Bezirk Nürnberg hatte sich das Arbeitsgericht in der ersten Hälfte von 1948 nur mit 500 Fällen zu befassen, in der ersten Hälfte von 1949 schon mit 2559. Diese enorme Steigerung ergab sich, obwohl „ein großer Teil industrieller Streitigkeiten noch vor Klageerhebung durch die Vermittlung der Gewerkschaften, Betriebsräte und Arbeitgeberverbände beigelegt" wurde $^{297}$.

Die Konfrontation in den Betrieben nahm mehr und mehr zu. Von Dezember 1948 bis Dezember 1949 stieg die Zahl der bei allen bayerischen Arbeitsgerichten anhängigen Klagen von ca. 4000 auf rund $7500^{298}$. Nicht wenige Arbeitgeber glaubten, nun wieder Methoden des Manchester-Kapitalismus anwenden zu können. Das Landesarbeitsamt Nordbayern berichtete am 2. Februar 1949, daß viele Betriebe nicht einmal die Tariflöhne bezahlten und sich manche Arbeitgeber angesichts knapper Finanzen dazu hinreißen ließen, „die einbehaltenen Arbeitnehmeranteile zur Sozialversicherung und für Lohnsteuer" nicht abzuführen. Zahlreiche Arbeitgeber spielten sogar mit dem Gedanken, „bei plötzlich auftretenden wirtschaftlichen Schwierigkeiten“ die „Arbeitsverhältnisse ohne jegliche Einhaltung einer Kündigungsfrist“ zu lösen ${ }^{299}$.

Für eine Gruppe der Bevölkerung war die Kur der Währungsreform, wie sich bald herausstellte, schlimmer als die Krankheit selbst: die Flüchtlinge und Vertriebenen. Bis zum Juni 1948 hatte die Integration der Neubürger in den Wirtschaftsprozeß gute Fortschritte gemacht. „Mit dem abrupten Ende des Wirtschaftens unter den Bedingungen einer verschleierten Inflation ... verflog dieser schöne Schein, die ,Seifenblase einer reibungslosen Eingliederung zerplatzte. ${ }^{300}$ Das Los der Flüchtlinge und Heimatvertriebenen wurde nun noch schwerer als in den Jahren zuvor. „Durch die Währungsreform“, so hieß es im Monatsbericht des Kreisbeauftragten für das Flüchtlings-

${ }^{295}$ RegPräs an bay. Staatsregierung, in: BayHStA, Reg von Mittelfranken, Berichterstattung 1947, AZ 1-64, Bd. 5.

${ }^{296}$ Fränkische Landeszeitung vom 27. Januar 1949.

${ }^{297}$ Arbeitsgerichtspräsident von Nürnberg an den Präsidenten des Landesarbeitsgerichts Bayern, 23. November 1950, in: Arbeitsgericht Nürnberg, Akten ohne Signatur.

${ }^{298}$ Vgl. Bayern in Zahlen, Heft 4/1950, S. 204.

${ }^{299}$ In: BayHStA, Landesarbeitsamt Nordbayem, Lagebericht 1949.

${ }^{300}$ Bauer, Flüchtlinge und Flüchtlingspolitik, S. 212. 
wesen der Stadt Fürth vom 30. Juli 1948, „wurden die Ausgewiesenen in ihren Lebensbedingungen auf das empfindlichste getroffen. Neben der Tatsache, daß für sie keinerlei Mittel mehr zur Verfügung stehen, schwindet aber auch jede Hoffnung, sie in der nächsten Zeit in den Arbeitsprozeß einzugliedern. “301

Am schlimmsten war die Situation der Flüchtlinge, die erst nach dem Währungsschnitt in die Westzonen gekommen waren. Vielen fehlte das Geld, um die aufgerufenen Lebensmittelrationen kaufen zu können, andere sahen sich außerstande, das Schulgeld für ihre Kinder aufzubringen. Der Flüchtling Hans Feldner schrieb deshalb am 12. Juli 1948 an den Stadtrat von Ansbach: „Mein Kind Christa ... besucht derzeit die 2.a-Klasse der Theresien-Oberschule. Ich bin Flüchtling und muß meine Familie mit 4 Kindern mit Handarbeit ernähren. Ich habe wöchentlich 41,50 DM Lohn, zahle monatlich 22,50 DM Miete und habe noch viele lebensnotwendige Anschaffungen für Hausrat und Kleidung zu machen. Meine Frau betreibt zur Unterstützung meines wirtschaftlichen Fortkommens ein Wandergewerbe, das jedoch im letzten Halbjahr nur 3500 RM Umsatz gebracht hat, seit der Währungsreform überhaupt nichts. Da das Kind gute schulische Leistungen aufweist, möchte ich es gerne die Schule weiterbesuchen lassen. Falls die angekündigte allgemeine Schulgeldbefreiung ausbleibt, bin ich mit Beginn des neuen Schuljahres ohnedies gezwungen, das Kind in die Volksschule zurückzugeben, da ich meinen ältesten Sohn zur Oberrealschule angemeldet habe. Ich bin derzeit auch nicht in der Lage, alle 3 schulpflichtigen Kinder in den Genuß der Ferienspeisung kommen zu lassen, da mein Einkommen kaum zur Beschaffung der Lebensmittel und Zahlung der Miete ausreicht.“302

Vielen Flüchtlingen und Vertriebenen blieb kaum eine andere Möglichkeit, als um öffentliche Fürsorge einzukommen. Der Kundenkreis der Fürsorgeämter wuchs so nach der Währungsreform Monat für Monat an. In der Stadt Ansbach lebten im Juni 1948 über 750 Personen von der Fürsorge, im September waren es $1350^{303}$. Am wenigsten hatten die Bauern unter den Folgen des Währungsschnitts zu leiden. Ganz blieben aber auch sie nicht verschont. Knechte und Mägde kündigten und suchten ihr Glück lieber in der Stadt, wo sie besseren Lohn erhielten ${ }^{304}$. Vor allem aber konnten die Preise für landwirtschaftliche Produkte mit denen der von den Bauern benötigten industriellen Erzeugnisse (Maschinen, Geräte, Kunstdünger etc.) nicht Schritt halten. Mehr und mehr gingen die Bauern deshalb wieder zum Brauch der Vorwährungsreformzeit über, ihre Produkte auf dem erneut entstehenden Schwarzen Markt anzubie$\operatorname{ten}^{305}$. „Die Stimmung unter den Bauern ist sehr gedrückt und teilweise sogar gereizt", hieß es im Bericht des Landwirtschaftsamtes Fürth an die Militärregierung vom 27. September 1948. Man könne es einem „Stand, der seit mehr als zehn Jahren unun-

${ }^{301}$ Stadtverwaltung Fürth, Nr. 460.

${ }^{302}$ Eine ganze Reihe ähnlicher Beispiele findet sich in: Stadtarchiv Ansbach, ABc D/4/34.

${ }^{303}$ Vgl. Jahresbericht der Stadt Ansbach für 1948, in: Ebenda, ABc T/6/4; vgl. OB Ansbach an MilReg, Stimmungsbericht vom 7. Juli 1948, in dem es unter Hinweis auf die steigende Zahl der Fürsorgeempfänger hieß: „Um nun zu vermeiden, daß unter den Antragstellern ein Personenkreis fürsorgemäßig betreut wird, der dies um deswillen nicht verdient, weil er bislang ehrlicher Arbeit aus dem Wege gegangen ist, beabsichtigt der Stadtrat ... die Wohlfahrtsunterstützung für arbeitsfähige Personen in eine produktive umzuwandeln. Dies würde bedeuten, daß jeder arbeitsfähige Wohlfahrtsempfänger unter Zugrundelegung des in Frage kommenden Tariflohnes seine ihm gewährte Unterstützung bei Notstandsarbeiten der Stadt abzuverdienen hat." Stadtverwaltung Ansbach, EAP 022-95/19.

${ }^{304} \mathrm{Vgl}$. Monatsbericht des LR Fürth vom Dezember 1948, in: NA, RG 260, 9/97-1/2.

${ }^{305} \mathrm{Vgl}$. Fränkische Landeszeitung vom 3. Juli 1948. 
terbrochen unter ständigem und zeitweise stärkstem Ablieferungszwange steht und dessen Wirtschaftssubstanz von Tag zu Tag geringer wird“, nicht verargen, wenn er allmählich die Geduld verliere. „Ein Wurm krümmt sich, wenn er getreten wird.“306

Die zahlreichen sozialen Härten nach der Währungsreform machten schließlich Erhard zur Zielscheibe wütender Attacken. Im Kreuzfeuer der Kritik standen die von ihm verfochtene Politik einer Liberalisierung der Wirtschaft und die unerhörten Preissteigerungen seit dem 20. Juni. Im zweiten Halbjahr 1948, nach den Worten Erhards „einem der dramatischsten in der deutschen Wirtschaftsgeschichte ${ }^{\text {“307, }}$, mehrten sich die Stimmen, die einen grundsätzlichen Kurswechsel forderten. Die heftigste Kritik kam aus den Reihen der SPD und der Gewerkschaften, die dem Architekten der liberalen Wirtschaftspolitik vorwarfen, den Raubzug auf die Taschen der minderbemittelten Bevölkerung nicht zu stoppen und einseitig die Unternehmer zu bevorzugen. Aber auch innerhalb der Unionsparteien begann man an der Richtigkeit seiner Politik zu zweifeln; vor allem aus dem Lager der bayerischen CSU mußte Erhard harte Kritik einstecken. Sein Konzept schien gescheitert, und nicht nur die CSU beschäftigte sich mit dem Gedanken, den Wirtschaftsdirektor zu stürzen ${ }^{308}$. Besondere Brisanz erhielt das Ringen um die Wirtschaftspolitik dadurch, daß in weiten Teilen der Bevölkerung der Eindruck entstanden war, der Staat sei zu schwach, um das Mißverhältnis zwischen Arbeitslohn und Preisniveau zu beseitigen. „Nur Selbsthilfe kann Preissteigerungen abstoppen“, lautete etwa das Fazit einer dreistündigen Debatte der Fürther Betriebsräte, die Anfang August 1948 in einer „Stimmung völliger Verzweiflung“ ernsthaft über Käuferstreiks und andere Boykottmaßnahmen berieten ${ }^{309}$.

Die „Mißstimmung in den untersten Schichten der Bevölkerung gegen Produktionsmittelinhaber und Handel ${ }^{\text {“310 }}$, die schon vor der Währungsreform beträchtlich gewesen war, wuchs im „heißen Herbst“ 1948 weiter an, weil, so glaubten jedenfalls die Verbraucher, viele Händler die Mangellage dazu ausnützten, Wucherpreise zu verlangen. In vielen Fällen entlud sich diese Mißstimmung. In Fürth kam es zu Tumulten auf dem Wochenmarkt ${ }^{311}$. In Augsburg wurden Kaufleute tätlich bedroht, in Nürnberg mußte die Polizei einige Händler vor einer aufgebrachten Menge schützen. Die Fränkische Landeszeitung berichtete am 7. August ebenfalls über Handgreiflichkeiten auf dem Markt: „Eine große Menschenmenge protestierte seit den frühen Morgenstunden gegen die hohen Preise verschiedener Obst- und Gemüsehändler ... Als die Käufer die Auslagen eines Obststandes einrissen und gegen den Händler eine drohende Haltung einnahmen, rettete der Verkäufer seine Person und seine gefährdete Ware in den Apsis-Raum der St. Gumbertus-Kirche. Marktbesucher, die trotz dieser Boykott-Aktion bei den Obsthändlern Ware kauften, wurden von der protestierenden Menge geohrfeigt und in einem Fall zu Boden geschlagen." ${ }^{\text {"312 }}$

${ }^{306}$ Bericht vom 27. September 1948, in: NA, RG 260, 9/97-1/1. Vgl. auch LR Fürth an MilReg, Monatsbericht für September 1948, in: NA, RG 260, 9/97-1/1.

${ }^{307}$ Zit. nach Gerold Ambrosius, Die Durchsetzung der Sozialen Marktwirtschaft in Westdeutschland 1945-1949, Stuttgart 1977, S. 183.

${ }^{308}$ Vgl. Nürnberger Nachrichten, Fürther Ausgabe, vom 3. November 1948 und Ambrosius, Soziale Marktwirtschaft, S. $187 \mathrm{f}$.

${ }^{309}$ Nürnberger Nachrichten, Fürther Ausgabe, vom 7. August 1948.

${ }^{310} \mathrm{OB}$ Ansbach an MilReg, Stimmungsbericht vom 28. September 1948, in: Stadtverwaltung Ansbach, EAP 022-95/19.

${ }^{311} \mathrm{Vgl}$. Nürnberger Nachrichten, Fürther Ausgabe, vom 7. August 1948.

312 Fränkische Landeszeitung vom 7. August 1948. 
Diese Ausschreitungen bereiteten auch den Gewerkschaften Kopfzerbrechen. Schon die spontanen Streiks und wilden Demonstrationen vom Frühjahr 1948 hatten die Gewerkschaftsspitze mit Besorgnis erfüllt ${ }^{313}$. Um sich die Entwicklung nicht erneut aus den Händen gleiten zu lassen, entschloß sie sich nach langem Zögern und trotz vieler Warnungen aus dem eigenen Lager, einen eintägigen Generalstreik „gegen die Anarchie auf den Warenmärkten und gegen das weitere Auseinanderklaffen von Löhnen und Preisen“ für den 12. November 1948 auszurufen. Der Gewerkschaftsrat verlangte vor allem drakonische Maßnahmen gegen Wucherer, Steuerbetrüger und Horter und die Rückkehr zur strengen Bewirtschaftung im Ernährungssektor, kurz: die „Verkündung des wirtschaftlichen Notstandes“ und die nachträgliche Korrektur der von Ludwig Erhard verfolgten marktwirtschaftlichen Politik ${ }^{314}$.

Doch der halbherzige Versuch der Gewerkschaften, in einer Art „Feiertagsstreik“ (Theo Pirker) das Ruder in der Wirtschaftspolitik herumzureißen, scheiterte. Die bürgerliche Mehrheit im Wirtschaftsrat brandmarkte den Generalstreik als „Gefährdung des Wiederaufbaus der Wirtschaft “315 und wies den Antrag der Sozialdemokraten, den Exponenten der liberalen Wirtschaftspolitik Ludwig Erhard als Direktor der Verwaltung für Wirtschaft zu entlassen, entschieden zurück. Damit war der Höhepunkt der Angriffe auf die Marktwirtschaft überschritten, Erhard saß fester im Sattel als vorher. Die Kritik an seinem wirtschaftspolitischen Kurs verstummte zwar nicht, seine Gegner taten sich aber zunehmend schwerer, Gehör zu finden, als sich um die Jahreswende 1948/49, trotz der rapide ansteigenden Arbeitslosigkeit, die immer wieder Erinnerungen an die trostlosen Jahre 1930-1933 wachrief, erste Anzeichen einer wirtschaftlichen Erholung einstellten.

\section{Es geht aufwärts}

Im März 1949 veröffentlichte das Bayerische Staatsministerium für Arbeit und soziale Fürsorge einen Bericht über Arbeit und Wirtschaft in Bayern. Sein Tenor lautete: Die Lage ist ernst, aber nicht hoffnungslos. Es wäre unangemessen, „die derzeitigen Depressionserscheinungen auf dem Arbeitsmarkt etwa der Arbeitsmarktentwicklung in den Jahren der Weltwirtschaftskrise nach 1929 gleichzustellen. Die Weltwirtschaftskrise war ... letzten Endes eine Überproduktionskrise, die mit zunehmender Arbeitslosigkeit durch immer größere Absatzschwierigkeiten verschärft wurde. Heute dagegen bietet der in Deutschland bestehende Nachholbedarf eine der wesentlichen Stützen der Wirtschaft ... So besteht die begründete Hoffnung, daß die derzeitigen Schwierigkeiten nur vorübergehender Natur sein werden. ${ }^{\text {316 }}$ Diese Hoffnung trog tatsächlich nicht. Das Jahr 1949 blieb zwar hinsichtlich der Beschäftigungslage ein Jahr

\footnotetext{
${ }^{313}$ Vgl. Gerhard Beier, Der Demonstrations- und Generalstreik vom 12. November 1948, Frankfurt/Köln 1975, S. 89.

${ }^{314}$ Vgl. Süddeutsche Zeitung vom 9. November 1948. Vgl. auch Beier, Generalstreik, S. 34-45. Zum Generalstreik in Bayern vgl. BayHStA, MA 130882.

${ }^{315}$ Ambrosius, Soziale Marktwirtschaft, S.86.

316 BayHStA - ohne Signatur.
} 
der „andauernden Stagnation“, zugleich stieg aber der Index der industriellen Produktion beträchtlich an. Im ersten Halbjahr 1949 betrug er in Bayern 87,9 (1936=100), im zweiten Halbjahr bereits 96,4. Zu den Branchen mit den größten Zuwachsraten gehörte die Elektrotechnik, deren Indexziffern sich zwischen 1. Halbjahr 1948 und 2. Halbjahr 1949 von 60,4 auf 182,6 erhöhten ${ }^{317}$.

Der wirtschaftliche Aufschwung machte sich auch bei den Arbeiterfamilien bemerkbar, die sich nun endlich wieder richtig satt essen konnten. Verglichen mit dem Tiefstand der 100. Zuteilungsperiode vom 31. März bis 27. April 1947 (Monatsrationen von nur $210 \mathrm{~g}$ Fett und $600 \mathrm{~g}$ Fleisch) war im Juni 1949 die Fettration mit $875 \mathrm{~g}$ und die Fleischration mit $1000 \mathrm{~g}$ fast schon üppig. Wer über ausreichend Geld verfügte, konnte überdies in den wieder gut bestückten Geschäften kaufen, was das Herz begehrte ${ }^{318}$. Dies war nun eher möglich, denn in den ersten Monaten des Jahres 1949 begannen die nach der Währungsreform unbarmherzig angestiegenen Preise leicht zu fallen. „Wende in der Preisentwicklung steht bevor!", verhieß die Fränkische Landeszeitung vom 5. Januar und behielt recht damit: „Nach Feststellungen der Preisüberwachungsbehörden in Ansbach hat sich die sinkende Preistendenz im Februar verstärkt. So sind die Preise für elektrotechnische Artikel und Beleuchtungskörper um fünfzehn Prozent, für Haus- und Küchengeräte um zehn bis fünfzehn Prozent gefallen. Die stärksten Senkungen verzeichneten Leder- und Schuhwaren. Hier sind die Preise um fünfundzwanzig bis dreißig Prozent gefallen ... Auch bei Wein wird ein weiteres Herabgehen der Preise erwartet. “319

Mit der Besserung der Lebensmittelversorgung verschwand allmählich auch das Phänomen der Unterernährung, der Gürtel konnte nun erstmals wieder einige Löcher weiter geschnallt werden ${ }^{320}$. Was im Hungerwinter von 1947 als makabrer Scherz empfunden worden wäre, war nun Wirklichkeit: Zeitungsannoncen priesen bereits Rezepte für Abmagerungskuren an. Zugleich zeichnete sich eine Linderung der drükkendsten Wohnungsprobleme ab. Überall, in den schwerzerstörten Städten des Ruhrgebietes ebenso wie in Frankfurt oder Würzburg, das gleichsam noch in letzter Minute dem Erdboden gleichgemacht worden war, entschlossen sich die Ratsherren zu großzügigen Wohnungsbauprogrammen; auch die Länder schütteten große Mengen an Geld für den Bau von Wohnungen aus. In München beispielsweise standen 194915 bis 18 Millionen Mark zu Verfügung, die schnell ihre Wirkung taten: „Die Lücken in den Straßenzeilen schließen sich mehr und mehr, wenn zum großen Teil auch nur durch die geschäftlichen Notmaßnahmen der Behelfsbauten“, beobachtete ein Reporter der Süddeutschen Zeitung schon im Mai $1949^{321}$.

\footnotetext{
${ }^{317}$ Vgl. Statistisches Jahrbuch für Bayern 1952, S. 176.

${ }^{318}$ Zur 127. Zuteilungsperiode vgl. einen Bericht des Stadtrats von Fürth an die Militärregierung vom 14. Juli 1949 über Versorgungslage, in: NA, RG 260, 9/96-3/7-8.

319 Fränkische Landeszeitung vom 12. Mārz 1949.

${ }^{320} \mathrm{Vgl}$. etwa die Monatsberichte des OB Fürth an RegPrās aus dem Jahre 1949, in: Stadtverwaltung Fürth, EAP 4.

${ }^{321}$ Süddeutsche Zeitung vom 12. April und 28. Mai 1949.
} 
Wohndichte (=Personen je Wohnraum) am 1.2.1947 und am 13.9.1950322

$\begin{array}{lcc} & 1947 & 1950 \\ \text { Stadt Ansbach } & 1,87 & 1,26 \\ \text { Stadt Fürth } & 1,73 & 1,25 \\ \text { Landkreis Ansbach } & 1,84 & 1,37 \\ \text { Landkreis Fürth } & 1,81 & 1,35 \\ \text { Bayern } & 1,98 & 1,33\end{array}$

Bald verlor auch das einst brennende Problem der ansteckenden Krankheiten an Schärfe. 1947 hatte man in Mittelfranken noch über 15000 Krätzeerkrankungen registriert; drei Jahre später liefen bei den Gesundheitsämtern nur noch vereinzelte Meldungen über Krätzekranke ein. Auch Typhus und Tuberkulose, die in den zurückliegenden Jahren Hunderte und Aberhunderte hingerafft hatten, gingen etwas zurück. Und die Kindersterblichkeit, die 1945 in Mittelfranken mit 15,4 Toten auf 100 Geborene einen ähnlichen dramatischen Wert wie 1915 erreicht hatte, konnte ebenfalls eingedämmt werden. 1950 starben nur noch fünf von 100 Neugeborenen; das war der niedrigste Wert seit der Einführung der Säuglingssterblichkeitsstatistik 1849/50 323 .

Im Frühjahr 1949, als die sogenannte Magenfrage weitgehend gelöst und die Wohnungsverhältnisse sich etwas gebessert hatten, ließen sich langsam auch andere Bedürfnisse und Wünsche befriedigen. Viele Frauen und Mädchen konnten jetzt endlich die umgearbeiteten Wehrmachtsmäntel und fadenscheinig gewordenen Röcke, die jahrelang hatten herhalten müssen, ausrangieren. Ein bißchen Mode und ein bescheidener Luxus schienen wieder im Bereich des Möglichen zu liegen, wie ein Blick in den mittlerweile reichhaltigen Anzeigenteil der Zeitungen zeigt:

„Charmeuse-Unterkleider in vorzüglicher Qualität und schönen Motiven.“ "In den jungen Frühling ... im jugendlichen Mantel und Kostüm.“

„Zum 1. Mai wie aus dem Ei gepellt.“324

Die „schlechte Zeit“ war jetzt tatsächlich zu Ende.

Die Früchte der beginnenden wirtschaftlichen Konsolidierung kamen freilich nicht allen zugute. „Besonders in den Kreisen der Arbeitslosen herrscht Ratlosigkeit, wie das Leben so weitergehen soll“, so die Landpolizei von Ober- und Mittelfranken im Frühjahr $1949^{325}$. Der Regierungspräsident kam in seinem Monatsbericht an die Staatsregierung vom 14. April 1949 zu einem ähnlichen Ergebnis: „Die Stimmung der Bevölkerung wird nach wie vor durch den krisenhaften Zustand der Wirtschaft beeinflußt. Die im Steigen begriffene Arbeitslosigkeit löst in weiten Kreisen lebhafte Beunruhigung aus ... Die Löhne entsprechen nicht im mindesten den derzeitigen hohen Lebenshaltungskosten. " ${ }^{\text {326 }}$ Und im Monatsbericht des Oberbürgermeisters von Ans-

${ }^{322}$ Vgl. Statistisches Jahrbuch für Bayern 1947, S. 400 f. und Statistisches Jahrbuch für Bayern 1952, S. 532. Vgl. dazu auch „Die Bauleistung Bayerns seit der Währungsreform“, in: Bayern in Zahlen, Monatshefte des Bayerischen Statistischen Landesamts, Mai 1951, 5. Jahrgang, S. $233 \mathrm{f}$.

${ }^{323} \mathrm{Vgl}$. Statistisches Jahrbuch für Bayern 1952, S. 55, 376, $378 \mathrm{f}$.

${ }^{324}$ Fränkische Landeszeitung vom 24. und 26. März 1949 und 30. April 1949.

${ }^{325}$ Landpolizei Ober- und Mittelfranken, Bezirksinspektion Ansbach, an Landpolizei Bayern, 2. Mai 1949, in: LRA Ansbach, EAP 01-016.

${ }^{326}$ RegPräs an bay. Staatsregierung, 14. April 1949, in: BayHStA, Reg von Mittelfranken, Berichterstattung 1948-1952. 
bach vom 5. Oktober 1949 hieß es: „Die Stimmung der Bevölkerung wird immer noch stärkstens beeinflußt von der krisenhaften Situation der Wirtschaft. Auf dem Arbeitsmarkt ist keineswegs eine Besserung eingetreten und lastet die Arbeitslosigkeit vielfach wie ein schwerer Alpdruck auf den von ihr betroffenen Kreisen ... Es würde wahrhaftig nicht Wunder nehmen, wenn diese Empörung sich einmal in anderen als bisher gewohnten und zweifelsohne etwas unangenehmeren Formen Luft machen würde. “327

Auch an der verzweifelten Lage der Flüchtlinge und Vertriebenen hatte sich 1949 noch kaum etwas geändert. Die Zahl der Neubürger war seit Ende 1946, als man schon geglaubt hatte, der Höhepunkt des Zustroms sei überschritten, noch einmal beträchtlich angestiegen. Insbesondere nach dem erfolgreichen kommunistischen Staatsstreich in Prag im Frühjahr 1948 hatten viele Deutsche ihre tschechische Heimat verlassen und in den Westzonen Zuflucht gesucht. In der Stadt Ansbach nahm die Zahl der Flüchtlinge von etwa 4400 (1946) auf ca. 7600 (=23 Prozent der gesamten Stadtbevölkerung), in der Stadt Fürth von 12100 (1946) auf ca. 15000 (=15 Prozent) zu. In den beiden Landkreisen, wo der Flüchtlingsanteil 1946 schon etwa 20-24 Prozent betragen hatte, waren nun ca. 24-27 Prozent der Gesamtbevölkerung Flüchtlinge und Vertriebene ${ }^{328}$.

Die „Diktatur der leeren Kassen“ nach der Währungsreform stellte die Eingliederung der Flüchtlinge vor enorme Schwierigkeiten ${ }^{329}$. In Ansbach, das fast aus den Nähten platzte, war es 1949 noch immer nicht gelungen, alle Elendsquartiere aufzulösen und für eine menschenwürdige Unterbringung der Flüchtlinge zu sorgen. „Die Aussichten auf eine Besserung sind im Augenblick noch denkbar minimal“, so Ansbachs Oberbürgermeister im Januar 1949, „nachdem die Möglichkeit der Finanzierung eines großzügigen Wohnungsbaues anscheinend noch in einiger Ferne liegt.“"330 In Fürth hatte sich dagegen die Lage etwas entspannt. Hier war der größte Teil der Neubürger bereits in privaten Wohnungen untergebracht. Wenn es sich häufig auch nur um unbeheizbare kleine Zimmer und zugige Dachkammern handelte, es waren doch die eigenen vier Wände. In den Lagern blieb gewissermaßen das Strandgut von Vertreibung und Flucht zurück: die Alten und Kranken, Verzweifelten und Gebrochenen, die nach schlimmen Erlebnissen resigniert hatten und lieber im irgendwie doch geborgenen Lagermilieu blieben, als „selbst um das tägliche Brot““331 zu kämpfen. „Sie sind in ihrer Mehrzahl erwerbslos“, so charakterisierte das Fürther Flüchtlingsamt diese Personengruppe, „besitzen weder Hausrat noch Möbel und wären nicht in der Lage, in einer privaten Wohnung ihren Mietsverpflichtungen nachzukommen.“ Soweit sie in Arbeit standen, hatten sie im Lager „nur einen geringen Teil der Kosten für die Miete, Licht, Heizung und Verpflegung zu tragen“"332.

\footnotetext{
${ }^{327}$ Stadtverwaltung Ansbach, EAP 022-95/19.

${ }^{328}$ Vgl. dazu Die Flüchtlinge in Bayern. Ergebnisse einer Sonderauszählung aus der Volks- und Berufszählung vom 29. Oktober 1946, Heft 142 der Beiträge zur Statistik Bayerns, S.21; Monatsbericht des Stadtrats von Ansbach, 1. September 1949, in: Stadtverwaltung Ansbach, EAP 022-95/19.

${ }^{329}$ OB Ansbach an MilReg, Stimmungsbericht vom 5. Januar 1949, in: Stadtverwaltung Ansbach, EAP 022-95/ 19.

${ }^{330}$ Ebenda.

${ }^{331}$ RegPräs an bay. Staatsregierung, 10. Februar 1949, in: BayHStA, Reg von Mittelfranken, Berichterstattung 1948-1952.

332 Bericht vom 1. Februar 1949, in: Stadtverwaltung Fürth, EAP 460.
} 
Von den zehn Lagern, die Mitte 1948 in Fürth bestanden hatten, waren im Sommer 1949 (außer drei Durchgangslagern mit einer Aufnahmefähigkeit von etwa 350 Personen) noch das große Lager auf dem Gelände der ehemaligen Dynamit-Nobel-Werke, das Espanlager mit etwa 120 Personen und Schloß Burgfarrnbach, in dem meistens 150 bis 200 Personen wohnten, übriggeblieben. „Der Gesundheitszustand der Lagerflüchtlinge ... kann als normal bezeichnet werden“, hieß es im Monatsbericht des Fürther Flüchtlingsamtes vom 31. Juli 1949. „Die wohnhygienischen Verhältnisse in den Lagern ... haben sich wesentlich gebessert." Lediglich die Zustände im Durchgangslager Ronwaldbunker, jenes riesigen überirdischen Betonkomplexes, der kurz nach Kriegsbeginn von den Siedlern der Ronwaldsiedlung selbst erbaut und dann im Krieg als eines der ersten Gebäude in Fürth von einer Bombe fast ganz zerstört worden war, erinnerten noch an die haarsträubenden Verhältnisse der Jahre 1946/47: „Das Fehlen einer natürlichen Belüftung macht sich besonders jetzt, während der heißen Jahreszeit, bemerkbar. Die maschinelle Belüftungsanlage muß mit Rücksicht auf die Kinder und alten Leute des Nachts abgestellt werden. Die vorhandenen Luftzuführungsöffnungen sind jedoch völlig unzureichend, so daß nach einigen Stunden die Luftverhältnisse unerträglich werden. “333

Neben einer menschenwürdigen Unterbringung der Flüchtlinge war ihre Eingliederung in das Wirtschaftsleben das dringendste Problem. Die nach der Währungsreform zu beobachtende überdurchschnittliche Arbeitslosigkeit der Neubürger verschärfte sich 1949 noch weiter. „Wenn ein Landkreis über 30 Prozent aller arbeitseinsatzfähigen Flüchtlinge als arbeitslos meldet, so ist das typisch für den ganzen Regierungsbezirk", berichtete der Ansbacher Regierungspräsident im Mai 1949 an die bayerische Staatsregierung ${ }^{34}$. Das Flüchtlingsgesetz vom 19. Februar 1947, das auf das „organische Aufgehen“ der Neubürger in der einheimischen Bevölkerung abzielte, erleichterte zwar vielen Flüchtlingen die Gründung selbständiger Existenzen, zahlreiche geplante Notmaßnahmen standen aber nur auf dem Papier. An die Richtlinie des bayerischen Innenministeriums über die Beschlagnahme gewerblicher Räume für Flüchtlingsbetriebe beispielsweise hielt sich kaum jemand. Jedesmal, wenn die zuständigen örtlichen Stellen und Referate eingeschaltet wurden, versandeten die „von oben“ kommenden Direktiven. Auch die 1945/46 groß angekündigte Bodenreform blieb stecken; bis 1949 hatten ganze fünf Flüchtlingsbauern aus dem Ansbacher Landkreis bei Regensburg und bei Oberasbach in der Nähe von Fürth Siedlerstellen zugewiesen bekommen. Fünf weitere, ein sudetendeutscher und vier Bukowina-Bauern, hatten Pachtland für fünf Jahre auf dem Urlas, einem ehemaligen Wehrmachtsgelände im Nordosten von Ansbach, erhalten ${ }^{335}$.

Das war nur ein Tropfen auf den heißen Stein, aber, so die Versprechungen, es sollte in allen Belangen bald anders werden. Wie wenig von solchen Ankündigungen vorläufig noch zu halten war, zeigte die Bilanz über die Industrieansiedlung von Flüchtlingen, die im September 1950 im Rahmen der Arbeitsstättenzählung gezogen wurde: „Der Anteil der Flüchtlingsbetriebe an der Industrie Mittelfrankens ist nicht bedeutend“, lautete das Endergebnis. 1950 gab es 5200 Flüchtlingsbetriebe (=7 Pro-

\footnotetext{
${ }^{333}$ Monatsbericht des Flüchtlingsamtes an Stadtrat Fürth, 31. Juli 1949, in: Stadtverwaltung Fürth, EAP 460.

${ }^{334}$ RegPräs an bay. Staatsregierung, 12. Mai 1949, in: BayHStA, Reg von Mittelfranken, Berichterstattung 1948-1952.

${ }^{335}$ Vgl. Fränkische Landeszeitung vom 8. Februar 1949.
} 
zent aller Betriebe) in Mittelfranken, die mit einer Belegschaft von zusammen 16000 Personen (zwei Drittel davon Flüchtlinge) nur etwa 4 Prozent aller Arbeitnehmer Mittelfrankens beschäftigten ${ }^{336}$.

Wesentlich bessere Chancen hatten die Flüchtlinge dagegen im öffentlichen Dienst. Vor allem bei den Bediensteten in den Landratsämtern und Rathäusern der Kleinstädte lag der Anteil der Flüchtlinge oft weit über dem Anteil der Flüchtlinge an der Gesamtbevölkerung. Die größeren Städte - u.a. auch Fürth - konnten mit dieser Entwicklung allerdings nicht Schritt halten.

Eingliederung der Flüchtlinge in den öffentlichen Dienst $1949^{337}$

$$
\text { Einheimische Flüchtlinge }
$$

$\begin{array}{lrr}\text { Stadt Ansbach } & 443 & 81 \\ \text { Stadt Fürth } & 1866 & 137 \\ \text { Landkreis Ansbach } & 58 & 38\end{array}$

Als im September 1949 mit dem Zusammentritt des Bundestages ${ }^{338}$ die Gründung der Bundesrepublik Deutschland besiegelt wurde, hausten in der mittelfränkischen Provinz noch immer beträchtliche Teile der Bevölkerung in Elendsquartieren, ohne Hoffnung auf eine baldige Besserung ihrer trostlosen Lage. Im September 1949 erreichte die Arbeitslosigkeit mit 14 Prozent (in Bayern) den höchsten Stand seit Kriegsende. „Das furchtbare Gespenst der Arbeitslosigkeit, das die Bevölkerung bereits vor 1933 kennenlernte“, so Regierungspräsident Schregle, „droht viele Existenzen, die sich bisher mühsam über Wasser gehalten haben, zu vernichten.“339 „Das Versagen der regierenden Stellen wird gerade in diesem Punkt am scbärfsten kritisiert", hieß es im Monatsbericht der Polizeiinspektion Ansbach vom 1. August 1949. „Ein armes Volk wie das deutsche kann es sich heute nicht leisten, ein Heer von Arbeitslosen zu unterhalten, nachdem so viel Arbeit vorhanden wäre ... Man kann immer wieder hören: , In der deutschen Demokratie wird viel zu viel geredet und geschrieben, aber viel zu wenig gehandelt'، “340

Antidemokratische Ressentiments, wie sie $1946 / 47$ bei den „ewig Gestrigen aus den nazistischen Lagern“"341 und in Teilen der sozial und politisch desintegrierten Flüchtlinge aufgetreten waren, nahmen deshalb nach der Währungsreform weiter zu; geschürt vor allem durch die Erbitterung über die sozialen Folgen der Währungsumstellung, die viele als Schlag gegen den kleinen Mann empfanden. Daß diese Mißstimmung nicht zu unterschätzen war, unterstrich das hervorragende Abschneiden des demagogischen Volkstribuns Alfred Loritz und seiner Wirtschaftlichen Aufbau-Verei-

${ }^{336} \mathrm{Vgl}$. dazu „Die Industrie der Heimatvertriebenen in Mittelfranken“, in: Bayern in Zahlen, Monatshefte des Bayerischen Statistischen Landesamts, Januar 1952, 6. Jahrgang, S. 8 f.

${ }^{337} \mathrm{Vgl}$. Aufstellung über die Eingliederung der Flüchtlinge im Regierungsbezirk Mittelfranken vom 19. Juli 1949, in: BayHStA, MInn 80136.

${ }^{338}$ Vgl. Erich Mende, Die neue Freiheit. 1945-1961, München/Berlin 1984, S. $112 \mathrm{ff}$. Vgl. auch den Artikel von Rüdiger von Wechmar in: Die Welt vom 4. September 1949.

${ }^{339}$ RegPräs an bay. Staatsregierung, 15. März 1949, in: BayHStA, Reg von Mittelfranken, Berichterstattung 1948-1952.

${ }^{340}$ Bericht vom 1. August 1949, in: LRA Ansbach, EAP 01-016.

${ }^{341} \mathrm{OB}$ Ansbach an MilReg, Stimmungsbericht vom 16. September 1947, in: Stadtverwaltung Ansbach, EAP $022-95 / 19$. 
nigung bei der Bundestagswahl. Sein Sammelsurium autoritärer Rezepte, parteienfeindlicher Ressentiments und ständischer Romantizismen fand in ehemaligen NSHochburgen und in Flüchtlingskreisen „starken Widerhall ${ }^{4342}$. Andererseits konnte aber niemand verkennen, daß sich die deutsche Wirtschaft seit 1948 in einem ständigen Auftrieb befand. Der Export nahm zu, manche Branchen erzielten bereits jetzt enorme Gewinne. Weite Kreise ließen sich von dieser ungebrochenen Dynamik mitreißen; bald vergaßen auch viele, die sich 1948 als die Betrogenen der Währungsreform betrachtet hatten, ihren alten Groll. In diesem Klima der Zuversicht und des aufkeimenden Zukunftsoptimismus besaßen die neuen staatlichen Institutionen gute Chancen, größere Attraktivität zu entfalten als der glanz- und glücklose Weimarer Staat. Die Festigung des demokratischen Staates hing freilich ab vom weiteren Erfolg der wirtschaftlichen Erholung, die sich seit der Währungsreform angebahnt hatte, und im gleichen Maße von der sozialpolitischen Flankierung dieses Erfolges, an der es 1949 noch weitgehend fehlte. 